\title{
THE EFFECT OF A SIMULTANEOUS SPEECH DISCRIMINATION TASK ON NAVIGATION IN A VIRTUAL ENVIRONMENT
}

\author{
A Thesis \\ Presented to \\ The Academic Faculty \\ by \\ Jeffrey T. Lindsay \\ In Partial Fulfillment \\ of the Requirements for the Degree \\ Master of Science in the \\ School of Psychology
}

Georgia Institute of Technology

May, 2006 


\section{THE EFFECT OF A SPEECH DISCRIMINATION TASK ON NAVIGATION IN A VIRTUAL ENVIRONMENT}

Approved by:

Dr. Bruce N. Walker, Advisor School of Psychology

Georgia Institute of Technology

Dr. Gregory M. Corso

School of Psychology

Georgia Institute of Technology

Dr. Arthur D. Fisk

School of Psychology

Georgia Institute of Technology

Date Approved: August 9, 2005 


\section{ACKNOWLEDGEMENTS}

I wish to thank my advisor Dr. Bruce Walker for his invaluable counsel and sharp insight on research issues addressed here as well as years of work that has led me to this point. Without his talent for marrying together diverse academic fields, the SWAN system would never have come as far as it has. I would also like to thank Dr. Greg Corso and Dr. Arthur Fisk for their valuable contributions in helping to shape this thesis and their participation in my committee.

I would like to gratefully acknowledge the Georgia Institute of Technology's School of Psychology and all of the faculty and staff that have helped to make the last nine years of education so enriching.

Finally, the most important and heartfelt acknowledgment of gratitude goes to my amazing wife Claire. Without her love and support, this thesis most certainly would not have been possible. 


\section{TABLE OF CONTENTS}

ACKNOWLEDGEMENTS

iv

LIST OF TABLES vii

LIST OF FIGURES viii

SUMMARY $\quad$ ix

\section{CHAPTER}

1 Introduction 1

Necessity of Nonvisual Navigation

$\begin{array}{ll}\text { Existing Interfaces } & 2\end{array}$

$\begin{array}{ll}\text { Prior Investigation } & 2\end{array}$

$\begin{array}{ll}\text { SWAN } & 4\end{array}$

Questions to be Tested 5

$\begin{array}{lr}\text { Signal Detection and Masking } & 6\end{array}$

$\begin{array}{ll}\text { Single versus Dual Sound } & 7\end{array}$

$\begin{array}{lr}\text { Attention } & 8\end{array}$

$\begin{array}{lr}\text { Experimental Validation } & 9\end{array}$

2 Hypotheses 11

3 Methods 12

$\begin{array}{ll}\text { Participants } & 12\end{array}$

SWAN Navigation Task Interface 12

Stimuli: Speech Discrimination Task 12

$\begin{array}{ll}\text { Apparatus } & 13\end{array}$

$\begin{array}{ll}\text { Procedure } & 16\end{array}$ 
Data Collection

4 Results

5 Discussion

APPENDIX B: Speech Discrimination Data

APPENDIX C: TLX Data

APPENDIX D: Demographic Data 


\section{LIST OF TABLES}

Page

Table 1: Time and path efficiency means by task and beacon type for the SWAN single task and the SWAN dual task 


\section{LIST OF FIGURES}

\section{Page}

Figure 1: The relation and interaction of the experimental equipment 14

Figure 2: Study outline $\quad 16$

Figure 3: Time efficiencies by beacon type for the SWAN single and SWAN dual task phases

Figure 4: Path efficiencies by beacon type for the SWAN single and SWAN dual task phases

Figure 5: Speech discrimination task reaction times

Figure 6: Speech discrimination task accuracy

Figure 7: Reported workload 


\section{SUMMARY}

Moving through varied and complex environments every day is something that most people do with ease. However, if the input from the visual system is unavailable (e.g., damage to the optic nerves or smoke in a burning building), navigating and avoiding obstacles becomes much more demanding. It is therefore desirable to develop a navigation aide for use where visual input has become unavailable. There is a small body of research concerning such navigation aides and their efficacy. However, many issues that may have serious human factors repercussions for such a system are unexplored. This study was conducted in order to examine the effect of an attentionally demanding distractor task on wayfinding performance with an audio only navigation aide, in this case the System for Wearable Audio Navigation (SWAN). The distractor task was found to have a significant impact on wayfinding performance, which decreased when both tasks were performed simultaneously. However, performance on the distractor task improved during this time, in some cases reaching performance levels similar to when the distractor task was performed by itself. This result may be due to participants shifting attention to the task they perceive to be more difficult when asked to do both simultaneously, in this case the distractor task. 


\section{CHAPTER 1}

\section{INTRODUCTION}

Moving through varied and complex environments every day is something that most people do with ease. However, if the input from the visual system is unavailable (e.g., damage to the optic nerves or smoke in a burning building), navigating and avoiding obstacles becomes much more demanding. It is therefore highly desirable to develop a navigation aide for use where visual input has become unavailable. There is a small body of research concerning such navigation aides and their efficacy. However, many issues that may have serious human factors repercussions for such a system are unexplored. This study was conducted in order to examine the effect of an attentionally demanding distractor task on wayfinding performance with an audio only navigation aide, in this case the System for Wearable Audio Navigation (SWAN).

\section{Necessity of Nonvisual Navigation}

A recent report from the World Health Organization (Resnikoff et al., 2004) estimates the number of visually impaired individuals worldwide to be over 161 million, with nearly 37 million of those individuals being blind. In the United States alone, it has been estimated that there are over 11 million visually impaired persons, more than a million of whom are blind (De l'Aune, 2002). Given these numbers, it is clear that there exists a relatively large group of people for whom navigation can be a serious difficulty. For a blind or visually impaired individual without some form of assistance (e.g., a sighted guide) moving from one location to another is not only a hard task, but also a potentially dangerous one. Errors in navigation (e.g., wandering into a bad neighborhood)

or deviations from a path (e.g., stepping into the street) can have serious repercussions and are often more difficult for visually impaired individuals to avoid. This makes the 
development of a system to aid visually impaired individuals in navigating the environment very important.

In addition to the blind, there are other individuals who also stand to benefit from the development of a navigation aide. In certain situations sighted individuals may also be denied the use of visual input for navigation, such as when they cannot see (e.g., a firefighter in a smoky building) or their vision is already occupied with another task. Because there are so many instances where individuals may have greatly reduced access to visual input for moving through their environment, the development of a non-visual navigation aide is highly critical to improving their performance. As visual navigation cues are not an option, such a system must use an alternative sensory modality or modalities to convey information to the user. Some attempts have been made to develop such a system using audition.

\section{Existing Interfaces}

One of the oldest auditory navigation interfaces is the Personal Guidance System (PGS) (Loomis, Golledge, Klatzky, Speigle, \& Tietz, 1994; Loomis, Herbert, \& Cicinelli, 1990). The PGS interface consists of a virtual 3D auditory environment where a computer creates spatialized speech beacons such that the beacon is perceived to come from the same place as the object to which the beacon refers (e.g., a doorway). Loomis et al. (1990) found that a "simple" virtual 3D auditory environment has the potential to provide navigation information to a visually impaired traveler, so their system uses speech beacons and spoken directions (e.g., repeating "Left, left, left...") for navigation. Similarly, the Drishti system (Helal, Moore, \& Ramachandran, 2001) also uses a synthesized speech interface, very similar to that of PGS, but with a more complex mapping system that takes user preferences and environmental factors into account.

\section{Prior Investigation}


The idea of using sound beacons to aid navigation is not a new one. Despite this, relatively little work has been done to examine the effects of such beacons on performance. Tran, Letowski, and Abouchacra (2000) have studied the effect of beacon types on localization and navigation. The 10 beacons used in their studies ranged from pure tones to complex sounds, including both speech and non-speech sounds. They found that beacon type had a significant effect on both number of errors made in localizing the sound (i.e., accuracy) and the user's comfort level. Based on their findings, they suggested that any acoustic beacon intended for use in navigation tasks should be a wideband non-speech sound. It is also important to note that users in that study reported that speech beacons were found to be more annoying than non-speech beacons by participants.

Given the findings of Tran et al. (2000) that speech as an auditory beacon is harder to localize in a virtual environment than non-speech beacons, and human factors principles suggesting avoidance of the speech channel when not absolutely necessary (e.g., Salvendy, 1997), our own auditory navigation projects (e.g., Walker \& Lindsay, in press) have focused on non-speech audio.

Walker and Lindsay (in press) began by studying the effects of beacon sounds on audio-only navigation. They found a significant effect of beacon sound on time efficiency (how quickly a user travels the prescribed path) and path efficiency (how closely a user follows the prescribed path). In particular, of those sounds tested they determined a pink noise burst to be the best in terms of both efficiencies.

Walker and Lindsay (in press) also looked at how the capture radius of an auditory beacon can affect performance. The capture radius of a beacon is the proximity 
to a beacon's location a user must achieve before the system will consider the user to have reached the beacon. Their research showed that capture radius can have a significant impact on performance, with radii too large or too small leading to inefficiency and possible real world safety concerns. A radius of $1.5 \mathrm{~m}$ was the best of those tested.

\section{SWAN}

The SWAN system, used in Walker and Lindsay's research, has an auditory interface composed of spatialized, non-speech auditory icons and earcons that aid users in navigation and awareness of features in the environment. Sounds in SWAN are classified as beacon sounds, object sounds, and surface transition sounds.

Beacon sounds are used for navigation, indicating the path the user should follow to reach the desired destination. These sounds are placed (virtually) at waypoints along a route from the user's current location to the destination the user has selected. The sound is spatialized, appearing to emanate from the direction of the waypoint. As a user approaches a waypoint, the tempo of the beacon sound increases. When the user reaches the waypoint, the current beacon sound ceases and the beacon for the next waypoint becomes audible. Using this trail of beacon sounds the SWAN is able to guide users through their environment.

Object sounds and surface transition sounds provide users with information about the environment as they move along the path of beacon sounds. Object sounds indicate features in the environment that could potentially be of interest (e.g., a water fountain or restroom) or hazardous (e.g., a table blocking the hallway). Surface transitions are sounds that denote changes in the surface the user is walking on (e.g., transition from carpet to 
tile). These can often indicate important boundaries (e.g., transition from sidewalk to street).

The SWAN interface is designed to be used on a wearable device. Various types of sensors (e.g., GPS) gather information about the user's location and surroundings, which is then displayed via the SWAN audio interface. In addition to the wearable version, there is a virtual environment version for interface development and indoor testing. While SWAN is not the only interface of this kind to have been developed, it does have a potentially important distinction of using non-speech auditory stimuli instead of speech stimuli.

\section{Questions to be Tested}

Though the SWAN system was designed using human factors principles and the limited existing research on such a system, there remain important questions to be explored:

1) Sound design. Though Tran et al. (2000) have done work on this, it was important to replicate and extended their work using the SWAN interface. Walker and Lindsay (in press) began this effort. As the auditory beacons are the backbone of the system, exploring what sounds are good beacons and what characteristics of those sounds are important is critical for the SWAN to be effective. A good beacon must be easy to localize, and this has been found to be facilitated by sounds that are broad spectrum and have a short duration.

2) Interaction issues. Another critical aspect of designing this type of interface concerns how the beacons interact with the user and vice versa (i.e., what variables affect users' behavior when using the interface). This includes issues 
such as how capture radius affects performance, how closely waypoints should be located, whether front/back confusions are a potential problem, and so on. Walker and Lindsay (in press) have begun examining these issues as well by exploring the effect of varying capture radius on users' performance with the SWAN system. Though there remains work yet to be done, these initial studies have provided a basis for further exploration of these critical issues.

3) Multiple tasks/multiple sounds. This major issue has yet to be examined using the SWAN interface. There is much underlying theoretical research that deals with aspects of a multiple task/multiple sound situation such as signal detection (i.e., can you hear the beacons in these situations?), masking (i.e., are some sounds preventing others from being noticed?), and attentional issues (i.e., can users attend to other sounds/tasks beyond the basic SWAN navigation task?). The present study begins to address research in this line.

\section{Signal Detection and Masking}

One of the fundamental issues in any interface is whether the user can detect informative signals from the interface. An extremely informative and elaborate interface is of no benefit if people who use it have difficulty noticing the stimuli that are intended to convey the information. Thus the most basic distinction a person must make is whether the target sound is present or not. In the most likely usage scenarios for the SWAN interface, there will be at least some degree of background noise (cars, etc.), raising the possibility that the user may not detect the relevant audio cues. This situation has been well described by signal detection theory (Swets, Tanner, \& Birdsall, 1961). Obviously the desire for this application is to maximize the number of times the SWAN stimuli are 
detected (i.e., increase the number of "hits"). Signal detection theory indicates that this can be affected by increasing the discriminability between the background noise and the target, and also by altering a user's response bias. For purposes of the SWAN interface, the most reliable method of improving the detection rate of the target sounds is to increase the discriminability. How this is to be done in an actual implementation is an important issue.

Similar research has been done on masking, which occurs when one stimulus prevents the detection of another. In essence, detection of the target stimulus is prevented by the occurrence of the masking sound. In a signal detection-type paradigm where the target and masker are presented at the same time this is referred to as simultaneous masking. However, there are other types of masking that can also occur. Forward masking occurs when the presentation of the masking sound occurs prior to the presentation of the target sound and the target is less likely to be detected. Similarly backward masking occurs when a masking sound presented just after the target sound lowers the chances of hearing the target. In these last two types of masking the masker is not occurring at the same time as the target, but it is still interfering with detection of that target. The properties of these types of masking have been well documented and exploited for practical applications (e.g., compressing .wav sound files to .mp3). It is important that stimulus sounds in the SWAN interface be designed such that the likelihood of their being masked by common background noises is minimized.

\section{Single versus Dual Sound}

In addition to detecting the presence of a sound or sounds from the interface, it is also critical that the sounds be distinguishable. When sounds arrive at the ear, they are 
nothing more than a series of pressure waves, with no inherent indicators of what source may have generated a given set of waves. With two or more sound sources, the brain must process the waves in order to segregate this collection of waves into what people perceive as distinct sources of sound, a process referred to as auditory scene analysis (Bregman, 1990). Bregman has found several principles that are important in understanding how this analysis is accomplished and what sound characteristics contribute to scene analysis (Bregman, 1993). These principles suggest ways in which the sound presentation in the SWAN system might be structured in order to facilitate their distinction from external sounds. Assuming that users are able to successfully segregate sounds, they then must attend to the appropriate sound and respond correctly.

\footnotetext{
Attention

There have been many theories and definitions proposed as to what attention is, and the role it plays in how people experience the world around them. At the same time, audition has long played a role in research on attention, probably most famously involving dichotic listening experiments (e.g., Cherry, 1953). In these classic selective attention tasks participants were asked to shadow (repeat back aloud) whatever was heard in one ear, while at the same time a different audio track played in the other ear. Participants were typically asked questions about the unshadowed (i.e., unattended) ear after they had finished the shadowing task. Often participants did not notice features or changes in the stimuli of the unattended ear, such as a change from English to German (Cherry, 1953) or repetition of the same word list thirty-five times (Moray, 1959). Despite evidence that some stimuli in the unattended ear may be processed 'deeply' (i.e., at a semantic level) (Corteen, 1972; Triesman, 1960), participants often fail to recall
} 
hearing stimuli in the unattended ear and do not tend to act on instructions presented in that ear (Moray, 1959).

In research on the SWAN system (Walker \& Lindsay, 2003, 2004, in press) I have clearly demonstrated that users of the system are able to successfully navigate when focused solely on the navigation task. While encouraging and informative as a proof of concept and useful for examining interface characteristics, successful performance in a selective attention paradigm is not necessarily reflective of the conditions under which users in the real world would make use of the system. A more likely scenario involves some type of divided attention task, with users (1) monitoring the SWAN for navigation guidance, (2) listening for information about their surroundings such as cars, and (3) performing some other task such as holding a conversation or listening to music. Thus, given the likely usage scenario of SWAN, it is important to consider the effects of attention-dividing tasks on navigation, and vice versa.

Research on auditory divided attention shows that it is often more difficult to perform a listening task if there is a distractor sound or distractor task present. In the case of SWAN usage, the presence of speech is a common distractor to the navigation task. If this speech discrimination stimulus requires an immediate response, it is possible that the delayed response time could result in danger to the user (e.g., reacting more slowly to the sound of screeching car brakes while walking on the sidewalk). It is therefore important in developing an interface such as the SWAN that such scenarios be well understood.

\section{Experimental Validation}

Based on the limits of existing research in auditory navigation aide interfaces, it is clear that there are a number of fundamental research questions to be addressed. The 
study conducted here was intended to examine the effects of a dual task paradigm on the SWAN interface. If additional, simultaneous tasks harm performance in the SWAN navigation task it will be a significant limitation to the interface. Thus I had participants navigate through maps (i.e., courses) using the virtual version of SWAN, either with or without a concurrent listening task (a speech discrimination task). I considered effects of divided attention on the performance of both tasks. 


\section{CHAPTER 2}

\section{HYPOTHESES}

1) I predicted that when the SWAN navigation task was completed alone, performance would be similar to that found in prior studies using the system (e.g., Walker \& Lindsay, in press).

2) When the speech discrimination task was completed alone (i.e., not as a distractor task), performance would be in line with results for the task found in prior work (e.g., Brungart et al. 2001) that has shown a relatively good rate of correct responses depending on the conditions.

3) In the dual task paradigm I expected to see a slight overall decrease in performance for both tasks. Both tasks are similar enough that some decline in performance was likely, however I expected there to be a significantly larger decrease in performance in the speech discrimination task than in the SWAN navigation task because the SWAN navigation task stimuli are constantly present, resulting in less of a decrement in performance due to a lapse in attention to the SWAN navigation task.

4) I expected overall performance on the SWAN navigation task to be better for participants who used the noise beacon sound compared to those who used the sonar beacon sound.

5) My expectation was that participants' subjective workload ratings of each phase of the experiment would remain relatively low, though it would be higher for the dual task portion of the experiment than the single task parts. 


\section{CHAPTER 3}

\section{METHODS}

\section{Participants}

Thirty undergraduates from the Georgia Institute of Technology (15 male, 15 female, $18-26$ years of age, mean $=21.5$, standard deviation $=2.87$ ) participated for course credit. All participants reported normal hearing, and did not have any prior experience with either of the experimental tasks.

\section{SWAN Navigation Task Interface}

Tran et al. (2000) studied 10 different stimuli for navigation beacons. Walker and Lindsay (in press) have examined performance with three of these sounds (a pink noise burst, a $1 \mathrm{kHz}$ pure tone and a sonar pulse). In the present study, the stimuli were the two sounds that had led to the best performance in these previous studies (noise and sonar). Both are $1 \mathrm{~s}$ long and of equal loudness. Listeners completed the navigation task with one of the sounds that was repeated periodically as a navigation aide.

\section{Stimuli: Speech Discrimination Task}

The stimuli in the speech discrimination task consisted of speech sounds drawn from the Coordinate Response Measure (CRM) speech corpus (Bolia, Nelson, Ericson, \& Simpson, 2000). These stimuli are recorded speech segments based on a speech intelligibility task developed by Moore (1981). Stimuli in the corpus are composed of phrases in the format "Ready (call sign) go to (color) (number) now." Each phrase is spoken using all possible combinations of call signs ("Arrow," "Baron," "Charlie," “Eagle," "Hopper," "Laker," "Ringo,” and “Tiger”), colors (“blue," "green,” "red,” and 
"white") and the numbers one through eight. A sample sentence would be, "Ready Charlie go to green four now." There are four male and four female speakers who each speak all 256 possible call sign/color/number combinations for a total of 2048 phrases in the corpus. All of the phrases are of similar duration across talkers and have been scaled to have the same RMS power. For the purposes of this study, only stimuli from the four male speakers were selected for use in the speech discrimination task. The task required the participant to monitor a series of speech sounds for a given target phrase. The speech target was placed in a stream of auditory stimuli with distracter stimuli similar to the target. This task is very similar to that studied by Brungart et al. (2001) and used a subset of the same stimuli. Participants made a verbal response to indicate the presence of the target and the correct information associated with it.

\section{Apparatus}

For the configuration of the experimental equipment see Figure 1. 


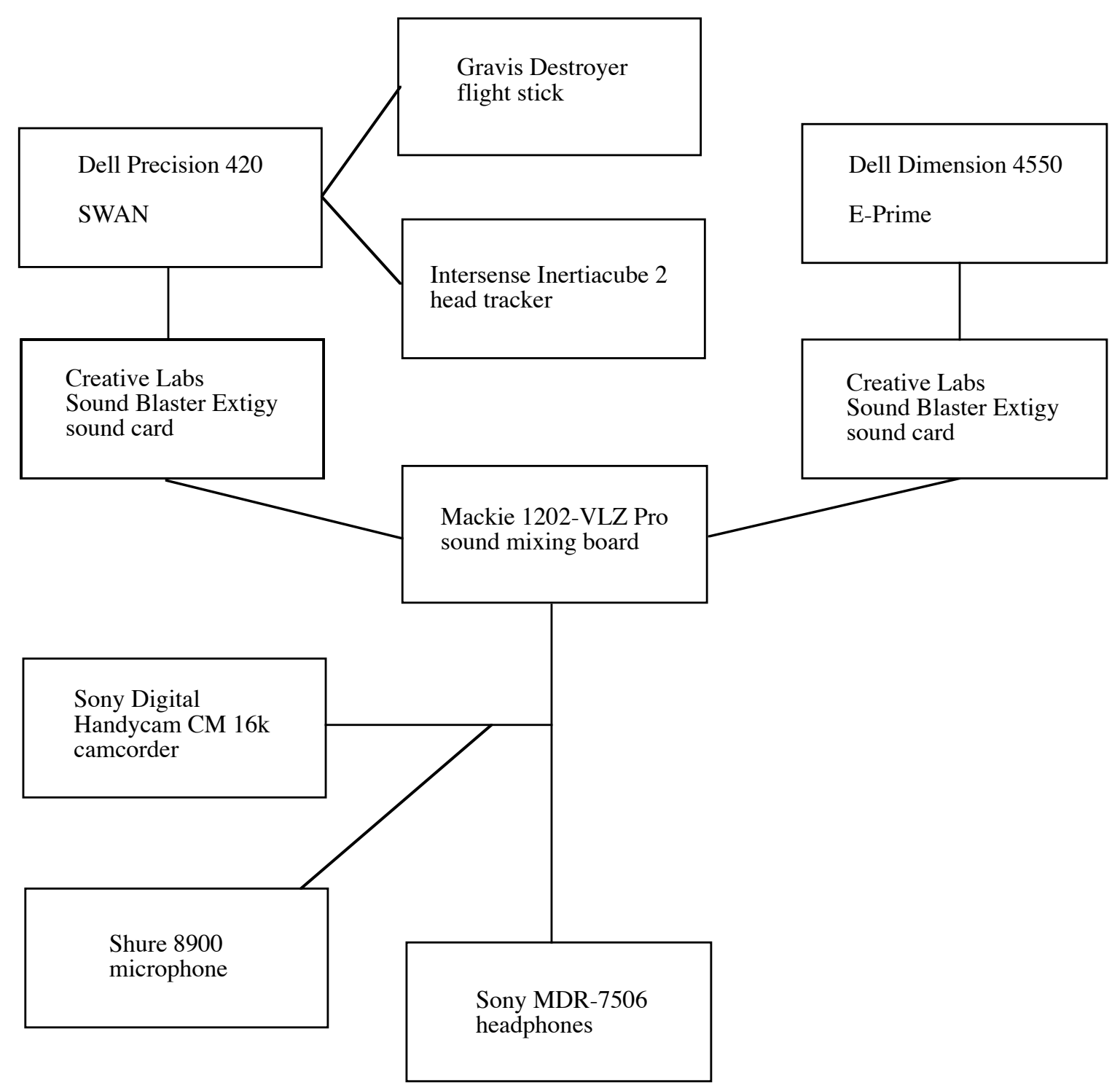

Figure 1: The relation and interaction of the experimental equipment

The navigation task was conducted in a virtual reality environment (VR) built using the Simple Virtual Environments (SVE) software package (Kessler, Kooper, \& Hodges, 1998). The study was run on a Dell Precision 420 PC running at $600 \mathrm{Mhz}$ with $128 \mathrm{MB}$ of RAM. Participants' head position and orientation was recorded using an Intersense InertiaCube 2 head tracker. A Gravis Destroyer PC joystick (Model \# 10501) that has been modified into a 'flight stick' controlled a participant's forward and backward 
movement within the virtual environment. The base of the joystick has been removed, so that only the stick remains. There are two buttons on the stick, one corresponding to forward movement and the other to backward movement. A Creative Labs SoundBlaster Extigy external sound card performed all the 3D audio rendering using the generalized head related transfer functions (HRTFs) built into the card.

The speech discrimination task was run using a Dell Dimension 4550 running at 2.67 Ghz with 256MB of RAM. The speech stimuli were organized and presented using mp3 file-playing software. The sound was played through a Creative Labs Soundblaster Extigy external sound card. Sound stimuli from the two tasks were mixed on a Mackie 1202-VLZ Pro sound mixing board and played through Sony MDR-7506 closed ear headphones. Experimental sessions were recorded on videotape, allowing the combined SWAN navigation and speech discrimination task audio, the participants' verbal responses, and the person's movements in the VR to all be captured on a single timestamped video recording.

As mentioned, this study was conducted using the VR version of the SWAN. Given that Tran et al. (2000) found azimuthal localization of an auditory beacon in a virtual environment to be comparable to that of the beacon in a real environment, the use of VR in this study should have had no effect on the results. The use of the VR has several benefits. It drastically reduces the potential for injury to a participant that could otherwise be present in walking without the aid of vision. In addition, having participants navigate through a VR world eliminates the issue of measurement error on the location sensors used in the wearable version of SWAN. Using a VR also allows much tighter 
control of the environmental conditions during the experiment. Further, the purpose of this study was to address attentional issues, not locomotion.

A computerized version of the NASA-TLX ${ }^{1}$ (Hart \& Staveland, 1988) was administered to assess subjective workload at various stages of the experiment (see below).

\section{Procedure}

As mentioned, there were two tasks in this study, the SWAN beacon navigation task and the speech discrimination task. Figure 2 depicts the flow of the experiment.

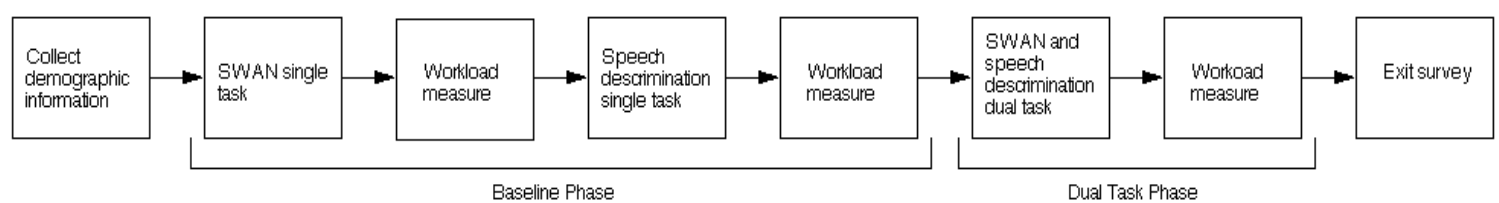

Figure 2: Study outline

In the Baseline phase of the study, participants performed each of the tasks alone (i.e., only the navigation task, then only the discrimination task) as a baseline measurement. When performed alone, the speech discrimination task stimuli were presented sequentially with a 7 s break between trials (see Brungart, 2001). In the Dual Task phase of the study participants were asked to perform the navigation task and the discrimination task simultaneously. When it was a distracter task, the speech discrimination trials were not presented one immediately after the other. Rather, one trial occurred during each

\footnotetext{
${ }^{1}$ According to recent work (see Rubio, Diaz, Martin, \& Puente, 2004) the NASA-TLX should be adequate to assess the subjective workload perceived by participants during each portion of the study. The NASATLX is desirable in the context of this experiment over comparable measures due to the fact that a computer version is readily available and it has a relatively low cost to administer in terms of time.
} 
segment of the map. The point at which it occurred during the segment was determined by a participant's distance from the next beacon's capture radius. This distance was constant across participants, but varied from path segment to path segment. This ensured that a) each participant received an equal number of speech discrimination trials and b) the speech discrimination stimuli were presented when the beacon sound in the SWAN task was at the same tempo for each participant. After each of the three task sets (navigation, discrimination, and navigation+discrimination) participants completed a subjective workload measure.

\section{Data Collection}

There were three types of raw data collected during this study:

1) A text file containing time and position data from the SWAN VR system. The text file contains participants' positions within the VR, as well as the pitch, yaw and roll of their head, all recorded approximately every $200 \mathrm{~ms}$.

2) A time-stamped video with an audio track composed of a combination of all the auditory stimuli and the participants' verbal responses. The video is comprised of a time-stamped recording of participants during the study. The audio track in the video consists of the navigation task stimuli, the speech discrimination task stimuli, and the participants' verbal responses to the latter task.

3) The videotape was manually analyzed and coded after the experiment to extract data regarding the speech discrimination task.

4) A text file containing the results of the computerized NASA-TLX inventory. 


\section{CHAPTER 4}

\section{RESULTS}

Participants' position and time were recorded as they performed the navigation task, and were analyzed to compute the dependent variables of path efficiency and time efficiency during the task, as in Walker and Lindsay (in press). These metrics are used in order to allow the distance traveled and the time it takes to travel that distance to be normalized across all the SWAN trials, accounting for the fact that the paths in each trial are not the same length. Participants' speed and accuracy in correctly identifying target phrases were used to measure performance in the speech discrimination task, as in Brungart et al. (2001). By obtaining a baseline measure of performance for each task during the first part of the experiment it was possible to determine if there was a change in performance in either of the two tasks when they were done concurrently.

Initially, the results of the SWAN single task were plotted in terms of time efficiency (Figure 3) and path efficiency (Figure 4) with the plots split by beacon sound. Across trials, the noise beacon lead to a more efficient performance across the task than the sonar beacon, especially with regard to time efficiency. The means and standard errors of these trials can be seen in Table 1 . 
Table 1: Time and path efficiency means by task and beacon type

\begin{tabular}{|c|c|c|c|c|c|c|c|c|}
\hline \multirow{4}{*}{ SWAN Single Task 1} & \multicolumn{3}{|c|}{$\begin{array}{c}\text { Time Efficiency } \\
\end{array}$} & \multicolumn{5}{|c|}{$\begin{array}{l}\text { Path Efficiency } \\
\end{array}$} \\
\hline & \multirow{2}{*}{$\begin{array}{c}\text { Noise Beacon } \\
\text { Mean }\end{array}$} & \multicolumn{2}{|c|}{ Sonar Beacon } & \multirow[b]{2}{*}{ Std error } & \multirow{2}{*}{$\begin{array}{c}\text { Noise Beacon } \\
\text { Mean }\end{array}$} & \multicolumn{3}{|c|}{ Sonar Beacon } \\
\hline & & Std error & Mean & & & Std error & Mean & Std error \\
\hline & \begin{tabular}{|l|l}
60.94 & \\
\end{tabular} & 8.93 & 51.91 & 6.46 & \begin{tabular}{|l|l}
51.78 & \\
\end{tabular} & 6.74 & 50.33 & 6.21 \\
\hline SWAN Single Task 2 & 126.47 & 6.00 & 108.05 & 5.19 & 82.52 & 3.19 & 74.30 & 4.31 \\
\hline SWAN Single Task 3 & 138.26 & 4.18 & 104.16 & 6.24 & 86.05 & 4.17 & 72.68 & 4.82 \\
\hline SWAN Single Task 4 & 147.70 & 7.07 & 138.89 & 4.82 & 88.96 & 3.76 & 93.08 & 2.05 \\
\hline sWAN Single Task 5 & 144.52 & 4.38 & 134.52 & 4.79 & 89.88 & 3.31 & 88.97 & 3.12 \\
\hline SWAN Dual Task 1 & 100.70 & 3.91 & 143.24 & 3.15 & 44.00 & 2.59 & 64.90 & 1.87 \\
\hline SWAN Dual Task 2 & 93.93 & 15.54 & 76.51 & 15.66 & 38.30 & 9.31 & 28.60 & 7.82 \\
\hline
\end{tabular}

Also, as can be seen in Figures 3 and 4, participants are clearly improving according to both metrics as their practice with the system increases. In order to test the statistical significance of these results, a multivariate analysis of variance (MANOVA) was conducted on the results with beacon type as a between participants independent variable and performance across trials (the effect of practice) as a within-subjects independent variable. The two dependent measures were path efficiency and time efficiency. Significant main effects of both beacon type, $F(2,27)=4.413, p<.05$, Wilk's Lambda $=$ .754 , and practice, $F(8,21)=114.590, p<.05$, Wilk's Lambda $=.022$, were found, moderated by a significant interaction between beacon sound and practice, $F(8,21)=$ 3.106, $p<.05$, Wilk's Lambda $=.458$. Further analysis examining each dependent measure singly found a significant difference for both time efficiency, $F(4,112)=$ $201.601, p<.05$, and path efficiency, $F(4,112)=30.494, p<.05$, for practice, but only time efficiency showed a significant effect, $F(4,112)=3.559, p<.05$, for the interaction between beacon type and practice. The Greenhouse-Geisser correction was used to account for possible violations of sphericity.

The goal of the SWAN single task phase of the study had been to get participants to reach an asymptotic level of performance for both measures. This was accomplished 
and can be seen in Figures 3 and 4. Given that this had occurred, the main comparison of interest could then be made between performance on the SWAN task in the SWAN single task and the dual task segments of the study. Only the last two trials in the SWAN single task were used in this comparison, since the desired comparison was between peak single task performance and performance during a dual task situation. The means and standard errors of these results can be seen in Table 1.

The dual task only contained two blocks total, both of which were included in the analysis. This comparison showed a clear decrease in performance in terms of both time efficiency and path efficiency during the dual task phase compared to the single task phase for both beacon types. This can be seen clearly in Figure 3 for time efficiency and Figure 4 for path efficiency.

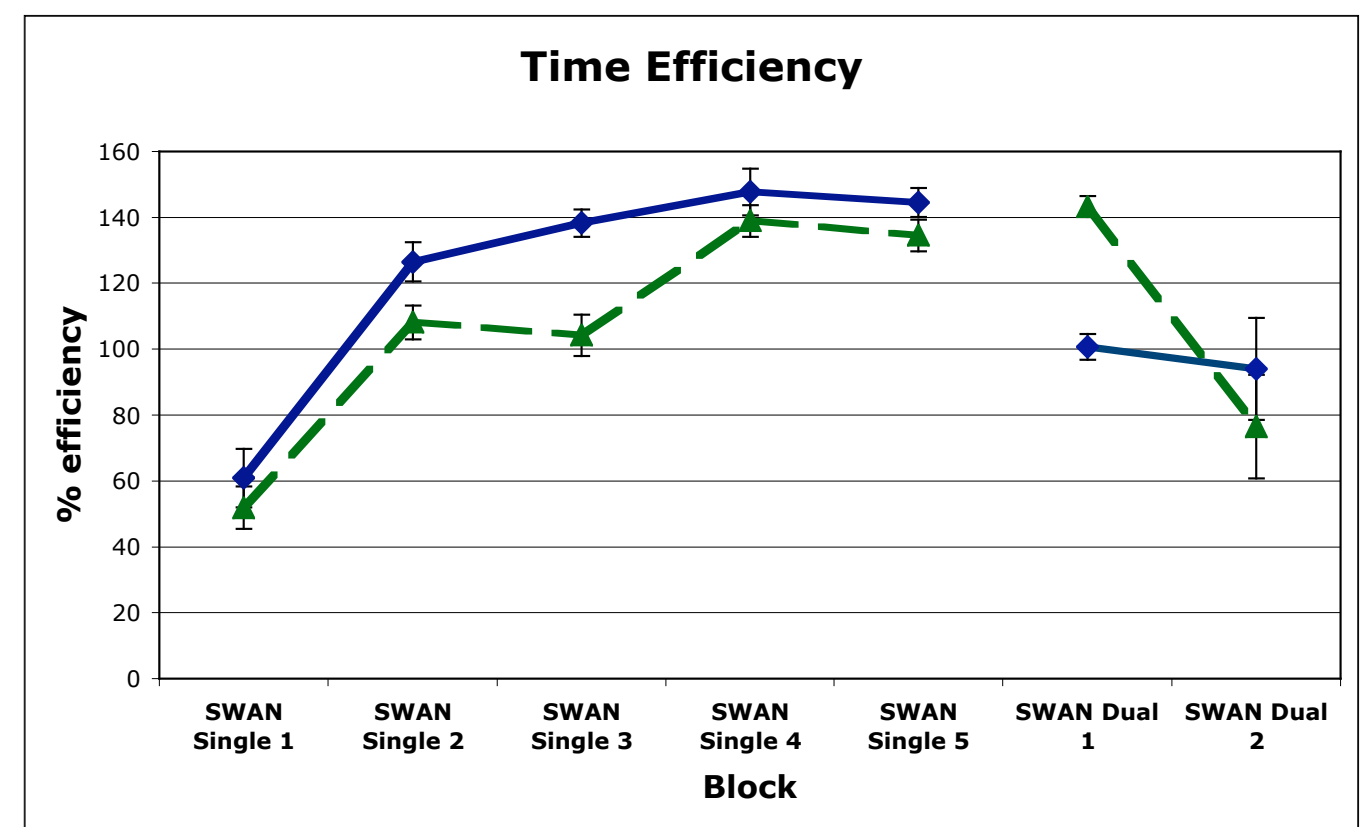

Figure 3: Time efficiencies by beacon type for the SWAN navigation task in the single and dual task phases. The solid line represents the noise beacon and the dashed line represents the sonar beacon. 


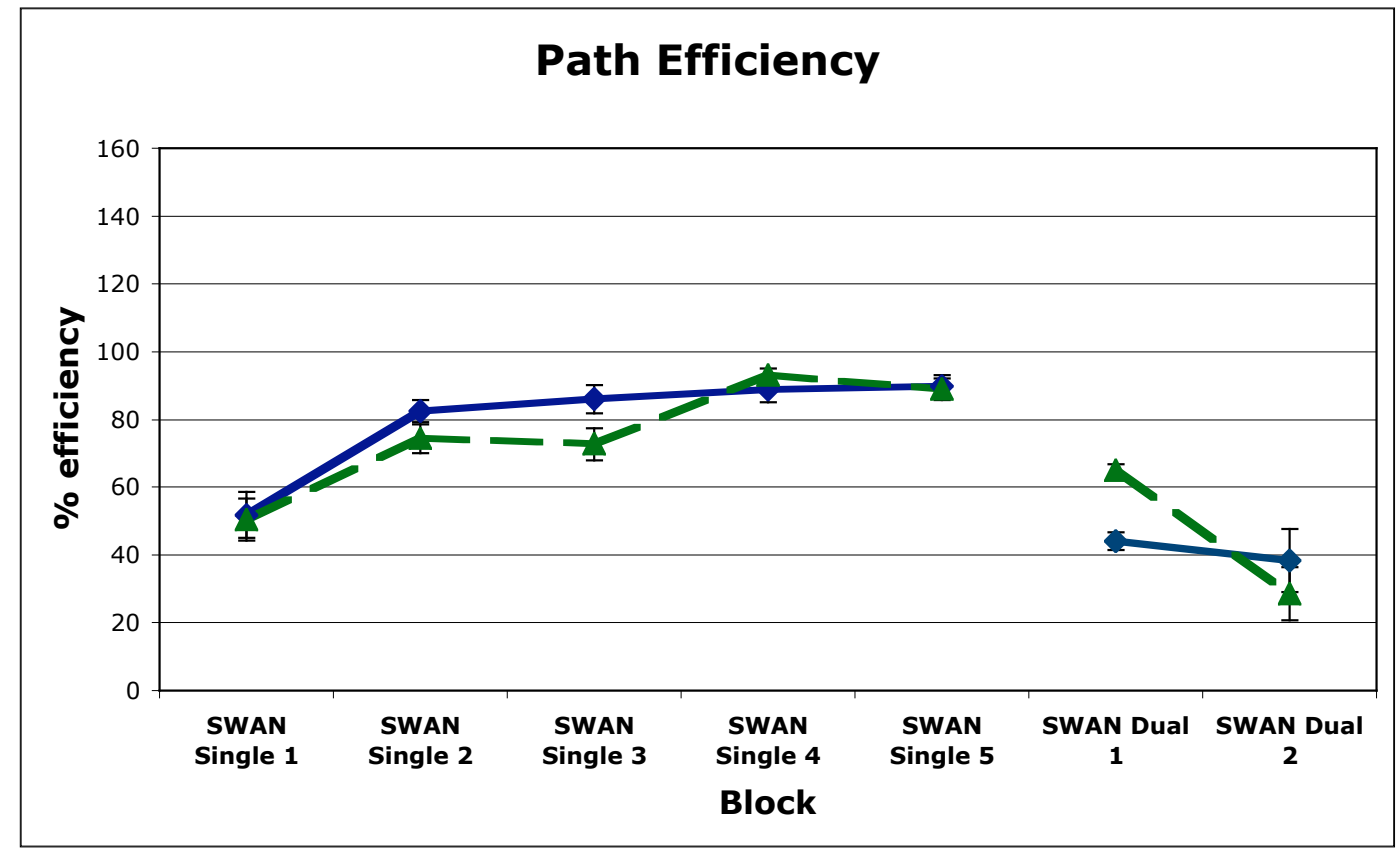

Figure 4: Path efficiencies by beacon type for the SWAN navigation task in the single and dual task phases. The solid line represents the noise beacon and the dashed line represents the sonar beacon.

Interestingly, the different beacon types showed a different rate of decline in performance during the dual task situation than in the single task phase, with the noise beacon not always showing better performance, as it had in the single task phase. These trends can also be seen clearly in Figures 3 and 4. A MANOVA was conducted to test the significance of these observations. Only the last two blocks of trials from the SWAN single task were compared to the two blocks of trials in the dual task portion of the study in this analysis. Beacon sound type was an independent between-subjects variable, and single versus dual task and performance across trials (the effect of practice) were independent within-subjects variables. The dependent measures were again time efficiency and path efficiency. A significant main effect of single versus dual task, $F(2,27)=52.354, p<.05$, Wilk's Lambda $=.205$, was found, moderated by a significant 
interaction between the single/dual task condition and beacon sound, $F(2,27)=4.046, p<$ .05 , Wilk's Lambda $=.769$. No significant main effect of beacon type was found. Further analysis examining each dependent measure singly found a significant effect of single versus dual task for path efficiency, $F(1,28)=43.851, p<.05$, but no such effect for time efficiency. A significant interaction for single versus dual task and beacon type was also found for time efficiency, $F(1,28)=7.324, p<.05$. The Greenhouse-Geisser correction was used in these univariate analyses to account for possible violations of sphericity. These effects can be observed in Figures 3 and 4.

In the speech discrimination task participants' reaction times and accuracy were recorded and compared between the single and dual task phases. The mean reaction times $($ Figure 5$)$ in the single task $($ mean $=1.492 \mathrm{~s}$, standard error $=.097 \mathrm{~s}$, and mean $=1.232 \mathrm{~s}$, standard error $=.080 \mathrm{~s}$ in Block 1 and Block 2 respectively) were higher than those in the dual task phase $($ mean $=.890 \mathrm{~s}$, standard error $=.063 \mathrm{~s}$ and mean $=.915 \mathrm{~s}$, standard error $=.060 \mathrm{~s}$ in Blocks 1 and 2 respectively). Contrastingly, participants' accuracies (Figure 6) during the single task phase $($ mean $=24 \%$, standard error $=1 \%$ and mean $=30 \%$, standard error $=2 \%$ in Blocks 1 and 2 respectively) were higher in the first block than in the first dual task block $($ mean $=15 \%$, standard error $=1 \%$ ), but by the second block of trials the accuracy during the dual task (mean $=30 \%$, standard error $=2 \%$ ) had risen to the same levels as in Block 2 of the single task. 


\section{Reaction Time}

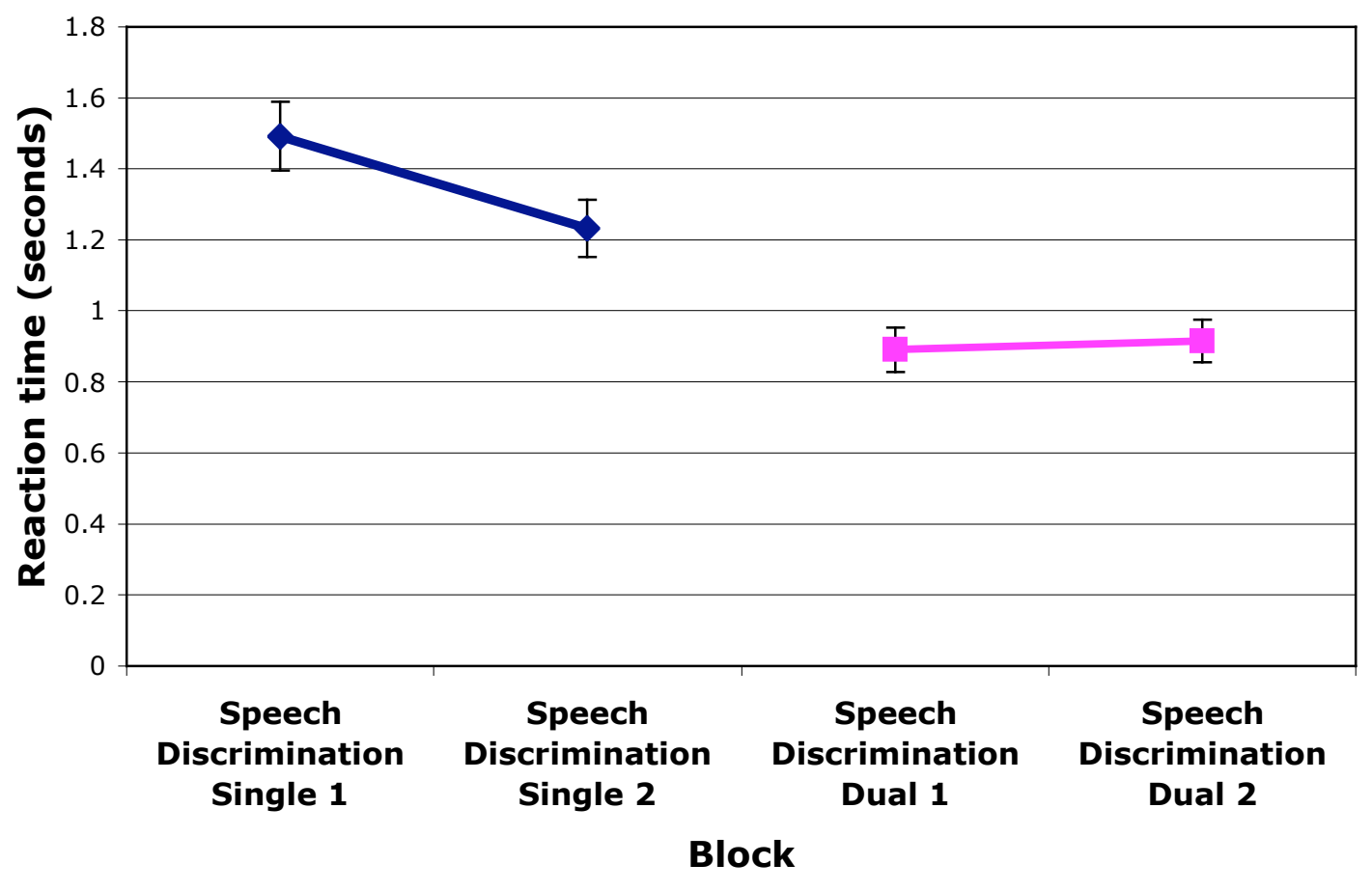

Figure 5: Speech discrimination task reaction times 


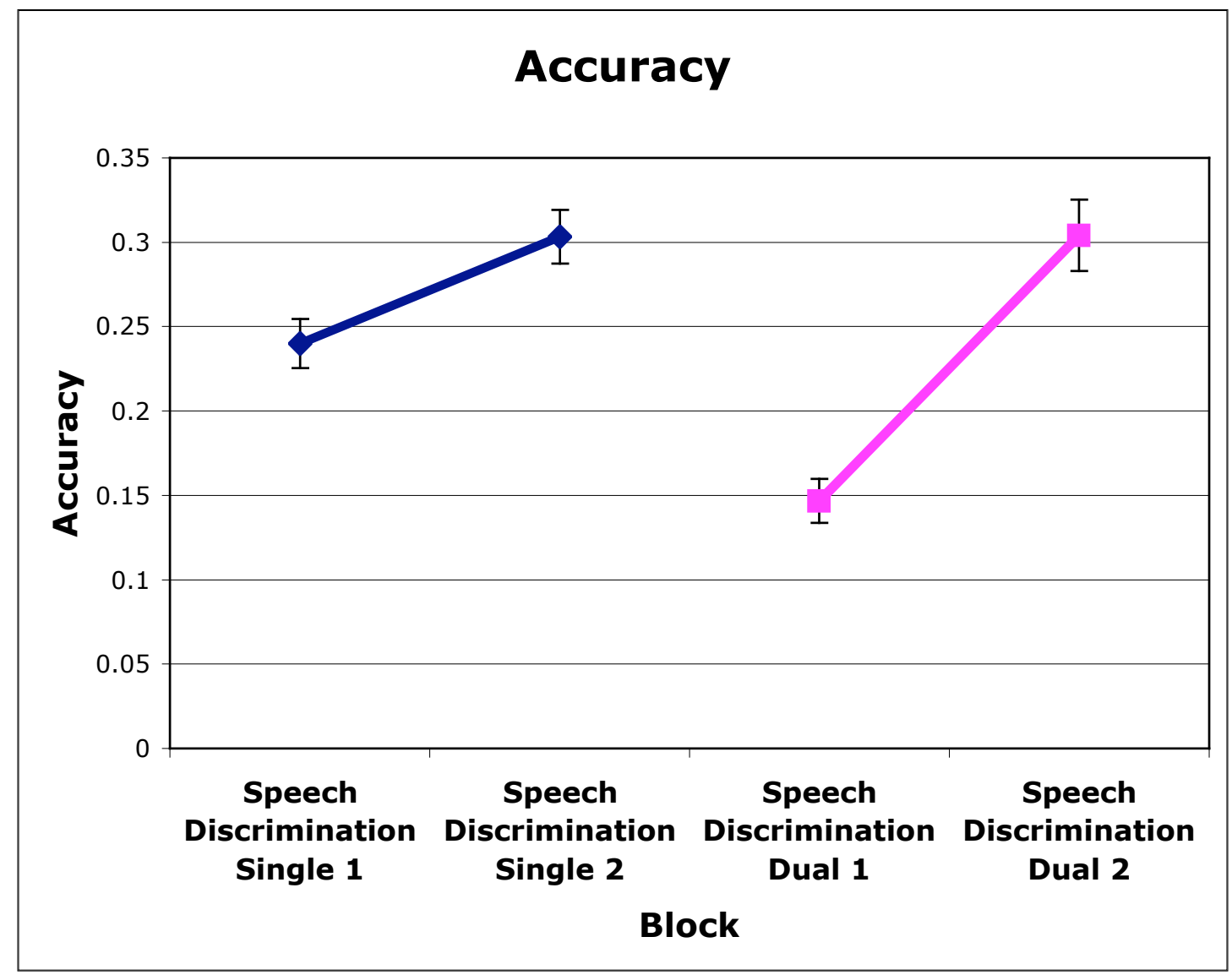

Figure 6: Speech discrimination task accuracy

These observations were analyzed using a MANOVA, with the independent within-subjects variables of single versus dual task and performance across trials (the effect of practice). The dependent measures were reaction time and accuracy. A significant effect, $F(2,27)=18.920, p<.05$, Wilk's Lambda $=.425$, was found for the single and dual task parts of the study as well as for practice, $F(2,27)=27.703, p<.05$, Wilk's Lambda $=.336$, moderated by a significant interaction between these two variables, $F(2,27)=9.364, p<.05$, Wilk's Lambda $=.599$. Both dependent measures were significant for all multivariate effects. 
Data recorded from the NASA-TLX were used to calculate a mean reported workload for use in assessing the perceived workload involved in the different task sets. The workload reported during the SWAN single task $($ mean $=39.42$, standard error $=$ 2.97) was much less than that reported during the speech discrimination single task (mean $=67.99$, standard error $=3.52$ ). The workload reported during the dual task phase (mean $=69.87$, standard error $=3.75)$ was very close to that reported during the speech discrimination single task and much higher than that reported during the SWAN single task. This trend can be seen in Figure 7.

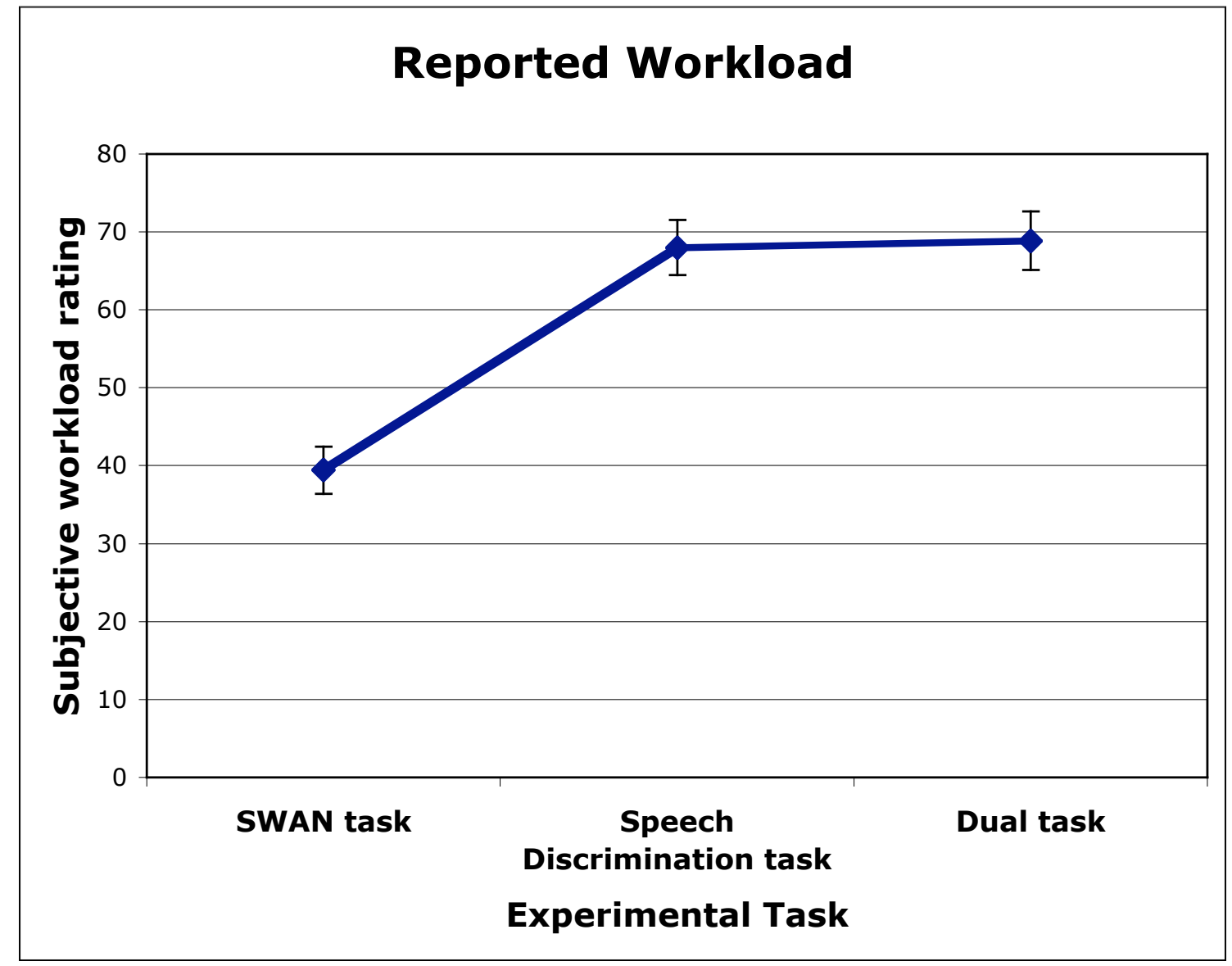

Figure 7: Reported workload 
A repeated measures analysis of variance (ANOVA) was performed to test the significance of these observations. The task being performed was the independent variable and reported workload was the dependent measure. This analysis found there to be a significant difference, $F(2,27)=36.415, p<.05$, in reported workload between the different phases of the study. Pairwise comparisons of the three phases using LSD (minimum mean difference $=.878$ ) showed a significant difference only between the SWAN single task and the other two tasks. 


\section{CHAPTER 5}

\section{DISCUSSION}

As I predicted, performance in the SWAN single task was similar to performance found in prior work with that task (Walker \& Lindsay, in press). The noise burst was once again found to be a better auditory navigation beacon than the sonar pulse. It has been theorized previously by Walker and Lindsay that this result may be due to its ease of localizability as a broad-spectrum noise. It is important to note, however, that while the difference in performance between the two beacon sounds may have been statistically significant, there are other important considerations in terms of practical significance, which will be discussed later.

The time and path efficiencies found in the SWAN navigation task were also similar to those found by Walker and Lindsay (in press). This replication supports their earlier findings of improvement in the navigation task based on practice. Additionally, the number of trials given in this portion of the experiment was beyond the number ever previously given in studies using the SWAN. The results approached asymptotic performance with the SWAN interface using the VR testing environment. This new data will be useful for comparison in future studies using the system. Also, as the asymptotic levels are in regions considered 'very good' performance, these results in the most basic sense demonstrate that people are capable of performing well on the SWAN navigation task after only a modest amount of practice.

Interestingly, the correct response percentage found in the speech discrimination single task was lower than that found in work by Brungart et al. (2001), contrary to what I previously hypothesized. It is possible that the results found in this study differ due to 
the variations between the way the speech discrimination task was done in this task compared to the original task used by Brungart et al. (2001). In the original task participants were given the speech stimuli and responded by using a mouse to click a target on a computer screen that matched the correct color and number (i.e. if the answer was 'blue 4' the correct response would be to click on a blue square on the screen that had a 4 inside it). However, participants responded verbally to the speech stimuli in the speech discrimination task in this study. This change in task could be responsible for the varying results. Regardless of the differences, performance in either study when listeners are trying to identify a target talker amidst two masking talkers with the same gender typically shows similarly poor accuracy. It should be noted that participants are performing well above chance (1/32 or $3.125 \%)$, but their performance is still not good in terms of practical concerns. Prior work by Brungart et al. (2001) has not included a measure of reaction time, so it is not possible to draw a comparison for that measure. The results of this task, combined with the reported workload would seem to indicate that it is not an easy task to perform, even in a single task paradigm. However, both accuracy and reaction time improved with practice during the single task phase, indicating that participants were able to perform the task. The speech discrimination task is a difficult task it is a good task to include in the dual task paradigm because it ensures that the dual task will be a taxing one.

Having considered the single task results, we arrive at the main question this study was intended to investigate, namely what effect a secondary task would have on performance in the SWAN task. As hypothesized, performance on each of the tasks in the dual task part of the study was worse overall than in the single task phase. This decrease 
in performance was observed in the time and path efficiencies of the SWAN task as well as the accuracy and response time in the speech discrimination task. However, I predicted that the largest decrease in performance during the dual task phase would occur in the speech discrimination task. This was not in fact, what occurred. Instead the largest drop in performance was observed in the SWAN task. This was surprising, given that the stimuli in the speech discrimination task are not persistent, and I had therefore hypothesized that performance in the task would suffer more from attentional lapses than the SWAN task with its persistent stimuli. Reasons for this result can be postulated by examining the relationships between the single and dual task performance more closely.

One possible explanation for these results is that participants, who were instructed to perform as well as possible on both tasks during the dual task phase, made a decision (conscious or not) to sacrifice SWAN performance in order to allow more cognitive resources to be devoted to the speech discrimination task. In essence they lessened their effort at what they perceived to be an easier task in order to improve their performance on a more difficult task. This idea is supported by the changes in performance observed between the single and dual task phases for both tasks. In the single task SWAN phase, average performance in terms of path and time efficiencies was very good. Performance increased throughout the single task. However, in the dual task, exactly the opposite occurred. Participants' performances became worse as the dual task phase progressed. Assuming that the difficulty of performing the dual task remained the same at the least, if not improving due to practice, then it would be expected that while performance on the SWAN task might be lower, there would not be a decrease as the dual task phase progressed. At the same time, performance on the speech discrimination task in the dual 
task phase was worse than in the single task in the beginning, but by the end of the dual task phase participants' mean accuracy had risen to the same level as the maximum achieved during the single task phase. Also, throughout the dual task phase paricipants' reaction times were faster than during the single task phase. In summary, participants' performance on the SWAN task declined as the dual task phase progressed while their performance on the speech discrimination task improved. This could support the theory that participants started shifting cognitive resources to the speech discrimination task during the dual task phase in order to attempt to maintain performance on that task, which consequently led to fewer resources being available for the SWAN navigation task, thus decreasing performance on that task.

The subjective workload ratings were found to be highest for the dual task portion of the experiment as was hypothesized. However, the reported workload for the speech discrimination single task was almost as high as that of the dual task. Both of these ratings were nearly double the workload rating of the SWAN single task. This suggests that participants, having performed both of the single tasks, did not perceive the dual task to be significantly harder than the speech discrimination task alone. It could indicate that a majority of the workload in the dual task phase was due to the speech discrimination task, but further study with an additional task ordering where the dual task occurred before either of the single tasks would be required to test this hypothesis.

There are important practical implications of these results for the use of the SWAN interface by visually impaired users or users for whom vision is not an option. While participants find the SWAN task has a relatively low workload, it still requires enough cognitive resources (or enough of the same cognitive resources) that introducing 
a secondary auditory task can possibly interfere with a user's ability to perform with the interface. This is obviously a potential cause for caution in further design and implementation of this interface. However, there are some important caveats. First, it should be noted that the speech discrimination task used here was a very hard task, which is made apparent both in participants' reported workloads as well as their measured performance. In many common SWAN usage scenarios, it is unlikely that a user would be required to perform another auditory task of this difficulty while using the SWAN, especially for any extended periods. Additionally, users in many cases would simply be able to stop moving and focus on the other auditory task and afterwards they could continue navigating with the SWAN interface. The second key point is that while performance declined during the dual task phase, it is not clear that this drop would have any practical significance in terms of a user's ability to navigate using the SWAN interface. Performance in terms of path and time efficiencies in SWAN single task situations are often high for practiced users, indicating that users are extremely adroit at following the paths indicated by the interface. The moderate drop in performance during the dual task phase observed in this study may be relatively negligible in terms of real world user performance.

While this study demonstrates that a secondary task does decrease SWAN performance, it is not possible to be certain as to the exact nature of the interaction between the two tasks. Further studies would allow this interaction to be examined in more detail. As both tasks are auditory, they definitely will use some of the same cognitive resources. Though the use of non-speech audio in the SWAN task is meant, in part, to avoid clashes with speech-based secondary tasks such as conversations. Future 
work to investigate this overlap and its role in decreased performance could also be interesting. Also, replicating this study with an easier or harder version of the speech discrimination task (e.g., less or more masking talkers, differing talker genders, etc.) would be interesting. Changing the secondary task in this way could offer insight in to what levels of difficulty in the secondary task lead to decreased performance on the SWAN task. It could also help to determine if subjectively reported workload is potentially a good indicator of when a secondary task is impairing performance in the SWAN task. This would have obvious practical value when implementing the SWAN system. 


\section{APPENDIX A}

\section{SWAN DATA}

\begin{tabular}{|c|c|c|c|c|c|c|}
\hline \multicolumn{7}{|l|}{$\begin{array}{l}\text { SWAN } \\
\text { single } \\
\text { task }\end{array}$} \\
\hline Subject & Condition & Мар & $\begin{array}{l}\text { Time } \\
\text { (secs) }\end{array}$ & $\begin{array}{l}\text { Overall } \\
\text { Distance }\end{array}$ & Time Mean & $\begin{array}{l}\text { Distance } \\
\text { Mean }\end{array}$ \\
\hline 5 & $\mathrm{~N}$ & 1 & 185.672 & 241.6814476 & & \\
\hline 7 & $\mathrm{~N}$ & 1 & 73.032 & 123.6557539 & & \\
\hline 9 & $\mathrm{~N}$ & 1 & 80.687 & 108.8343573 & & \\
\hline 11 & $\mathrm{~N}$ & 1 & 126.203 & 146.3201892 & & \\
\hline 13 & $\mathrm{~N}$ & 1 & 197.89 & 233.8699737 & & \\
\hline 15 & $\mathrm{~N}$ & 1 & 131.891 & 215.5085682 & & \\
\hline 17 & $\mathrm{~N}$ & 1 & 69.828 & 116.4795442 & & \\
\hline 21 & $\mathrm{~N}$ & 1 & 104.625 & 130.1813748 & & \\
\hline 23 & $\mathrm{~N}$ & 1 & 316.875 & 432.7380084 & & \\
\hline 25 & $\mathrm{~N}$ & 1 & 84.672 & 137.3605466 & & \\
\hline 27 & $\mathrm{~N}$ & 1 & 82.688 & 107.5912145 & & \\
\hline 29 & $\mathrm{~N}$ & 1 & 59.718 & 108.584082 & & \\
\hline 31 & $\mathrm{~N}$ & 1 & 104.344 & 123.217969 & & \\
\hline 33 & $\mathrm{~N}$ & 1 & 271.062 & 564.2571 & & \\
\hline 35 & $\mathrm{~N}$ & 1 & 162.171 & 106.4288373 & 136.7572 & 193.1139311 \\
\hline 5 & $\mathrm{~N}$ & 2 & 202.281 & 378.8056394 & & \\
\hline 7 & $\mathrm{~N}$ & 2 & 153.469 & 343.8909969 & & \\
\hline 9 & $\mathrm{~N}$ & 2 & 167.656 & 283.4732317 & & \\
\hline 11 & $\mathrm{~N}$ & 2 & 202.969 & 343.951743 & & \\
\hline 13 & $\mathrm{~N}$ & 2 & 188.625 & 335.8469286 & & \\
\hline 15 & $\mathrm{~N}$ & 2 & 239.859 & 417.4892123 & & \\
\hline 17 & $\mathrm{~N}$ & 2 & 135 & 290.2849826 & & \\
\hline 21 & $\mathrm{~N}$ & 2 & 149.953 & 298.1347253 & & \\
\hline 23 & $\mathrm{~N}$ & 2 & 203.218 & 382.6794738 & & \\
\hline 25 & $\mathrm{~N}$ & 2 & 200.375 & 404.9732706 & & \\
\hline 27 & $\mathrm{~N}$ & 2 & 165.234 & 299.5261935 & & \\
\hline 29 & $\mathrm{~N}$ & 2 & 152.797 & 294.6492013 & & \\
\hline 31 & $\mathrm{~N}$ & 2 & 260.406 & 437.1265851 & & \\
\hline 33 & $\mathrm{~N}$ & 2 & 186.281 & 359.9312489 & & \\
\hline 35 & $\mathrm{~N}$ & 2 & 193.563 & 281.8552243 & 186.7790667 & 343.5079105 \\
\hline 5 & $\mathrm{~N}$ & 3 & 163.797 & 293.2118499 & & \\
\hline 7 & $\mathrm{~N}$ & 3 & 159.078 & 378.5798235 & & \\
\hline 9 & $\mathrm{~N}$ & 3 & 189.687 & 287.5933889 & & \\
\hline 11 & $\mathrm{~N}$ & 3 & 160.422 & 287.6678913 & & \\
\hline 13 & $\mathrm{~N}$ & 3 & 171.312 & 280.8496912 & & \\
\hline
\end{tabular}




\begin{tabular}{|l|l|l|l|l|l|l|}
\hline 15 & N & 3 & 201.468 & 481.4968541 & & \\
\hline 17 & $\mathrm{~N}$ & 3 & 147.781 & 285.5419423 & & \\
\hline 21 & $\mathrm{~N}$ & 3 & 151.922 & 306.0084222 & & \\
\hline 23 & $\mathrm{~N}$ & 3 & 178.75 & 428.1054321 & & \\
\hline 25 & $\mathrm{~N}$ & 3 & 183.531 & 398.3289684 & & \\
\hline 27 & $\mathrm{~N}$ & 3 & 175.312 & 284.2243729 & & \\
\hline 29 & $\mathrm{~N}$ & 3 & 157.609 & 280.4760577 & & \\
\hline 31 & $\mathrm{~N}$ & 3 & 238.109 & 447.7818911 & & \\
\hline 33 & $\mathrm{~N}$ & 3 & 160.985 & 287.5802885 & & \\
\hline 35 & $\mathrm{~N}$ & 3 & 160.11 & 285.4495796 & 173.3248667 & 334.1930969 \\
\hline 5 & $\mathrm{~N}$ & 4 & 170.531 & 311.8154269 & & \\
\hline 7 & $\mathrm{~N}$ & 4 & 139.75 & 332.4857415 & & \\
\hline 9 & $\mathrm{~N}$ & 4 & 174.782 & 307.2867054 & & \\
\hline 11 & $\mathrm{~N}$ & 4 & 158.047 & 307.1123449 & & \\
\hline 13 & $\mathrm{~N}$ & 4 & 178.718 & 305.8338333 & & \\
\hline 15 & $\mathrm{~N}$ & 4 & 295.375 & 652.3438812 & & \\
\hline 17 & $\mathrm{~N}$ & 4 & 137.969 & 305.7959927 & & \\
\hline 21 & $\mathrm{~N}$ & 4 & 151.531 & 314.4740703 & & \\
\hline 23 & $\mathrm{~N}$ & 4 & 138.469 & 341.8006674 & & \\
\hline 25 & $\mathrm{~N}$ & 4 & 148.438 & 324.0636672 & & \\
\hline 27 & $\mathrm{~N}$ & 4 & 173.766 & 310.0316172 & & \\
\hline 29 & $\mathrm{~N}$ & 4 & 160.016 & 306.8500631 & & \\
\hline 31 & $\mathrm{~N}$ & 4 & 223.656 & 420.078831 & & \\
\hline 33 & $\mathrm{~N}$ & 4 & 197.61 & 351.509338 & & \\
\hline 35 & $\mathrm{~N}$ & 4 & 159.391 & 304.5936205 & 173.8699333 & 346.4050534 \\
\hline 5 & $\mathrm{~N}$ & 5 & 203.75 & 306.7708126 & & \\
\hline 7 & $\mathrm{~N}$ & 5 & 146.312 & 349.3019272 & & \\
\hline 9 & $\mathrm{~N}$ & 5 & 174.563 & 303.2655778 & & \\
\hline 11 & $\mathrm{~N}$ & 5 & 164.297 & 301.4233148 & & \\
\hline 13 & $\mathrm{~N}$ & 5 & 160.687 & 299.0463483 & & \\
\hline 15 & $\mathrm{~N}$ & 5 & 209.578 & 505.9769398 & & \\
\hline 17 & $\mathrm{~N}$ & 5 & 153.141 & 307.1457458 & & \\
\hline 21 & $\mathrm{~N}$ & 5 & 151.125 & 339.2326126 & & \\
\hline 23 & $\mathrm{~N}$ & 5 & 205.812 & 465.9087414 & & \\
\hline 25 & $\mathrm{~N}$ & 5 & 170.187 & 314.628753 & & \\
\hline 27 & $\mathrm{~N}$ & 5 & 172.828 & 305.4636907 & & \\
\hline 29 & $\mathrm{~N}$ & 5 & 172.25 & 308.6189781 & & \\
\hline 31 & $\mathrm{~N}$ & 5 & 173.687 & 332.5047431 & & \\
\hline 33 & $\mathrm{~N}$ & 5 & 204.313 & 319.3685897 & & \\
\hline 35 & $\mathrm{~N}$ & 5 & 160.297 & 302.0712644 & 174.8551333 & 337.3818693 \\
\hline 4 & $\mathrm{~S}$ & 1 & 144.125 & 218.4019881 & & \\
\hline 6 & $\mathrm{~S}$ & 1 & 132.188 & 204.8185076 & & \\
\hline 10 & $\mathrm{~S}$ & 1 & 173.454 & 398.0588181 & & \\
\hline 12 & $\mathrm{~S}$ & 1 & 154.031 & 157.2288539 & & \\
\hline 14 & $\mathrm{~S}$ & 1 & 94.906 & 107.2717953 & & \\
\hline & & & & & & \\
\hline
\end{tabular}




\begin{tabular}{|l|l|l|l|l|l|l|}
\hline 16 & S & 1 & 158.859 & 158.0263051 & & \\
\hline 18 & S & 1 & 115.625 & 183.282497 & & \\
\hline 20 & S & 1 & 117.735 & 221.7441645 & & \\
\hline 22 & S & 1 & 436.156 & 331.214707 & & \\
\hline 24 & S & 1 & 105.75 & 131.6845873 & & \\
\hline 26 & S & 1 & 111.5 & 116.9823716 & & \\
\hline 28 & S & 1 & 323.25 & 393.5743501 & & \\
\hline 30 & S & 1 & 181.312 & 141.2678117 & & \\
\hline 32 & S & 1 & 82.797 & 108.5864855 & & \\
\hline 36 & S & 1 & 76.078 & 108.3991837 & 160.5177333 & 198.7028284 \\
\hline 4 & S & 2 & 229.109 & 411.6749162 & & \\
\hline 6 & S & 2 & 213.187 & 387.0255139 & & \\
\hline 10 & S & 2 & 253.359 & 601.5424319 & & \\
\hline 12 & S & 2 & 227.922 & 342.0643527 & & \\
\hline 14 & S & 2 & 183.141 & 292.2168916 & & \\
\hline 16 & S & 2 & 223.454 & 351.3517727 & & \\
\hline 18 & S & 2 & 252.141 & 414.3069764 & & \\
\hline 20 & S & 2 & 224.969 & 499.7573489 & & \\
\hline 22 & S & 2 & 282.094 & 379.4610676 & & \\
\hline 24 & S & 2 & 177.969 & 295.1352771 & & \\
\hline 26 & S & 2 & 167.344 & 293.0551374 & & \\
\hline 28 & S & 2 & 301.281 & 455.1947083 & & \\
\hline 30 & S & 2 & 184.891 & 288.6470381 & & \\
\hline 32 & S & 2 & 167.484 & 286.2452415 & & \\
\hline 36 & S & 2 & 190.797 & 424.9141288 & 218.6094667 & 381.5061869 \\
\hline 4 & S & 3 & 261.297 & 453.9679578 & & \\
\hline 6 & S & 3 & 198.375 & 325.8067539 & & \\
\hline 10 & S & 3 & 361.344 & 856.2832626 & & \\
\hline 12 & S & 3 & 250.891 & 351.560499 & & \\
\hline 14 & S & 3 & 160.016 & 283.2625131 & & \\
\hline 16 & S & 3 & 198 & 311.9853819 & & \\
\hline 18 & S & 3 & 260.329 & 446.5380114 & & \\
\hline 20 & S & 3 & 205.766 & 403.1059103 & & \\
\hline 22 & S & 3 & 309.766 & 456.4707466 & & \\
\hline 24 & S & 3 & 178.938 & 279.7776346 & & \\
\hline 26 & S & 3 & 237.344 & 342.1480464 & & \\
\hline 28 & S & 3 & 246.5 & 427.5723523 & & \\
\hline 30 & S & 3 & 235.453 & 348.645854 & & \\
\hline 32 & S & 3 & 171.032 & 281.972155 & & \\
\hline 36 & S & 3 & 175.922 & 365.7245931 & 230.0648667 & 395.6547781 \\
\hline 4 & S & 4 & 192.016 & 334.5595664 & & \\
\hline 6 & S & 4 & 199.985 & 371.7996179 & & \\
\hline 10 & S & 4 & 150.453 & 364.4947338 & & \\
\hline 12 & S & 4 & 196.907 & 321.0763024 & & \\
\hline 14 & S & 4 & 163.782 & 308.8636011 & & \\
\hline & & & & & & \\
\hline
\end{tabular}




\begin{tabular}{|l|l|l|l|l|l|l|}
\hline 16 & S & 4 & 171.562 & 317.3234144 & & \\
\hline 18 & S & 4 & 253.735 & 409.008309 & & \\
\hline 20 & S & 4 & 157.984 & 354.1263997 & & \\
\hline 22 & S & 4 & 214.484 & 306.7250339 & & \\
\hline 24 & S & 4 & 172.719 & 301.8452086 & & \\
\hline 26 & S & 4 & 170.234 & 312.1802703 & & \\
\hline 28 & S & 4 & 197.25 & 323.5968423 & & \\
\hline 30 & S & 4 & 182.063 & 307.0777552 & & \\
\hline 32 & S & 4 & 193.265 & 304.3733022 & & \\
\hline 36 & S & 4 & 157.062 & 329.1899659 & 184.9000667 & 331.0826882 \\
\hline 4 & S & 5 & 172.454 & 302.984031 & & \\
\hline 6 & S & 5 & 165.125 & 318.908752 & & \\
\hline 10 & S & 5 & 195.781 & 465.6960456 & & \\
\hline 12 & S & 5 & 205.656 & 306.4699757 & & \\
\hline 14 & S & 5 & 160.844 & 303.7988052 & & \\
\hline 16 & S & 5 & 191.563 & 351.1701588 & & \\
\hline 18 & S & 5 & 272.032 & 460.9533721 & & \\
\hline 20 & S & 5 & 166.109 & 359.5549607 & & \\
\hline 22 & S & 5 & 219.516 & 355.8221716 & & \\
\hline 24 & S & 5 & 170.468 & 299.1058395 & & \\
\hline 26 & S & 5 & 165.046 & 299.002651 & & \\
\hline 28 & S & 5 & 210.703 & 352.2343324 & & \\
\hline 30 & S & 5 & 189.844 & 306.1298587 & & \\
\hline 32 & S & 5 & 166.078 & 301.6307347 & & \\
\hline 36 & S & 5 & 166.765 & 328.9375725 & 187.8656 & 340.8266174 \\
\hline Dual & & & & & & \\
task & & & & & & \\
\hline Subject & Condition & Map & Time & Overall & Time Mean & Distance \\
\hline 5 & N & 1 & 179.547 & 543.0585882 & & \\
\hline 7 & N & 1 & 173.953 & 576.8785601 & & \\
\hline 9 & N & 1 & 154.765 & 312.1220238 & & \\
\hline 11 & N & 1 & 136.406 & 332.1050562 & & \\
\hline 13 & N & 1 & 212.781 & 469.8833887 & & \\
\hline 15 & N & 1 & 379.735 & 1294.509319 & & \\
\hline 17 & N & 1 & 125.312 & 339.4761841 & & \\
\hline 21 & N & 1 & 334.406 & 1133.514117 & & \\
\hline 23 & N & 1 & 591.579 & 1889.092305 & & \\
\hline 25 & N & 1 & 298.265 & 944.3800627 & & \\
\hline 27 & N & 1 & 171.953 & 412.9644969 & & \\
\hline 29 & N & 1 & 185.109 & 307.9009605 & & \\
\hline 31 & N & 1 & 322.703 & 944.3311012 & & \\
\hline 33 & N & 1 & 183.266 & 409.7458563 & & \\
\hline 35 & N & 1 & 264.937 & 292.902482 & 247.6478 & \\
\hline 5 & & & 123.625 & 318.4881311 & & \\
\hline
\end{tabular}




\begin{tabular}{|l|l|l|l|l|l|l|}
\hline 7 & N & 2 & 169.687 & 608.6733811 & & \\
\hline 9 & N & 2 & 126 & 270.5927132 & & \\
\hline 11 & N & 2 & 104.5 & 284.0700956 & & \\
\hline 13 & N & 2 & 158.109 & 326.6637486 & & \\
\hline 15 & N & 2 & 480.359 & 1787.692716 & & \\
\hline 17 & N & 2 & 108.078 & 282.6678576 & & \\
\hline 21 & N & 2 & 362.812 & 1292.203128 & & \\
\hline 23 & N & 2 & 564.797 & 1847.744254 & & \\
\hline 25 & N & 2 & 271 & 910.5686588 & & \\
\hline 27 & N & 2 & 339.703 & 980.5583617 & & \\
\hline 29 & N & 2 & 142 & 268.1712623 & & \\
\hline 31 & N & 2 & 216.797 & 524.35135 & & \\
\hline 33 & N & 2 & 191.063 & 385.8733319 & & \\
\hline 35 & N & 2 & 159.234 & 264.726179 & 234.5176 & 690.2030113 \\
\hline 4 & S & 1 & 216.687 & 520.0409882 & & \\
\hline 6 & S & 1 & 204.078 & 526.5677104 & & \\
\hline 10 & S & 1 & 225.907 & 866.7632709 & & \\
\hline 12 & S & 1 & 154.562 & 298.1113834 & & \\
\hline 14 & S & 1 & 122.656 & 335.1164393 & & \\
\hline 16 & S & 1 & 153.594 & 377.1401998 & & \\
\hline 18 & S & 1 & 248.719 & 553.844536 & & \\
\hline 20 & S & 1 & 193.469 & 630.5379025 & & \\
\hline 22 & S & 1 & 154.032 & 405.1107394 & & \\
\hline 24 & S & 1 & 114.64 & 301.692763 & & \\
\hline 26 & S & 1 & 136.687 & 373.821647 & & \\
\hline 28 & S & 1 & 234.594 & 699.9478302 & & \\
\hline 30 & S & 1 & 169.406 & 314.4569068 & & \\
\hline 32 & S & 1 & 137.281 & 324.4837024 & & \\
\hline 36 & S & 1 & 145.219 & 389.2489169 & 174.1020667 & 461.1256624 \\
\hline 4 & S & 2 & 181.468 & 395.2405093 & & \\
\hline 6 & S & 2 & 115.828 & 345.0802858 & & \\
\hline 10 & S & 2 & 2257.266 & 8730.194705 & & \\
\hline 12 & S & 2 & 116.735 & 264.7900397 & & \\
\hline 14 & S & 2 & 133.328 & 314.9780529 & & \\
\hline 16 & S & 2 & 117.141 & 296.428792 & & \\
\hline 18 & S & 2 & 354.297 & 818.3709996 & & \\
\hline 20 & S & 2 & 128.89 & 276.4536838 & & \\
\hline 22 & S & 2 & 104.625 & 283.0145074 & & \\
\hline 24 & S & 2 & 104.5 & 264.7751337 & & \\
\hline 26 & S & 2 & 140.485 & 324.7795976 & & \\
\hline 28 & S & 2 & 190.828 & 640.8354363 & & \\
\hline 30 & S & 2 & 138.813 & 294.2737662 & & \\
\hline 32 & S & 2 & 112.078 & 276.1296656 & & \\
\hline 36 & S & 2 & 122.312 & 336.3105102 & 287.9062667 & 92479 \\
\hline & & & & & & \\
\hline
\end{tabular}




\section{APPENDIX B}

\section{SPEECH DISCRIMINATION DATA}

\begin{tabular}{|c|c|c|c|c|c|c|c|c|c|c|}
\hline Subject \# & Item \# & Cue Time & Reaction time & RT & Scoring & Item \# & Cue Time & Reaction time & RT & Scoring \\
\hline 6 & $\begin{array}{r}1 \\
\end{array}$ & $00: 22.20$ & \begin{tabular}{|c|}
$00: 24.10$ \\
\end{tabular} & $00: 01.90$ & $\begin{array}{l}0 \\
\end{array}$ & 2 & $00: 31.14$ & $00: 34.14$ & $00: 03.00$ & \\
\hline 7 & 1 & $00: 16.11$ & $00: 21.26$ & $00: 05.15$ & 0 & 2 & $00: 25.19$ & $00: 00.00$ & $00: 00.00$ & 0 \\
\hline 3 & 1 & $00: 15.13$ & $00: 17.11$ & $00: 01.98$ & 1 & 2 & $00: 24.19$ & $00: 25.07$ & $00: 00.88$ & 0 \\
\hline 4 & 1 & $00: 21.23$ & $00: 23.27$ & $00: 02.04$ & 0 & 2 & $00: 30.27$ & $00: 32.25$ & $00: 01.98$ & 0 \\
\hline 5 & 1 & $00: 28.27$ & $00: 29.17$ & $00: 00.90$ & 1 & 2 & $00: 38.08$ & $00: 39.24$ & $00: 01.16$ & \\
\hline 9 & 1 & $00: 20.25$ & $00: 22.20$ & $00: 01.95$ & 0 & 2 & $00: 29.28$ & $00: 31.18$ & $00: 01.90$ & 0 \\
\hline 10 & 1 & $00: 24.15$ & $00: 25.19$ & $00: 01.04$ & 1 & 2 & $00: 33.17$ & $00: 35.13$ & $00: 01.96$ & 0 \\
\hline 11 & 1 & $00: 22.14$ & $00: 24.09$ & $00: 01.95$ & 0 & 2 & $00: 31.23$ & $00: 33.04$ & $00: 01.81$ & 0 \\
\hline 12 & 1 & $00: 18.16$ & $00: 20.05$ & $00: 01.89$ & 1 & 2 & $00: 27.21$ & $00: 28.18$ & $00: 00.97$ & \\
\hline 13 & 1 & $00: 15.05$ & $00: 16.05$ & $00: 01.00$ & 1 & 2 & $00: 24.10$ & $00: 25.11$ & $00: 01.01$ & 0 \\
\hline 14 & 1 & $00: 12.23$ & $00: 14.22$ & $00: 01.99$ & 0 & 2 & $00: 21.25$ & $00: 25.03$ & $00: 03.78$ & 0 \\
\hline 15 & 1 & $00: 15.08$ & $00: 17.11$ & $00: 02.03$ & 1 & 2 & $00: 24.14$ & $00: 25.06$ & $00: 00.92$ & 0 \\
\hline 16 & 1 & $00: 25.13$ & $00: 28.07$ & $00: 02.94$ & 1 & 2 & $00: 34.17$ & $00: 35.07$ & $00: 00.90$ & 0 \\
\hline 17 & 1 & $00: 11.16$ & $00: 12.07$ & $00: 00.91$ & 1 & 2 & $00: 20.12$ & $00: 21.18$ & $00: 01.06$ & 0 \\
\hline 18 & 1 & $00: 18.06$ & $00: 18.14$ & $00: 00.08$ & 0 & 2 & $00: 27.06$ & $00: 27.15$ & $00: 00.09$ & \\
\hline 20 & 1 & $00: 14.29$ & $00: 16.05$ & $00: 01.76$ & 1 & 2 & $00: 24.04$ & $00: 24.29$ & $00: 00.25$ & 0 \\
\hline 21 & 1 & $00: 14.19$ & $00: 15.15$ & $00: 00.96$ & 1 & 2 & $00: 23.19$ & $00: 24.15$ & $00: 00.96$ & 0 \\
\hline 22 & 1 & $00: 18.20$ & $00: 18.27$ & $00: 00.07$ & 1 & 2 & $00: 28.04$ & $00: 28.15$ & $00: 00.11$ & 0 \\
\hline 23 & 1 & $00: 14.14$ & $00: 15.21$ & $00: 01.07$ & 0 & 2 & $00: 23.20$ & $00: 24.15$ & $00: 00.95$ & \\
\hline 24 & 1 & $00: 17.01$ & $00: 18.00$ & $00: 00.99$ & 0 & 2 & $00: 26.00$ & $00: 26.23$ & $00: 00.23$ & 0 \\
\hline 25 & 1 & $00: 15.16$ & $00: 15.29$ & $00: 00.13$ & 1 & 2 & $00: 24.21$ & $00: 25.06$ & $00: 00.85$ & 0 \\
\hline 26 & 1 & $00: 14.11$ & $00: 15.04$ & $00: 00.93$ & 1 & 2 & $00: 23.14$ & $00: 24.11$ & $00: 00.97$ & 0 \\
\hline 27 & 1 & $00: 15.29$ & $00: 16.29$ & $00: 01.00$ & 1 & 2 & $00: 25.01$ & $00: 25.28$ & $00: 00.27$ & \\
\hline 28 & 1 & $00: 12.03$ & $00: 15.28$ & $00: 03.25$ & 0 & 2 & $00: 20.29$ & $00: 21.23$ & $00: 00.94$ & 0 \\
\hline 29 & 1 & $00: 12.17$ & $00: 13.03$ & $00: 00.86$ & 1 & 2 & $00: 21.20$ & $00: 22.09$ & $00: 00.89$ & 0 \\
\hline 30 & 1 & $00: 16.08$ & $00: 20.06$ & $00: 03.98$ & 1 & 2 & $00: 25.22$ & $00: 26.20$ & $00: 00.98$ & \\
\hline 31 & 1 & $00: 14.10$ & $00: 16.08$ & $00: 01.98$ & 1 & 2 & $00: 23.22$ & $00: 25.05$ & $00: 01.83$ & 0 \\
\hline 32 & 1 & $00: 13.00$ & $00: 14.01$ & $00: 01.01$ & 1 & 2 & $00: 22.09$ & $00: 23.09$ & $00: 01.00$ & 0 \\
\hline 33 & 1 & $00: 13.07$ & $00: 15.29$ & $00: 02.22$ & 0 & 2 & $00: 22.18$ & $00: 25.19$ & $00: 03.01$ & 0 \\
\hline 34 & 1 & $00: 13.06$ & $00: 14.04$ & $00: 00.98$ & 1 & 2 & $00: 22.16$ & $00: 23.06$ & $00: 00.90$ & \\
\hline 35 & 1 & $00: 12.12$ & $00: 15.01$ & $00: 02.89$ & 1 & 2 & $00: 21.20$ & $00: 22.12$ & $00: 00.92$ & 0 \\
\hline
\end{tabular}

\begin{tabular}{|c|c|c|c|c|c|c|c|c|c|c|}
\hline Item \# & Cue Time & Reaction time & RT & Scoring & Item \# & Cue Time & Reaction time & RT & Scoring & Item \# \\
\hline 3 & $00: 40.17$ & $\begin{array}{r}00: 41.14 \\
\end{array}$ & $00: 00.97$ & $\begin{array}{r}0 \\
\end{array}$ & 4 & $00: 49.26$ & \begin{tabular}{|c|}
$00: 52.26$ \\
\end{tabular} & $00: 03.00$ & 0 & 5 \\
\hline 3 & $00: 47.25$ & $00: 48.08$ & $00: 00.83$ & 0 & 4 & $00: 57.20$ & $00: 00.00$ & $00: 00.00$ & 0 & 5 \\
\hline 3 & $00: 33.20$ & $00: 34.10$ & $00: 00.90$ & 0 & 4 & $00: 42.22$ & $00: 43.20$ & $00: 00.98$ & 0 & 5 \\
\hline 3 & $00: 40.00$ & $00: 41.11$ & $00: 01.11$ & 0 & 4 & $00: 49.16$ & $00: 50.26$ & $00: 01.10$ & 0 & 5 \\
\hline 3 & $00: 46.28$ & $00: 49.12$ & $00: 02.84$ & 0 & 4 & $00: 56.04$ & $00: 57.16$ & $00: 01.12$ & 0 & 5 \\
\hline 3 & $00: 39.05$ & $00: 40.09$ & $00: 01.04$ & 0 & 4 & $00: 48.01$ & $00: 50.29$ & $00: 02.28$ & 0 & 5 \\
\hline 3 & $00: 42.20$ & $00: 44.25$ & $00: 02.05$ & 0 & 4 & $00: 51.20$ & $00: 53.08$ & $00: 01.88$ & 0 & 5 \\
\hline 3 & $00: 40.20$ & $00: 42.27$ & $00: 02.07$ & 0 & 4 & $00: 49.22$ & $00: 52.20$ & $00: 02.98$ & 0 & 5 \\
\hline 3 & $00: 36.20$ & $00: 38.10$ & $00: 01.90$ & 0 & 4 & $00: 45.22$ & $00: 48.02$ & $00: 02.80$ & 0 & 5 \\
\hline 3 & $00: 33.12$ & $00: 34.09$ & $00: 00.97$ & 0 & 4 & $00: 42.12$ & $00: 43.26$ & $00: 01.14$ & 0 & 5 \\
\hline 3 & $00: 30.25$ & $00: 33.27$ & $00: 03.02$ & 0 & 4 & $00: 40.03$ & $00: 00.00$ & $00: 00.00$ & 0 & 5 \\
\hline 3 & $00: 33.12$ & $00: 34.11$ & $00: 00.99$ & 0 & 4 & $00: 42.23$ & $00: 43.02$ & $00: 00.79$ & 0 & 5 \\
\hline 3 & $00: 43.20$ & $00: 44.07$ & $00: 00.87$ & 0 & 4 & $00: 52.19$ & $00: 55.00$ & $00: 02.81$ & 0 & 5 \\
\hline 3 & $00: 29.13$ & $00: 30.14$ & $00: 01.01$ & 0 & 4 & $00: 38.16$ & $00: 40.09$ & $00: 01.93$ & 0 & 5 \\
\hline 3 & $00: 36.08$ & $00: 36.16$ & $00: 00.08$ & 0 & 4 & $00: 45.04$ & $00: 45.10$ & $00: 00.06$ & 0 & 5 \\
\hline 3 & $00: 33.06$ & $00: 36.04$ & $00: 02.98$ & 0 & 4 & $00: 42.06$ & $00: 43.02$ & $00: 00.96$ & 0 & 5 \\
\hline 3 & $00: 32.23$ & $00: 32.29$ & $00: 00.06$ & 0 & 4 & $00: 41.21$ & $00: 00.00$ & $00: 00.00$ & 0 & 5 \\
\hline 3 & $00: 37.03$ & $00: 38.12$ & $00: 01.09$ & 0 & 4 & $00: 46.02$ & $00: 46.21$ & $00: 00.19$ & 0 & 5 \\
\hline 3 & $00: 32.26$ & $00: 35.05$ & $00: 02.79$ & 0 & 4 & $00: 41.20$ & $00: 00.00$ & $00: 00.00$ & 0 & 5 \\
\hline 3 & $00: 35.00$ & $00: 36.22$ & $00: 01.22$ & 0 & 4 & $00: 44.02$ & $00: 48.00$ & $00: 03.98$ & 0 & 5 \\
\hline 3 & $00: 33.22$ & $00: 36.24$ & $00: 03.02$ & 0 & 4 & $00: 42.23$ & $00: 46.14$ & $00: 03.91$ & 0 & 5 \\
\hline 3 & $00: 32.14$ & $00: 33.26$ & $00: 01.12$ & 0 & 4 & $00: 41.16$ & $00: 42.12$ & $00: 00.96$ & 0 & 5 \\
\hline 3 & $00: 33.28$ & $00: 34.24$ & $00: 00.96$ & 0 & 4 & $00: 43.01$ & $00: 43.26$ & $00: 00.25$ & 0 & 5 \\
\hline 3 & $00: 29.29$ & $00: 32.13$ & $00: 02.84$ & 0 & 4 & $00: 39.00$ & $00: 39.18$ & $00: 00.18$ & 0 & 5 \\
\hline 3 & $00: 30.19$ & $00: 31.17$ & $00: 00.98$ & 0 & 4 & $00: 39.20$ & $00: 42.07$ & $00: 02.87$ & 0 & 5 \\
\hline 3 & $00: 34.18$ & $00: 36.07$ & $00: 01.89$ & 0 & 4 & $00: 43.17$ & $00: 46.28$ & $00: 03.11$ & 0 & 5 \\
\hline 3 & $00: 32.19$ & $00: 33.07$ & $00: 00.88$ & 0 & 4 & $00: 41.23$ & $00: 43.19$ & $00: 01.96$ & 0 & 5 \\
\hline 3 & $00: 31.11$ & $00: 32.09$ & $00: 00.98$ & 0 & 4 & $00: 40.15$ & $00: 41.04$ & $00: 00.89$ & 0 & 5 \\
\hline 3 & $00: 31.19$ & $00: 32.24$ & $00: 01.05$ & 0 & 4 & $00: 40.19$ & $00: 43.09$ & $00: 02.90$ & 0 & 5 \\
\hline 3 & $00: 31.15$ & $00: 31.28$ & $00: 00.13$ & 0 & 4 & $00: 40.16$ & $00: 41.08$ & $00: 00.92$ & 0 & 5 \\
\hline 3 & $00: 30.20$ & $00: 31.09$ & $00: 00.89$ & 0 & 4 & $00: 39.23$ & $00: 41.18$ & $00: 01.95$ & 0 & 5 \\
\hline
\end{tabular}




\begin{tabular}{|c|c|c|c|c|c|c|c|c|c|c|}
\hline Cue Time & Reaction time & RT & Scoring & Item \# & Cue Time & Reaction time & RT & Scoring & Item \# & Cue Time \\
\hline $00: 58.20$ & 01:00.01 & $00: 01.81$ & $\begin{array}{r}0 \\
\end{array}$ & 6 & $01: 07.20$ & \begin{tabular}{|c|}
$01: 09.14$ \\
\end{tabular} & $00: 01.94$ & \begin{tabular}{|l|}
0 \\
\end{tabular} & \begin{tabular}{|r|}
7 \\
\end{tabular} & $01: 16.27$ \\
\hline $01: 06.05$ & $01: 07.00$ & $00: 00.95$ & 0 & 6 & $01: 15.05$ & $01: 15.28$ & $00: 00.23$ & 0 & 7 & $01: 24.05$ \\
\hline $00: 51.24$ & $00: 52.14$ & $00: 00.90$ & 0 & 6 & $01: 00.21$ & $01: 01.14$ & $00: 00.93$ & 0 & 7 & $01: 09.29$ \\
\hline $00: 58.09$ & $00: 59.06$ & $00: 00.97$ & 0 & 6 & $01: 07.11$ & $01: 09.13$ & $00: 02.02$ & 0 & 7 & $01: 16.17$ \\
\hline $01: 05.05$ & $01: 07.23$ & $00: 02.18$ & 0 & 6 & $01: 14.06$ & $01: 14.25$ & $00: 00.19$ & 0 & 7 & $01: 23.11$ \\
\hline $00: 57.13$ & $00: 59.13$ & $00: 02.00$ & 0 & 6 & $01: 06.07$ & $01: 08.18$ & $00: 02.11$ & 0 & 7 & $01: 15.16$ \\
\hline $01: 00.26$ & $01: 01.28$ & $00: 01.02$ & 0 & 6 & $01: 09.24$ & $01: 10.15$ & $00: 00.91$ & 0 & 7 & $01: 19.03$ \\
\hline $00: 59.02$ & $01: 00.16$ & $00: 01.14$ & 0 & 6 & $01: 07.27$ & $01: 09.04$ & $00: 01.77$ & 0 & 7 & $01: 16.28$ \\
\hline $00: 54.24$ & $00: 55.24$ & $00: 01.00$ & 0 & 6 & $01: 03.24$ & $01: 06.23$ & $00: 02.99$ & 0 & 7 & $01: 12.27$ \\
\hline $00: 51.21$ & $00: 53.13$ & $00: 01.92$ & 0 & 6 & $01: 00.14$ & $01: 01.11$ & $00: 00.97$ & 0 & 7 & $01: 09.18$ \\
\hline $00: 49.04$ & $00: 51.10$ & $00: 02.06$ & 0 & 6 & $00: 58.02$ & $01: 01.06$ & $00: 03.04$ & 0 & 7 & $01: 07.07$ \\
\hline $00: 51.22$ & $00: 52.14$ & $00: 00.92$ & 0 & 6 & $01: 00.21$ & $01: 01.27$ & $00: 01.06$ & 0 & 7 & $01: 09.25$ \\
\hline $01: 01.26$ & $01: 03.23$ & $00: 01.97$ & 0 & 6 & $01: 10.23$ & $01: 11.27$ & $00: 01.04$ & 0 & 7 & $01: 20.04$ \\
\hline $00: 47.21$ & $00: 48.25$ & $00: 01.04$ & 0 & 6 & $00: 56.20$ & $00: 59.14$ & $00: 02.94$ & 0 & 7 & $01: 05.21$ \\
\hline $00: 54.10$ & $00: 54.23$ & $00: 00.13$ & 0 & 6 & $01: 03.14$ & $01: 03.18$ & $00: 00.04$ & 0 & 7 & $01: 12.22$ \\
\hline $00: 51.14$ & $00: 55.24$ & $00: 04.10$ & 0 & 6 & $01: 00.15$ & $01: 01.00$ & $00: 00.85$ & 0 & 7 & $01: 09.18$ \\
\hline $00: 50.28$ & $00: 52.01$ & $00: 01.73$ & 0 & 6 & $00: 59.26$ & $00: 00.00$ & $00: 00.00$ & 0 & 7 & $01: 08.21$ \\
\hline $00: 55.09$ & $00: 56.06$ & $00: 00.97$ & 0 & 6 & $01: 04.10$ & $01: 04.26$ & $00: 00.16$ & 0 & 7 & $01: 13.13$ \\
\hline $00: 51.02$ & $00: 52.11$ & $00: 01.09$ & 0 & 6 & $00: 59.27$ & $01: 02.08$ & $00: 02.81$ & 0 & 7 & $01: 09.04$ \\
\hline $00: 53.06$ & $00: 55.16$ & $00: 02.10$ & 0 & 6 & $01: 02.04$ & $01: 02.29$ & $00: 00.25$ & 0 & 7 & $01: 11.13$ \\
\hline $00: 51.29$ & $00: 52.21$ & $00: 00.92$ & 0 & 6 & $01: 00.27$ & $01: 01.23$ & $00: 00.96$ & 0 & 7 & $01: 10.03$ \\
\hline $00: 50.23$ & $00: 52.07$ & $00: 01.84$ & 0 & 6 & $00: 59.24$ & $01: 00.12$ & $00: 00.88$ & 0 & 7 & $01: 09.00$ \\
\hline $00: 52.10$ & $00: 53.13$ & $00: 01.03$ & 0 & 6 & $01: 01.28$ & $01: 01.27$ & $-00: 00.01$ & 0 & 7 & $01: 10.15$ \\
\hline $00: 48.05$ & $00: 50.11$ & $00: 02.06$ & 0 & 6 & $00: 57.04$ & $00: 58.20$ & $00: 01.16$ & 0 & 7 & $01: 06.05$ \\
\hline $00: 48.21$ & $00: 49.20$ & $00: 00.99$ & 0 & 6 & $00: 57.25$ & $00: 59.19$ & $00: 01.94$ & 0 & 7 & $01: 06.27$ \\
\hline $00: 52.29$ & $00: 54.10$ & $00: 01.81$ & 0 & 6 & $01: 01.23$ & $01: 03.18$ & $00: 01.95$ & 0 & 7 & $01: 11.01$ \\
\hline $00: 50.26$ & $00: 51.11$ & $00: 00.85$ & 0 & 6 & $00: 59.29$ & $01: 00.09$ & $00: 00.80$ & 0 & 7 & $01: 09.03$ \\
\hline $00: 49.15$ & $00: 50.27$ & $00: 01.12$ & 0 & 6 & $00: 58.04$ & $00: 59.14$ & $00: 01.10$ & 0 & 7 & $01: 07.23$ \\
\hline $00: 49.26$ & $00: 50.05$ & $00: 00.79$ & 0 & 6 & $00: 58.26$ & $01: 02.29$ & $00: 04.03$ & 0 & 7 & $01: 07.29$ \\
\hline $00: 49.28$ & $00: 50.10$ & $00: 00.82$ & 0 & 6 & $00: 58.25$ & $00: 59.09$ & $00: 00.84$ & 0 & 7 & $01: 07.28$ \\
\hline $00: 48.29$ & $00: 50.02$ & $00: 01.73$ & 0 & 6 & $00: 57.27$ & $00: 59.23$ & $00: 01.96$ & 0 & 7 & $01: 07.02$ \\
\hline
\end{tabular}

\begin{tabular}{|c|c|c|c|c|c|c|c|c|c|c|}
\hline Reaction time & RT & Scoring & Item \# & Cue Time & Reaction time & RT & Scoring & Item \# & Cue Time & Reaction time \\
\hline $01: 18.05$ & $00: 01.78$ & 0 & 8 & $01: 25.26$ & $01: 27.09$ & $00: 01.83$ & 0 & 9 & $01: 34.27$ & $01: 36.10$ \\
\hline $01: 25.07$ & $00: 01.02$ & 0 & 8 & $01: 33.05$ & $01: 35.15$ & $00: 02.10$ & 0 & 9 & $01: 42.08$ & $01: 44.11$ \\
\hline $01: 10.28$ & $00: 00.99$ & 0 & 8 & $01: 18.27$ & $01: 19.25$ & $00: 00.98$ & 0 & 9 & $01: 28.01$ & $01: 28.22$ \\
\hline $01: 17.28$ & $00: 01.11$ & 0 & 8 & $01: 25.15$ & $01: 26.18$ & $00: 01.03$ & 0 & 9 & $01: 34.19$ & $01: 35.11$ \\
\hline $01: 24.01$ & $00: 00.90$ & 0 & 8 & $01: 32.09$ & $01: 34.17$ & $00: 02.08$ & 0 & 9 & $01: 41.13$ & $01: 44.28$ \\
\hline $01: 18.08$ & $00: 02.92$ & 0 & 8 & $01: 24.14$ & $01: 26.06$ & $00: 01.92$ & 0 & 9 & $01: 33.11$ & $01: 35.16$ \\
\hline $01: 20.05$ & $00: 01.02$ & 0 & 8 & $01: 27.28$ & $01: 28.22$ & $00: 00.94$ & 0 & 9 & $01: 37.00$ & $01: 39.07$ \\
\hline $01: 18.24$ & $00: 01.96$ & 1 & 8 & $01: 25.29$ & $01: 28.12$ & $00: 02.83$ & 0 & 9 & $01: 35.02$ & $01: 37.14$ \\
\hline $01: 16.04$ & $00: 03.77$ & 0 & 8 & $01: 21.28$ & $01: 23.03$ & $00: 01.75$ & 0 & 9 & $01: 30.29$ & $01: 33.08$ \\
\hline $01: 10.13$ & $00: 00.95$ & 0 & 8 & $01: 18.19$ & $01: 19.21$ & $00: 01.02$ & 0 & 9 & $01: 27.21$ & $01: 29.08$ \\
\hline $01: 10.25$ & $00: 03.18$ & 0 & 8 & $01: 16.06$ & $01: 17.22$ & $00: 01.16$ & 0 & 9 & $01: 25.05$ & $01: 27.21$ \\
\hline $01: 11.07$ & $00: 01.82$ & 0 & 8 & $01: 19.00$ & $01: 19.22$ & $00: 00.22$ & 0 & 9 & $01: 28.00$ & $01: 28.22$ \\
\hline $01: 21.22$ & $00: 01.18$ & 0 & 8 & $01: 28.27$ & $01: 29.28$ & $00: 01.01$ & 0 & 9 & $01: 37.00$ & $01: 39.00$ \\
\hline $01: 08.11$ & $00: 02.90$ & 0 & 8 & $01: 14.28$ & $01: 16.11$ & $00: 01.83$ & 0 & 9 & $01: 23.28$ & $01: 25.03$ \\
\hline $01: 12.28$ & $00: 00.06$ & 0 & 8 & $01: 21.13$ & $01: 21.20$ & $00: 00.07$ & 0 & 9 & $01: 30.17$ & $01: 31.02$ \\
\hline $01: 14.20$ & $00: 05.02$ & 0 & 8 & $01: 18.18$ & $01: 19.02$ & $00: 00.84$ & 0 & 9 & $01: 27.20$ & $01: 29.08$ \\
\hline $00: 00.00$ & $00: 00.00$ & 0 & 8 & $01: 18.00$ & $01: 19.27$ & $00: 01.27$ & 0 & 9 & $01: 27.05$ & $01: 27.28$ \\
\hline $01: 13.25$ & $00: 00.12$ & 0 & 8 & $01: 18.00$ & $01: 23.29$ & $00: 05.29$ & 0 & 9 & $01: 31.13$ & $01: 32.02$ \\
\hline $01: 09.12$ & $00: 00.08$ & 1 & 8 & $01: 18.03$ & $01: 19.10$ & $00: 01.07$ & 0 & 9 & $01: 27.05$ & $01: 29.16$ \\
\hline $01: 14.17$ & $00: 03.04$ & 0 & 8 & $01: 20.10$ & $01: 22.26$ & $00: 02.16$ & 0 & 9 & $01: 29.12$ & $01: 30.04$ \\
\hline $01: 10.15$ & $00: 00.12$ & 0 & 8 & $01: 19.03$ & $01: 20.28$ & $00: 01.25$ & 0 & 9 & $01: 28.04$ & $01: 29.01$ \\
\hline $01: 09.20$ & $00: 00.20$ & 1 & 8 & $01: 17.29$ & $01: 19.07$ & $00: 01.78$ & 0 & 9 & $01: 26.27$ & $01: 27.21$ \\
\hline $01: 11.16$ & $00: 01.01$ & 1 & 8 & $01: 19.15$ & $01: 20.10$ & $00: 00.95$ & 0 & 9 & $01: 28.15$ & $01: 29.13$ \\
\hline $01: 09.01$ & $00: 02.96$ & 0 & 8 & $01: 15.10$ & $01: 17.17$ & $00: 02.07$ & 0 & 9 & $01: 24.07$ & $01: 25.02$ \\
\hline $01: 10.13$ & $00: 03.86$ & 0 & 8 & $01: 15.29$ & $01: 16.18$ & $00: 00.89$ & 0 & 9 & $01: 25.03$ & $01: 25.28$ \\
\hline $01: 12.10$ & $00: 01.09$ & 0 & 8 & $01: 20.01$ & $01: 21.17$ & $00: 01.16$ & 0 & 9 & $01: 29.03$ & $01: 29.29$ \\
\hline $01: 09.17$ & $00: 00.14$ & 0 & 8 & $01: 18.02$ & $01: 18.18$ & $00: 00.16$ & 0 & 9 & $01: 27.03$ & $01: 27.20$ \\
\hline $01: 08.19$ & $00: 00.96$ & 0 & 8 & $01: 16.18$ & $01: 17.29$ & $00: 01.11$ & 0 & 9 & $01: 25.20$ & $01: 26.07$ \\
\hline $01: 12.04$ & $00: 04.75$ & 0 & 8 & $01: 16.29$ & $01: 18.04$ & $00: 01.75$ & 0 & 9 & $01: 26.03$ & $01: 26.13$ \\
\hline $01: 08.09$ & $00: 00.81$ & 0 & 8 & $01: 16.29$ & $01: 17.14$ & $00: 00.85$ & 0 & 9 & $01: 26.00$ & $01: 26.15$ \\
\hline $01: 08.18$ & $00: 01.16$ & 0 & 8 & $01: 16.01$ & $01: 16.28$ & $00: 00.27$ & 0 & 9 & $01: 25.04$ & $01: 27.17$ \\
\hline
\end{tabular}




\begin{tabular}{|c|c|c|c|c|c|c|c|c|c|c|}
\hline RT & Scoring & Item \# & Cue Time & Reaction time & RT & Scoring & Item \# & Cue Time & Reaction time & RT \\
\hline $00: 01.83$ & 1 & 10 & $01: 43.29$ & \begin{tabular}{|c|}
$01: 45.18$ \\
\end{tabular} & $00: 01.89$ & \begin{tabular}{|l|}
1 \\
\end{tabular} & 11 & $02: 02.28$ & $02: 05.20$ & $00: 02.92$ \\
\hline $00: 02.03$ & 1 & 10 & $01: 51.06$ & $01: 52.16$ & $00: 01.10$ & 0 & 11 & $02: 16.15$ & $02: 18.27$ & $00: 02.12$ \\
\hline $00: 00.21$ & 1 & 10 & $01: 37.03$ & $01: 38.08$ & $00: 01.05$ & 1 & 11 & $02: 00.28$ & $02: 01.27$ & $00: 00.99$ \\
\hline $00: 00.92$ & 1 & 10 & $01: 43.16$ & $01: 44.00$ & $00: 00.84$ & 1 & 11 & $02: 05.00$ & $02: 06.05$ & $00: 01.05$ \\
\hline $00: 03.15$ & 1 & 10 & $01: 50.12$ & $01: 51.00$ & $00: 00.88$ & 1 & 11 & $02: 07.17$ & $02: 10.17$ & $00: 03.00$ \\
\hline $00: 02.05$ & 1 & 10 & $01: 42.13$ & $01: 44.11$ & $00: 01.98$ & 1 & 11 & $02: 01.18$ & $02: 04.12$ & $00: 02.94$ \\
\hline $00: 02.07$ & 1 & 10 & $01: 45.29$ & $01: 46.29$ & $00: 01.00$ & 1 & 11 & $02: 08.12$ & 02:09.11 & $00: 00.99$ \\
\hline $00: 02.12$ & 1 & 10 & $01: 44.02$ & $01: 45.13$ & $00: 01.11$ & 1 & 11 & $02: 01.23$ & $02: 02.27$ & $00: 01.04$ \\
\hline $00: 02.79$ & 1 & 10 & $01: 40.00$ & $01: 44.09$ & $00: 04.09$ & 1 & 11 & $02: 05.15$ & $02: 08.25$ & $00: 03.10$ \\
\hline $00: 01.87$ & 1 & 10 & $01: 36.20$ & $01: 37.23$ & $00: 01.03$ & 0 & 11 & $01: 55.01$ & $01: 56.03$ & $00: 01.02$ \\
\hline $00: 02.16$ & 1 & 10 & $01: 34.09$ & $01: 37.25$ & $00: 03.16$ & 0 & 11 & $01: 55.11$ & $01: 56.17$ & $00: 01.06$ \\
\hline $00: 00.22$ & 0 & 10 & $01: 36.28$ & $01: 38.00$ & $00: 01.72$ & 1 & 11 & $01: 56.04$ & $: 56.20$ & $00: 00.16$ \\
\hline $00: 02.00$ & 1 & 10 & $01: 47.00$ & $01: 47.21$ & $00: 00.21$ & 0 & 11 & 04.20 & 06.05 & $00: 01.85$ \\
\hline $00: 01.75$ & 1 & 10 & $01: 32.24$ & $01: 34.27$ & $00: 02.03$ & 0 & 11 & $01: 53.29$ & $01: 55.09$ & $00: 01.80$ \\
\hline $00: 00.85$ & 0 & 10 & $01: 39.23$ & $01: 40.08$ & $00: 00.85$ & 0 & 11 & $01: 56.17$ & $01: 57.22$ & $00: 01.05$ \\
\hline $00: 01.88$ & 1 & 10 & $01: 36.22$ & $01: 39.08$ & $00: 02.86$ & 1 & 11 & $01: 57.23$ & $01: 58.25$ & $00: 01.02$ \\
\hline $00: 00.23$ & 1 & 10 & $01: 35.29$ & $01: 36.24$ & $00: 00.95$ & 1 & 11 & $02: 08.22$ & $02: 09.28$ & $00: 01.06$ \\
\hline $00: 00.89$ & 1 & 10 & $01: 40.17$ & $01: 41.28$ & $00: 01.11$ & 1 & 11 & $02: 02.24$ & $02: 03.04$ & $00: 00.80$ \\
\hline $00: 02.11$ & 1 & 10 & $01: 36.05$ & 40.00 & $00: 03.95$ & 1 & 11 & $02: 00.07$ & $02: 00.21$ & $00: 00.14$ \\
\hline $00: 00.92$ & 1 & 10 & $01: 38.13$ & $01: 40.13$ & $00: 02.00$ & 1 & 11 & $01: 57.23$ & $02: 01.21$ & $00: 03.98$ \\
\hline $00: 00.97$ & 1 & 10 & $01: 37.05$ & $01: 38.01$ & $00: 00.96$ & 0 & 11 & $01: 52.15$ & $01: 52.28$ & $00: 00.13$ \\
\hline $00: 00.94$ & 1 & 10 & $01: 35.28$ & $01: 37.09$ & $00: 01.81$ & 1 & 11 & $01: 53.21$ & $01: 55.02$ & $00: 01.81$ \\
\hline $00: 00.98$ & 1 & 10 & $01: 37.12$ & 8.26 & 1.14 & 0 & 11 & 5.07 & 57.05 & $00: 01.98$ \\
\hline $00: 00.95$ & 1 & 10 & $01: 33.11$ & $01: 35.24$ & $00: 02.13$ & 1 & 11 & $01: 54.00$ & $01: 56.06$ & $00: 02.06$ \\
\hline $00: 00.25$ & 0 & 10 & $01: 34.01$ & $01: 34.28$ & $00: 00.27$ & 1 & 11 & $01: 50.17$ & $01: 52.04$ & $00: 01.87$ \\
\hline $00: 00.26$ & 1 & 10 & $01: 38.03$ & $01: 39.19$ & $00: 01.16$ & 1 & 11 & $01: 58.18$ & $01: 59.11$ & $00: 00.93$ \\
\hline $00: 00.17$ & 0 & 10 & $01: 36.03$ & $01: 36.29$ & $00: 00.26$ & 1 & 11 & $01: 53.09$ & $01: 54.08$ & $00: 00.99$ \\
\hline $00: 00.87$ & 1 & 10 & $01: 34.20$ & $01: 35.18$ & $00: 00.98$ & 1 & 11 & $01: 49.19$ & $01: 50.12$ & $00: 00.93$ \\
\hline $00: 00.10$ & 1 & 10 & $01: 35.05$ & $01: 36.05$ & $00: 01.00$ & 1 & 11 & $01: 51.14$ & $01: 54.07$ & $00: 02.93$ \\
\hline $00: 00.15$ & 1 & 10 & $01: 35.04$ & $01: 35.12$ & $00: 00.08$ & 1 & 11 & $01: 56.05$ & $01: 56.15$ & $00: 00.10$ \\
\hline $00: 02.13$ & 1 & 10 & $01: 34.04$ & $01: 35.07$ & $00: 01.03$ & 1 & 11 & $01: 51.02$ & $01: 52.19$ & $00: 01.17$ \\
\hline
\end{tabular}

\begin{tabular}{|c|c|c|c|c|c|c|c|c|c|c|}
\hline Scoring & Item \# & Cue Time & Reaction time & RT & Scoring & Item \# & Cue Time & Reaction time & RT & Scoring \\
\hline 0 & 12 & $02: 11.17$ & $02: 12.22$ & $00: 01.05$ & $\begin{array}{r}1 \\
\end{array}$ & 13 & $02: 20.20$ & $02: 23.01$ & $00: 02.81$ & 0 \\
\hline 0 & 12 & $02: 25.28$ & $02: 26.27$ & $00: 00.99$ & 1 & 13 & $02: 34.27$ & $02: 35.21$ & $00: 00.94$ & 1 \\
\hline 0 & 12 & $02: 10.07$ & $02: 10.22$ & $00: 00.15$ & 1 & 13 & $02: 19.08$ & $02: 19.29$ & $00: 00.21$ & 0 \\
\hline 0 & 12 & $02: 14.12$ & $02: 16.14$ & $00: 02.02$ & 0 & 13 & $02: 23.14$ & $02: 23.28$ & $00: 00.14$ & 0 \\
\hline 0 & 12 & $02: 16.26$ & $02: 17.17$ & $00: 00.91$ & 1 & 13 & $02: 25.27$ & $02: 26.15$ & $00: 00.88$ & 1 \\
\hline 0 & 12 & $02: 11.05$ & $02: 12.13$ & $00: 01.08$ & 1 & 13 & $02: 19.29$ & $02: 21.21$ & $00: 01.92$ & 1 \\
\hline 0 & 12 & $02: 17.15$ & $02: 18.08$ & $00: 00.93$ & 1 & 13 & $02: 26.22$ & $02: 27.15$ & $00: 00.93$ & 0 \\
\hline 0 & 12 & $02: 10.28$ & $02: 12.27$ & $00: 01.99$ & 0 & 13 & $02: 19.29$ & $02: 21.17$ & $00: 01.88$ & 1 \\
\hline 0 & 12 & $02: 14.19$ & $02: 18.16$ & $00: 03.97$ & 0 & 13 & $02: 23.19$ & $02: 25.25$ & $00: 02.06$ & 0 \\
\hline 0 & 12 & $02: 04.07$ & $02: 05.03$ & $00: 00.96$ & 1 & 13 & $02: 13.08$ & $02: 14.06$ & $00: 00.98$ & 0 \\
\hline 0 & 12 & $02: 04.16$ & $02: 05.29$ & $00: 01.13$ & 1 & 13 & $02: 13.20$ & $02: 14.21$ & $00: 01.01$ & 1 \\
\hline 0 & 12 & $02: 05.09$ & $02: 05.20$ & $00: 00.11$ & 1 & 13 & $02: 14.10$ & $02: 14.27$ & $00: 00.17$ & 0 \\
\hline 0 & 12 & $02: 14.02$ & $02: 17.19$ & $00: 03.17$ & 0 & 13 & $02: 23.00$ & $02: 24.06$ & $00: 01.06$ & 1 \\
\hline 0 & 12 & 02:03.01 & $02: 04.06$ & $00: 01.05$ & 1 & 13 & $02: 12.03$ & $02: 13.44$ & $00: 01.41$ & 0 \\
\hline 0 & 12 & $02: 05.09$ & $00: 00.00$ & $00: 00.00$ & 0 & 13 & $02: 14.18$ & $02: 15.17$ & $00: 00.99$ & 0 \\
\hline 0 & 12 & 02:07.01 & $02: 08.14$ & $00: 01.13$ & 0 & 13 & $02: 16.06$ & $02: 19.01$ & $00: 02.95$ & 0 \\
\hline 0 & 12 & $02: 17.10$ & $02: 17.23$ & $00: 00.13$ & 1 & 13 & $02: 26.14$ & $02: 27.03$ & $00: 00.89$ & 1 \\
\hline 0 & 12 & $02: 11.23$ & $02: 12.19$ & $00: 00.96$ & 0 & 13 & $02: 20.27$ & $02: 22.16$ & $00: 01.89$ & 0 \\
\hline 0 & 12 & $02: 09.02$ & $02: 12.06$ & $00: 03.04$ & 0 & 13 & $02: 18.09$ & $02: 18.22$ & $00: 00.13$ & 1 \\
\hline 1 & 12 & $02: 06.26$ & $02: 10.09$ & $00: 03.83$ & 0 & 13 & $02: 16.03$ & $02: 17.00$ & $00: 00.97$ & 1 \\
\hline 0 & 12 & $02: 01.14$ & $02: 01.27$ & $00: 00.13$ & 0 & 13 & $02: 10.21$ & $02: 11.07$ & $00: 00.86$ & 1 \\
\hline 0 & 12 & $02: 02.26$ & $02: 03.25$ & $00: 00.99$ & 0 & 13 & $02: 12.02$ & $02: 12.19$ & $00: 00.17$ & 0 \\
\hline 0 & 12 & $02: 04.14$ & $02: 05.06$ & $00: 00.92$ & 0 & 13 & $02: 13.15$ & $02: 14.17$ & $00: 01.02$ & 1 \\
\hline 0 & 12 & $02: 03.03$ & $02: 06.03$ & $00: 03.00$ & 0 & 13 & $02: 12.06$ & $02: 14.12$ & $00: 02.06$ & 1 \\
\hline 0 & 12 & $01: 59.24$ & $02: 00.28$ & $00: 01.04$ & 0 & 13 & $02: 08.29$ & $02: 09.15$ & $00: 00.86$ & 0 \\
\hline 0 & 12 & $02: 07.19$ & $02: 08.03$ & $00: 00.84$ & 1 & 13 & $02: 16.22$ & $02: 17.15$ & $00: 00.93$ & 1 \\
\hline 0 & 12 & $02: 02.17$ & $02: 03.02$ & $00: 00.85$ & 1 & 13 & $02: 11.15$ & $02: 12.22$ & $00: 01.07$ & 0 \\
\hline 0 & 12 & $01: 58.20$ & $01: 59.10$ & $00: 00.90$ & 0 & 13 & $02: 07.26$ & $02: 08.09$ & $00: 00.83$ & 1 \\
\hline 0 & 12 & $02: 00.13$ & $02: 01.06$ & $00: 00.93$ & 1 & 13 & $02: 09.23$ & $02: 12.10$ & $00: 02.87$ & 0 \\
\hline 0 & 12 & $02: 05.02$ & $02: 05.15$ & $00: 00.13$ & 1 & 13 & $02: 14.12$ & $02: 14.19$ & $00: 00.07$ & 0 \\
\hline 0 & 12 & $02: 00.05$ & $02: 01.00$ & $00: 00.95$ & 1 & 13 & $02: 09.08$ & $02: 10.12$ & $00: 01.04$ & 0 \\
\hline
\end{tabular}




\begin{tabular}{|c|c|c|c|c|c|c|c|c|c|c|}
\hline Item \# & Cue Time & Reaction time & RT & Scoring & Item \# & Cue Time & Reaction time & RT & Scoring & Item \# \\
\hline 14 & $02: 29.17$ & \begin{tabular}{|c|}
$02: 30.16$ \\
\end{tabular} & $00: 00.99$ & \begin{tabular}{r|}
1 \\
\end{tabular} & $\begin{array}{r}15 \\
\end{array}$ & \begin{tabular}{|l|}
$02: 38.17$ \\
\end{tabular} & \begin{tabular}{|c|}
$02: 40.19$ \\
\end{tabular} & $00: 02.02$ & 0 & \begin{tabular}{|l|}
16 \\
\end{tabular} \\
\hline 14 & $02: 43.23$ & $02: 45.25$ & $00: 02.02$ & 0 & 15 & $02: 53.00$ & $02: 56.00$ & $00: 03.00$ & 0 & 16 \\
\hline 14 & $02: 28.03$ & $02: 28.25$ & $00: 00.22$ & 1 & 15 & $02: 37.02$ & $02: 37.27$ & $00: 00.25$ & 0 & 16 \\
\hline 14 & $02: 32.10$ & $02: 33.02$ & $00: 00.92$ & 1 & 15 & $02: 41.06$ & $02: 42.21$ & $00: 01.15$ & 0 & 16 \\
\hline 14 & $02: 34.26$ & $02: 35.16$ & $00: 00.90$ & 1 & 15 & $02: 43.20$ & $02: 45.09$ & $00: 01.89$ & 0 & 16 \\
\hline 14 & $02: 29.01$ & $02: 30.08$ & $00: 01.07$ & 1 & 15 & $02: 37.27$ & $02: 41.08$ & $00: 03.81$ & 0 & 16 \\
\hline 14 & $02: 35.18$ & $02: 36.06$ & $00: 00.88$ & 1 & 15 & $02: 44.21$ & $02: 45.08$ & $00: 00.87$ & 0 & 16 \\
\hline 14 & $02: 28.26$ & $02: 30.08$ & $00: 01.82$ & 1 & 15 & $02: 38.00$ & $02: 40.13$ & $00: 02.13$ & 0 & 16 \\
\hline 14 & $02: 32.19$ & $02: 34.03$ & $00: 01.84$ & 1 & 15 & $02: 41.17$ & $02: 43.01$ & $00: 01.84$ & 0 & 16 \\
\hline 14 & $02: 22.08$ & $02: 22.27$ & $00: 00.19$ & 1 & 15 & $02: 31.07$ & $02: 32.00$ & $00: 00.93$ & 0 & 16 \\
\hline 14 & $02: 22.16$ & $02: 26.00$ & $00: 03.84$ & 1 & 15 & $02: 31.14$ & $02: 35.17$ & $00: 04.03$ & 0 & 16 \\
\hline 14 & $02: 23.09$ & $02: 24.05$ & $00: 00.96$ & 1 & 15 & $02: 32.10$ & $02: 33.01$ & $00: 00.91$ & 0 & 16 \\
\hline 14 & $02: 31.28$ & $02: 33.26$ & $00: 01.98$ & 0 & 15 & $02: 40.29$ & $02: 42.11$ & $00: 01.82$ & 0 & 16 \\
\hline 14 & $02: 21.05$ & $02: 22.15$ & $00: 01.10$ & 1 & 15 & $02: 30.00$ & $02: 32.04$ & $00: 02.04$ & 0 & 16 \\
\hline 14 & $02: 23.19$ & $02: 23.22$ & $00: 00.03$ & 1 & 15 & $02: 32.19$ & $02: 33.16$ & $00: 00.97$ & 0 & 16 \\
\hline 14 & $02: 25.06$ & $02: 25.27$ & $00: 00.21$ & 1 & 15 & $02: 34.07$ & $02: 35.22$ & $00: 01.15$ & 0 & 16 \\
\hline 14 & $02: 35.12$ & $02: 35.27$ & $00: 00.15$ & 1 & 15 & $02: 44.09$ & $02: 45.17$ & $00: 01.08$ & 1 & 16 \\
\hline 14 & $02: 29.25$ & $02: 30.11$ & $00: 00.86$ & 1 & 15 & $02: 38.25$ & $02: 39.14$ & $00: 00.89$ & 0 & 16 \\
\hline 14 & $02: 27.10$ & $02: 30.26$ & $00: 03.16$ & 0 & 15 & $02: 36.12$ & $02: 37.07$ & $00: 00.95$ & 0 & 16 \\
\hline 14 & $02: 25.02$ & $02: 25.17$ & $00: 00.15$ & 1 & 15 & $02: 34.02$ & $02: 37.22$ & $00: 03.20$ & 0 & 16 \\
\hline 14 & $02: 19.19$ & $02: 20.03$ & $00: 00.84$ & 1 & 15 & $02: 28.22$ & $02: 30.01$ & $00: 01.79$ & 0 & 16 \\
\hline 14 & $02: 20.29$ & $02: 21.16$ & $00: 00.87$ & 1 & 15 & $02: 30.00$ & $02: 30.10$ & $00: 00.10$ & 0 & 16 \\
\hline 14 & $02: 22.17$ & $02: 23.16$ & $00: 00.99$ & 1 & 15 & $02: 31.20$ & $02: 32.18$ & $00: 00.98$ & 0 & 16 \\
\hline 14 & $02: 21.05$ & $02: 25.16$ & $00: 04.11$ & 0 & 15 & $02: 30.05$ & $02: 30.17$ & $00: 00.12$ & 0 & 16 \\
\hline 14 & $02: 17.29$ & $02: 18.21$ & $00: 00.92$ & 1 & 15 & $02: 26.29$ & $02: 28.15$ & $00: 01.86$ & 0 & 16 \\
\hline 14 & $02: 25.25$ & $02: 29.12$ & $00: 03.87$ & 0 & 15 & $02: 34.22$ & $02: 36.12$ & $00: 01.90$ & 0 & 16 \\
\hline 14 & $02: 20.22$ & $02: 21.25$ & $00: 01.03$ & 1 & 15 & $02: 29.26$ & $02: 30.18$ & $00: 00.92$ & 0 & 16 \\
\hline 14 & $02: 16.26$ & $02: 17.04$ & $00: 00.78$ & 1 & 15 & $02: 25.22$ & $02: 26.12$ & $00: 00.90$ & 0 & 16 \\
\hline 14 & $02: 18.19$ & $02: 19.17$ & $00: 00.98$ & 1 & 15 & $02: 27.19$ & $02: 30.18$ & $00: 02.99$ & 0 & 16 \\
\hline 14 & $02: 23.08$ & $02: 23.22$ & $00: 00.14$ & 1 & 15 & $02: 32.09$ & $02: 32.27$ & $00: 00.18$ & 0 & 16 \\
\hline 14 & $02: 18.07$ & $02: 19.03$ & $00: 00.96$ & 1 & 15 & $02: 27.08$ & $02: 28.17$ & $00: 01.09$ & 0 & 16 \\
\hline
\end{tabular}

\begin{tabular}{|c|c|c|c|c|c|c|c|c|c|c|}
\hline Cue Time & Reaction time & RT & Scoring & Item \# & Cue Time & Reaction time & \begin{tabular}{|l|} 
RT \\
\end{tabular} & Scoring & Item \# & Cue Time \\
\hline $02: 47.20$ & $02: 48.15$ & $00: 00.95$ & 1 & 17 & $02: 56.25$ & $02: 57.18$ & $00: 00.93$ & 0 & \begin{tabular}{|r|}
18 \\
\end{tabular} & $03: 05.24$ \\
\hline $03: 02.02$ & $03: 02.18$ & $00: 00.16$ & 1 & 17 & $03: 11.00$ & $03: 12.02$ & $00: 01.02$ & 0 & 18 & $03: 20.05$ \\
\hline $02: 46.09$ & $02: 46.25$ & $00: 00.16$ & 1 & 17 & $02: 55.09$ & $02: 56.06$ & $00: 00.97$ & 0 & 18 & $03: 04.12$ \\
\hline $02: 50.16$ & $02: 51.05$ & $00: 00.89$ & 1 & 17 & $02: 59.18$ & $03: 00.13$ & $00: 00.95$ & 0 & 18 & $03: 08.20$ \\
\hline $02: 52.26$ & $02: 53.14$ & $00: 00.88$ & 1 & 17 & $03: 02.29$ & $00: 00.00$ & $00: 00.00$ & 0 & 18 & $03: 11.02$ \\
\hline $02: 47.12$ & $02: 48.11$ & $00: 00.99$ & 1 & 17 & $02: 56.08$ & $02: 57.21$ & $00: 01.13$ & 0 & 18 & $03: 05.07$ \\
\hline $02: 53.19$ & $02: 54.04$ & $00: 00.85$ & 1 & 17 & $03: 02.24$ & $03: 03.15$ & $00: 00.91$ & 0 & 18 & $03: 11.23$ \\
\hline $02: 47.05$ & $02: 48.11$ & $00: 01.06$ & 1 & 17 & $02: 56.05$ & $02: 57.08$ & $00: 01.03$ & 0 & 18 & $03: 05.03$ \\
\hline $02: 50.21$ & $02: 51.20$ & $00: 00.99$ & 1 & 17 & $02: 59.24$ & $03: 00.27$ & $00: 01.03$ & 0 & 18 & $03: 08.28$ \\
\hline $02: 40.10$ & $02: 41.00$ & $00: 00.90$ & 1 & 17 & $02: 49.08$ & $02: 50.19$ & $00: 01.11$ & 0 & 18 & $02: 58.14$ \\
\hline $02: 40.17$ & $02: 41.25$ & $00: 01.08$ & 1 & 17 & $02: 49.22$ & $02: 50.22$ & $00: 01.00$ & 0 & 18 & $02: 58.21$ \\
\hline $02: 41.13$ & $02: 41.27$ & $00: 00.14$ & 1 & 17 & $02: 50.20$ & $02: 51.22$ & $00: 01.02$ & 0 & 18 & $02: 59.18$ \\
\hline $02: 50.00$ & $02: 50.24$ & $00: 00.24$ & 1 & 17 & $02: 59.02$ & $03: 00.16$ & $00: 01.14$ & 0 & 18 & $03: 08.08$ \\
\hline $02: 39.06$ & $02: 40.05$ & $00: 00.99$ & 0 & 17 & $02: 48.11$ & $02: 49.29$ & $00: 01.18$ & 0 & 18 & $02: 57.07$ \\
\hline $02: 41.24$ & $02: 41.27$ & $00: 00.03$ & 1 & 17 & $02: 50.25$ & $02: 51.02$ & $00: 00.77$ & 0 & 18 & $03: 00.04$ \\
\hline $02: 43.07$ & $02: 45.00$ & $00: 01.93$ & 0 & 17 & $02: 52.12$ & $02: 53.17$ & $00: 01.05$ & 0 & 18 & $03: 01.00$ \\
\hline $02: 53.12$ & $02: 53.24$ & $00: 00.12$ & 0 & 17 & $03: 02.10$ & $03: 04.16$ & $00: 02.06$ & 0 & 18 & $03: 11.12$ \\
\hline $02: 47.39$ & $02: 48.16$ & $00: 00.77$ & 1 & 17 & $02: 56.29$ & $02: 58.29$ & $00: 02.00$ & 1 & 18 & $03: 06.01$ \\
\hline $02: 45.07$ & $02: 45.14$ & $00: 00.07$ & 1 & 17 & $02: 54.11$ & $02: 54.14$ & $00: 00.03$ & 0 & 18 & $03: 03.13$ \\
\hline $02: 43.02$ & $02: 44.10$ & $00: 01.08$ & 1 & 17 & $02: 52.05$ & $02: 55.03$ & $00: 02.98$ & 0 & 18 & $03: 01.08$ \\
\hline $02: 37.21$ & $02: 38.07$ & $00: 00.86$ & 1 & 17 & $02: 46.24$ & $02: 47.06$ & $00: 00.82$ & 0 & 18 & $02: 55.27$ \\
\hline $02: 39.01$ & $02: 39.09$ & $00: 00.08$ & 1 & 17 & $02: 47.29$ & $02: 48.28$ & $00: 00.99$ & 0 & 18 & $02: 57.03$ \\
\hline $02: 40.20$ & $02: 41.17$ & $00: 00.97$ & 1 & 17 & $02: 49.29$ & $02: 51.01$ & $00: 01.72$ & 0 & 18 & $02: 59.01$ \\
\hline $02: 39.09$ & $02: 39.24$ & $00: 00.15$ & 1 & 17 & $02: 48.13$ & $02: 50.07$ & $00: 01.94$ & 0 & 18 & $02: 57.15$ \\
\hline $02: 35.28$ & $02: 36.25$ & $00: 00.97$ & 1 & 17 & $02: 45.02$ & $02: 46.18$ & $00: 01.16$ & 0 & 18 & $02: 54.05$ \\
\hline $02: 43.29$ & $02: 44.14$ & $00: 00.85$ & 1 & 17 & $02: 52.29$ & $02: 53.20$ & $00: 00.91$ & 0 & 18 & $03: 02.04$ \\
\hline $02: 38.22$ & $02: 39.12$ & $00: 00.90$ & 1 & 17 & $02: 47.28$ & $02: 49.12$ & $00: 01.84$ & 0 & 18 & $02: 56.29$ \\
\hline $02: 34.26$ & $02: 35.05$ & $00: 00.79$ & 1 & 17 & $02: 43.29$ & $02: 45.00$ & $00: 01.71$ & 0 & 18 & $02: 53.00$ \\
\hline $02: 36.21$ & $02: 37.10$ & $00: 00.89$ & 1 & 17 & $02: 46.00$ & $02: 47.19$ & $00: 01.19$ & 0 & 18 & $02: 55.03$ \\
\hline $02: 41.04$ & $02: 41.28$ & $00: 00.24$ & 1 & 17 & $02: 50.20$ & $02: 51.03$ & $00: 00.83$ & 0 & 18 & $02: 59.22$ \\
\hline $02: 36.21$ & $02: 38.07$ & $00: 01.86$ & 1 & 17 & $02: 45.13$ & $02: 47.17$ & $00: 02.04$ & 0 & 18 & $02: 54.15$ \\
\hline
\end{tabular}




\begin{tabular}{|c|c|c|c|c|c|c|c|c|c|c|}
\hline Reaction time & RT & Scoring & Item \# & Cue Time & Reaction time & RT & Scoring & Item \# & Cue Time & Reaction time \\
\hline $03: 06.22$ & $00: 00.98$ & \begin{tabular}{|l}
0 \\
\end{tabular} & 19 & 03:14.21 & $03: 15.21$ & $00: 01.00$ & 0 & 20 & $03: 23.28$ & $03: 24.17$ \\
\hline $03: 21.07$ & $00: 01.02$ & 0 & 19 & $03: 29.05$ & $03: 30.01$ & $00: 00.96$ & 0 & 20 & $03: 37.29$ & $03: 38.21$ \\
\hline $03: 05.00$ & $00: 00.88$ & 0 & 19 & $03: 13.09$ & $03: 14.06$ & $00: 00.97$ & 0 & 20 & $03: 22.06$ & $03: 22.29$ \\
\hline 03:09.29 & $00: 01.09$ & 0 & 19 & $03: 17.17$ & $03: 18.11$ & $00: 00.94$ & 0 & 20 & $03: 26.19$ & $03: 27.14$ \\
\hline $03: 12.09$ & $00: 01.07$ & 1 & 19 & $03: 20.04$ & $03: 20.24$ & $00: 00.20$ & 0 & 20 & $03: 29.01$ & $03: 29.23$ \\
\hline $03: 06.22$ & $00: 01.15$ & 0 & 19 & $03: 14.11$ & $03: 16.00$ & $00: 01.89$ & 0 & 20 & $03: 23.07$ & $03: 25.02$ \\
\hline $03: 12.22$ & $00: 00.99$ & 0 & 19 & $03: 20.24$ & $03: 21.10$ & $00: 00.86$ & 0 & 20 & $03: 29.20$ & $03: 30.08$ \\
\hline $03: 07.13$ & $00: 02.10$ & 0 & 19 & $03: 14.03$ & $03: 16.01$ & $00: 01.98$ & 0 & 20 & $03: 23.02$ & $03: 24.09$ \\
\hline $03: 09.26$ & $00: 00.98$ & 1 & 19 & $03: 17.24$ & $03: 18.20$ & $00: 00.96$ & 0 & 20 & $03: 26.23$ & $03: 30.05$ \\
\hline $02: 59.12$ & $00: 00.98$ & 0 & 19 & $03: 07.17$ & $03: 08.18$ & $00: 01.01$ & 0 & 20 & $03: 16.09$ & $03: 17.03$ \\
\hline $02: 59.16$ & $00: 00.95$ & 1 & 19 & $03: 07.22$ & $03: 08.15$ & $00: 00.93$ & 0 & 20 & $03: 16.17$ & 03:19.05 \\
\hline $03: 00.10$ & $00: 00.92$ & 0 & 19 & $03: 08.19$ & $03: 09.00$ & $00: 00.81$ & 0 & 20 & $03: 17.17$ & $03: 18.26$ \\
\hline $03: 08.26$ & $00: 00.18$ & 0 & 19 & $03: 17.06$ & $03: 18.23$ & $00: 01.17$ & 0 & 20 & $03: 26.06$ & $03: 27.05$ \\
\hline $02: 58.15$ & $00: 01.08$ & 0 & 19 & 03:06.09 & $03: 07.23$ & $00: 01.14$ & 0 & 20 & $03: 15.06$ & $03: 16.13$ \\
\hline 03:00.11 & $00: 00.07$ & 0 & 19 & $03: 08.23$ & $03: 09.02$ & $00: 00.79$ & 0 & 20 & $03: 17.23$ & $03: 17.29$ \\
\hline $03: 02.26$ & $00: 01.26$ & 1 & 19 & $03: 10.13$ & $03: 11.05$ & $00: 00.92$ & 0 & 20 & $03: 19.11$ & $03: 22.02$ \\
\hline $03: 13.14$ & $00: 02.02$ & 0 & 19 & $03: 20.16$ & $03: 21.18$ & $00: 01.02$ & 0 & 20 & $03: 29.12$ & $03: 30.03$ \\
\hline $03: 07.15$ & $00: 01.14$ & 1 & 19 & $03: 15.06$ & $03: 15.28$ & $00: 00.22$ & 0 & 20 & $03: 24.06$ & $03: 26.11$ \\
\hline $03: 04.16$ & $00: 01.03$ & 0 & 19 & $03: 12.13$ & $03: 12.19$ & $00: 00.06$ & 0 & 20 & $03: 21.11$ & $03: 23.05$ \\
\hline $03: 04.02$ & $00: 02.94$ & 0 & 19 & $03: 10.12$ & $03: 12.19$ & $00: 02.07$ & 0 & 20 & $03: 19.09$ & $03: 20.28$ \\
\hline $02: 56.09$ & $00: 00.82$ & 1 & 19 & $03: 04.26$ & $03: 05.21$ & $00: 00.95$ & 0 & 20 & $03: 13.22$ & $03: 14.11$ \\
\hline $02: 57.24$ & $00: 00.21$ & 0 & 19 & $00: 06.23$ & $00: 07.07$ & $00: 00.84$ & 0 & 20 & $00: 15.22$ & $00: 16.04$ \\
\hline $02: 59.26$ & $00: 00.25$ & 0 & 19 & $03: 08.00$ & $03: 08.24$ & $00: 00.24$ & 0 & 20 & $03: 16.28$ & $03: 17.23$ \\
\hline $02: 57.29$ & $00: 00.14$ & 0 & 19 & $03: 06.13$ & $03: 07.13$ & $00: 01.00$ & 0 & 20 & $03: 15.11$ & $03: 15.21$ \\
\hline $02: 55.19$ & $00: 01.14$ & 0 & 19 & $03: 03.03$ & $03: 04.03$ & $00: 01.00$ & 0 & 20 & $03: 12.02$ & $03: 13.19$ \\
\hline $03: 03.12$ & $00: 01.08$ & 1 & 19 & $03: 11.00$ & $03: 11.24$ & $00: 00.24$ & 0 & 20 & $03: 20.00$ & $03: 21.19$ \\
\hline $02: 58.19$ & $00: 01.90$ & 0 & 19 & $03: 05.24$ & $03: 06.22$ & $00: 00.98$ & 0 & 20 & $03: 14.27$ & $03: 16.00$ \\
\hline $02: 53.20$ & $00: 00.20$ & 0 & 19 & $03: 01.24$ & $03: 02.13$ & $00: 00.89$ & 0 & 20 & $03: 10.26$ & $03: 12.05$ \\
\hline $02: 55.29$ & $00: 00.26$ & 0 & 19 & $03: 04.02$ & $03: 04.14$ & $00: 00.12$ & 0 & 20 & $03: 12.26$ & $03: 16.16$ \\
\hline $03: 00.04$ & $00: 00.82$ & 1 & 19 & $03: 08.20$ & $03: 09.00$ & $00: 00.80$ & 0 & 20 & $03: 17.18$ & $03: 18.03$ \\
\hline $02: 57.21$ & $00: 03.06$ & 0 & 19 & $03: 03.16$ & $03: 05.00$ & $00: 01.84$ & 0 & 20 & $03: 12.08$ & $03: 13.15$ \\
\hline
\end{tabular}

\begin{tabular}{|c|c|c|c|c|c|c|c|c|c|c|}
\hline RT & Scoring & Item \# & Cue Time & Reaction time & RT & Scoring & Item \# & Cue Time & Reaction time & RT \\
\hline $00: 00.89$ & 0 & 21 & $00: 32.15$ & $00: 33.18$ & $00: 01.03$ & 0 & \begin{tabular}{|r|}
22 \\
\end{tabular} & $00: 55.24$ & $00: 56.21$ & $00: 00.97$ \\
\hline $00: 00.92$ & 0 & 21 & $00: 30.05$ & $00: 31.04$ & $00: 00.99$ & 1 & 22 & $00: 51.25$ & $00: 52.24$ & $00: 00.99$ \\
\hline $00: 00.23$ & 0 & 21 & $00: 29.19$ & $00: 30.02$ & $00: 00.83$ & 0 & 22 & $00: 42.00$ & $00: 42.25$ & $00: 00.25$ \\
\hline $00: 00.95$ & 0 & 21 & $00: 56.07$ & $00: 56.17$ & $00: 00.10$ & 1 & 22 & $01: 15.15$ & $01: 16.07$ & $00: 00.92$ \\
\hline $00: 00.22$ & 0 & 21 & $00: 22.02$ & $00: 23.08$ & $00: 01.06$ & 0 & 22 & $00: 37.23$ & $00: 38.14$ & $00: 00.91$ \\
\hline $00: 01.95$ & 0 & 21 & $00: 29.18$ & $00: 31.06$ & $00: 01.88$ & 0 & 22 & $00: 47.20$ & $00: 49.21$ & $00: 02.01$ \\
\hline $00: 00.88$ & 0 & 21 & $00: 19.08$ & $00: 19.21$ & $00: 00.13$ & 1 & 22 & $00: 44.13$ & $00: 45.09$ & $00: 00.96$ \\
\hline $00: 01.07$ & 0 & 21 & $00: 26.18$ & $00: 27.12$ & $00: 00.94$ & 0 & 22 & $00: 44.16$ & $0: 46.00$ & $00: 01.84$ \\
\hline $00: 03.82$ & 0 & 21 & $00: 22.27$ & $00: 23.24$ & $00: 00.97$ & 1 & 22 & $00: 41.27$ & $00: 42.17$ & $00: 00.90$ \\
\hline $00: 00.94$ & 0 & 21 & $00: 39.14$ & $00: 40.04$ & $00: 00.90$ & 0 & 22 & $00: 58.03$ & $00: 58.20$ & $00: 00.17$ \\
\hline $00: 02.88$ & 0 & 21 & $00: 50.11$ & $00: 51.16$ & $00: 01.05$ & 0 & 22 & 54.28 & 5.28 & $00: 01.00$ \\
\hline $00: 01.09$ & 0 & 21 & $00: 24.20$ & $00: 25.08$ & $00: 00.88$ & 1 & 22 & $00: 42.16$ & 42.26 & $00: 00.10$ \\
\hline $00: 00.99$ & 0 & 21 & $00: 26.19$ & $00: 27.16$ & $00: 00.97$ & 0 & 22 & $00: 51.08$ & $00: 51.26$ & $00: 00.18$ \\
\hline $00: 01.07$ & 0 & 21 & $00: 21.28$ & $00: 22.20$ & $00: 00.92$ & 1 & 22 & $00: 47.10$ & $00: 48.05$ & $00: 00.95$ \\
\hline $00: 00.06$ & 0 & 21 & $00: 39.21$ & $00: 39.26$ & $00: 00.05$ & 0 & 22 & $01: 18.07$ & $01: 18.21$ & $00: 00.14$ \\
\hline $00: 02.91$ & 0 & 21 & $00: 21.25$ & $00: 23.05$ & $00: 01.80$ & 0 & 22 & $00: 39.03$ & $00: 39.19$ & $00: 00.16$ \\
\hline $00: 00.91$ & 0 & 21 & $00: 35.00$ & $00: 35.14$ & $00: 00.14$ & 0 & 22 & $01: 09.23$ & $01: 10.12$ & $00: 00.89$ \\
\hline $00: 02.05$ & 0 & 21 & $00: 15.26$ & $00: 16.03$ & $00: 00.77$ & 0 & 22 & 3.10 & 3.18 & $00: 00.08$ \\
\hline $00: 01.94$ & 0 & 21 & $00: 22.06$ & $00: 23.12$ & $00: 01.06$ & 1 & 22 & $02: 43.10$ & $02: 44.04$ & $00: 00.94$ \\
\hline $00: 01.19$ & 0 & 21 & $00: 23.09$ & $00: 23.25$ & $00: 00.16$ & 1 & 22 & $00: 39.09$ & $00: 40.02$ & $00: 00.93$ \\
\hline $00: 00.89$ & 0 & 21 & $00: 21.10$ & $00: 22.06$ & $00: 00.96$ & 1 & 22 & $00: 34.18$ & $00: 36.03$ & $00: 01.85$ \\
\hline $00: 00.82$ & 0 & 21 & $00: 26.01$ & $00: 26.12$ & $00: 00.11$ & 1 & 22 & $00: 39.21$ & 0.02 & $00: 00.81$ \\
\hline $00: 00.95$ & 0 & 21 & $00: 24.11$ & $00: 25.05$ & $00: 00.94$ & 1 & 22 & $00: 42.02$ & $00: 42.20$ & $00: 00.18$ \\
\hline $00: 00.10$ & 0 & 21 & $00: 21.25$ & $00: 22.21$ & $00: 00.96$ & 0 & 22 & $00: 42.16$ & $00: 44.00$ & $00: 01.84$ \\
\hline $00: 01.17$ & 0 & 21 & $00: 16.13$ & $00: 16.28$ & $00: 00.15$ & 0 & 22 & $00: 39.09$ & $00: 40.14$ & $00: 01.05$ \\
\hline $00: 01.19$ & 0 & 21 & $00: 57.22$ & $00: 58.17$ & $00: 00.95$ & 0 & 22 & $01: 27.04$ & $1: 27.25$ & $00: 00.21$ \\
\hline $00: 01.73$ & 0 & 21 & $00: 23.05$ & $00: 24.01$ & $00: 00.96$ & 0 & 22 & $00: 46.28$ & $00: 48.12$ & $00: 01.84$ \\
\hline $00: 01.79$ & 0 & 21 & $00: 29.21$ & $00: 30.03$ & $00: 00.82$ & 1 & 22 & $00: 43.14$ & $00: 44.02$ & $00: 00.88$ \\
\hline $00: 03.90$ & 0 & 21 & $00: 23.20$ & $00: 24.11$ & $00: 00.91$ & 1 & 22 & $01: 09.22$ & $01: 11.16$ & $00: 01.94$ \\
\hline $00: 00.85$ & 0 & 21 & $00: 20.04$ & $00: 20.19$ & $00: 00.15$ & 0 & 22 & $00: 33.13$ & $00: 34.03$ & $00: 00.90$ \\
\hline $00: 01.07$ & 0 & 21 & $00: 29.04$ & $00: 29.16$ & $00: 00.12$ & 0 & 22 & $01: 02.21$ & $01: 03.02$ & $00: 00.81$ \\
\hline
\end{tabular}




\begin{tabular}{|c|c|c|c|c|c|c|c|c|c|c|}
\hline Scoring & Item \# & Cue Time & Reaction time & RT & Scoring & Item \# & Cue Time & Reaction time & RT & Scoring \\
\hline 1 & 23 & $01: 16.16$ & \begin{tabular}{|r|}
$01: 17.15$ \\
\end{tabular} & $00: 00.99$ & \begin{tabular}{|l|}
0 \\
\end{tabular} & \begin{tabular}{|r|}
24 \\
\end{tabular} & $01: 50.29$ & \begin{tabular}{|c|}
$01: 52.00$ \\
\end{tabular} & $00: 01.71$ & 0 \\
\hline 1 & 23 & $01: 03.20$ & $01: 04.08$ & $00: 00.88$ & 0 & 24 & $01: 23.24$ & $01: 24.18$ & $00: 00.94$ & 0 \\
\hline 1 & 23 & $01: 01.07$ & $01: 02.16$ & $00: 01.09$ & 0 & 24 & $01: 44.25$ & $01: 45.12$ & $00: 00.87$ & 0 \\
\hline 1 & 23 & $01: 24.06$ & $01: 24.20$ & $00: 00.14$ & 0 & 24 & $01: 43.29$ & $01: 44.07$ & $00: 00.78$ & 0 \\
\hline 1 & 23 & $00: 52.21$ & $00: 53.12$ & $00: 00.91$ & 0 & 24 & $01: 14.09$ & $01: 15.15$ & $00: 01.06$ & 0 \\
\hline 0 & 23 & $00: 54.25$ & $00: 56.07$ & $00: 01.82$ & 0 & 24 & $01: 16.21$ & $01: 17.24$ & $00: 01.03$ & 0 \\
\hline 1 & 23 & $00: 50.03$ & $00: 51.14$ & $00: 01.11$ & 0 & 24 & $01: 24.20$ & $01: 25.02$ & $00: 00.82$ & 0 \\
\hline 0 & 23 & $00: 49.18$ & $00: 50.16$ & $00: 00.98$ & 0 & 24 & $01: 10.14$ & $01: 11.03$ & $00: 00.89$ & 0 \\
\hline 1 & 23 & $00: 48.02$ & $00: 48.20$ & $00: 00.18$ & 0 & 24 & $01: 10.02$ & $01: 10.13$ & $00: 00.11$ & 0 \\
\hline 1 & 23 & $01: 03.07$ & $01: 04.00$ & $00: 00.93$ & 0 & 24 & $01: 26.19$ & $01: 27.02$ & $00: 00.83$ & 0 \\
\hline 1 & 23 & $01: 09.12$ & $01: 09.29$ & $00: 00.17$ & 0 & 24 & $01: 26.23$ & $01: 27.17$ & $00: 00.94$ & 0 \\
\hline 1 & 23 & $01: 10.06$ & $01: 10.18$ & $00: 00.12$ & 0 & 24 & $01: 50.18$ & $01: 51.04$ & $00: 00.86$ & 0 \\
\hline 1 & 23 & $00: 54.26$ & $00: 55.13$ & $00: 00.87$ & 0 & 24 & $01: 31.17$ & $01: 32.03$ & $00: 00.86$ & 0 \\
\hline 1 & 23 & $00: 50.23$ & $00: 51.24$ & $00: 01.01$ & 0 & 24 & $01: 07.20$ & $01: 09.16$ & $00: 01.96$ & 0 \\
\hline 0 & 23 & $01: 26.19$ & $00: 00.00$ & $00: 00.00$ & 0 & 24 & $02: 00.21$ & $02: 01.08$ & $00: 00.87$ & 0 \\
\hline 1 & 23 & $01: 15.21$ & $01: 16.02$ & $00: 00.81$ & 0 & 24 & $01: 40.01$ & $01: 40.08$ & $00: 00.07$ & 0 \\
\hline 1 & 23 & $02: 11.20$ & $02: 12.22$ & $00: 01.02$ & 0 & 24 & $02: 32.02$ & $02: 32.13$ & $00: 00.11$ & 0 \\
\hline 1 & 23 & $00: 39.17$ & $00: 40.03$ & $00: 00.86$ & 0 & 24 & $01: 10.04$ & $01: 10.17$ & $00: 00.13$ & 0 \\
\hline 1 & 23 & $02: 50.03$ & $02: 52.07$ & $00: 02.04$ & 0 & 24 & $03: 28.10$ & $03: 28.19$ & $00: 00.09$ & 0 \\
\hline 1 & 23 & $00: 43.09$ & $00: 43.20$ & $00: 00.11$ & 0 & 24 & $01: 00.21$ & $01: 01.10$ & $00: 00.89$ & 0 \\
\hline 1 & 23 & $01: 14.17$ & $01: 15.11$ & $00: 00.94$ & 0 & 24 & $01: 48.28$ & $01: 49.11$ & $00: 00.83$ & 0 \\
\hline 1 & 23 & $00: 43.25$ & $00: 44.14$ & $00: 00.89$ & 0 & 24 & $01: 03.13$ & $01: 04.03$ & $00: 00.90$ & 0 \\
\hline 1 & 23 & $00: 46.04$ & $00: 46.21$ & $00: 00.17$ & 0 & 24 & $01: 08.22$ & $01: 09.05$ & $00: 00.83$ & 0 \\
\hline 1 & 23 & $00: 49.22$ & $00: 50.05$ & $00: 00.83$ & 0 & 24 & $01: 08.03$ & $01: 08.13$ & $00: 00.10$ & 0 \\
\hline 1 & 23 & $00: 46.13$ & $00: 47.13$ & $00: 01.00$ & 0 & 24 & $01: 07.21$ & $01: 09.07$ & $00: 01.86$ & 0 \\
\hline 1 & 23 & $01: 32.11$ & $01: 32.29$ & $00: 00.18$ & 0 & 24 & $01: 52.15$ & $01: 53.03$ & $00: 00.88$ & 0 \\
\hline 1 & 23 & $00: 57.07$ & $00: 57.27$ & $00: 00.20$ & 0 & 24 & $01: 16.28$ & $01: 17.16$ & $00: 00.88$ & 0 \\
\hline 1 & 23 & $00: 48.22$ & $00: 49.10$ & $00: 00.88$ & 0 & 24 & $01: 11.03$ & $01: 11.16$ & $00: 00.13$ & 0 \\
\hline 0 & 23 & $01: 14.23$ & $01: 15.20$ & $00: 00.97$ & 0 & 24 & $01: 35.23$ & $01: 37.24$ & $00: 02.01$ & 0 \\
\hline 1 & 23 & $00: 37.04$ & $00: 38.07$ & $00: 01.03$ & 0 & 24 & $00: 59.08$ & $00: 59.24$ & $00: 00.16$ & 0 \\
\hline 1 & 23 & $01: 12.19$ & $01: 13.24$ & $00: 01.05$ & 0 & 24 & $01: 51.24$ & $01: 53.03$ & $00: 01.79$ & 0 \\
\hline
\end{tabular}

\begin{tabular}{|c|c|c|c|c|c|c|c|c|c|c|}
\hline Item \# & Cue Time & Reaction time & RT & Scoring & Item \# & Cue Time & Reaction time & RT & Scoring & Item \# \\
\hline 25 & $01: 59.16$ & $02: 00.17$ & $00: 01.01$ & 0 & 26 & $02: 26.18$ & $02: 27.17$ & $00: 00.99$ & 0 & 27 \\
\hline 25 & $01: 37.21$ & $01: 38.10$ & $00: 00.89$ & 0 & 26 & $01: 58.24$ & $02: 00.10$ & $00: 01.86$ & 0 & 27 \\
\hline 25 & $01: 53.29$ & $01: 54.17$ & $00: 00.88$ & 1 & 26 & $02: 02.09$ & $02: 02.29$ & $00: 00.20$ & 0 & 27 \\
\hline 25 & $01: 50.08$ & $01: 50.24$ & $00: 00.16$ & 0 & 26 & $02: 28.08$ & $02: 28.20$ & $00: 00.12$ & 0 & 27 \\
\hline 25 & $01: 31.14$ & $01: 32.04$ & $00: 00.90$ & 0 & 26 & $02: 05.22$ & $02: 06.13$ & $00: 00.91$ & 0 & 27 \\
\hline 25 & $01: 29.08$ & $01: 30.06$ & $00: 00.98$ & 0 & 26 & $01: 39.21$ & $01: 41.09$ & $00: 01.88$ & 0 & 27 \\
\hline 25 & $01: 40.03$ & $01: 40.24$ & $00: 00.21$ & 0 & 26 & $01: 46.24$ & $01: 48.01$ & $00: 01.77$ & 0 & 27 \\
\hline 25 & $01: 13.25$ & $01: 14.16$ & $00: 00.91$ & 0 & 26 & $01: 26.15$ & $01: 27.08$ & $00: 00.93$ & 0 & 27 \\
\hline 25 & $01: 22.08$ & $01: 22.19$ & $00: 00.11$ & 0 & 26 & $01: 38.14$ & $01: 39.15$ & $00: 01.01$ & 0 & 27 \\
\hline 25 & $01: 55.08$ & $01: 55.27$ & $00: 00.19$ & 0 & 26 & $02: 07.11$ & $02: 07.28$ & $00: 00.17$ & 0 & 27 \\
\hline 25 & $01: 30.29$ & $01: 31.17$ & $00: 00.88$ & 0 & 26 & $01: 50.06$ & $01: 52.11$ & $00: 02.05$ & 0 & 27 \\
\hline 25 & $02: 07.19$ & $02: 08.02$ & $00: 00.83$ & 0 & 26 & $02: 40.15$ & $02: 40.28$ & $00: 00.13$ & 0 & 27 \\
\hline 25 & $01: 38.18$ & $01: 39.07$ & $00: 00.89$ & 0 & 26 & $01: 47.01$ & $01: 47.24$ & $00: 00.23$ & 0 & 27 \\
\hline 25 & $01: 15.03$ & $01: 15.27$ & $00: 00.24$ & 0 & 26 & $01: 25.04$ & $01: 25.25$ & $00: 00.21$ & 0 & 27 \\
\hline 25 & $02: 16.10$ & $02: 16.20$ & $00: 00.10$ & 0 & 26 & $02: 30.01$ & $02: 30.05$ & $00: 00.04$ & 0 & 27 \\
\hline 25 & $01: 43.23$ & $01: 43.26$ & $00: 00.03$ & 0 & 26 & $01: 56.18$ & $01: 57.02$ & $00: 00.84$ & 0 & 27 \\
\hline 25 & $03: 14.28$ & $03: 15.11$ & $00: 00.83$ & 0 & 26 & $03: 41.03$ & $03: 41.11$ & $00: 00.08$ & 0 & 27 \\
\hline 25 & $01: 15.01$ & $01: 15.15$ & $00: 00.14$ & 0 & 26 & $01: 32.01$ & $01: 32.22$ & $00: 00.21$ & 0 & 27 \\
\hline 25 & $04: 28.12$ & $04: 28.21$ & $00: 00.09$ & 0 & 26 & $05: 07.16$ & $05: 07.16$ & $00: 00.00$ & 0 & 27 \\
\hline 25 & $01: 09.28$ & $01: 10.26$ & $00: 00.98$ & 0 & 26 & $01: 17.16$ & $01: 17.27$ & $00: 00.11$ & 0 & 27 \\
\hline 25 & $02: 54.04$ & $02: 54.20$ & $00: 00.16$ & 0 & 26 & $03: 52.29$ & $03: 53.24$ & $00: 00.95$ & 0 & 27 \\
\hline 25 & $01: 07.06$ & $01: 07.19$ & $00: 00.13$ & 0 & 26 & $01: 37.29$ & $01: 38.11$ & $00: 00.82$ & 0 & 27 \\
\hline 25 & $01: 19.07$ & $01: 19.21$ & $00: 00.14$ & 0 & 26 & $01: 29.05$ & $01: 29.24$ & $00: 00.19$ & 0 & 27 \\
\hline 25 & $01: 16.03$ & $01: 16.10$ & $00: 00.07$ & 0 & 26 & $01: 48.17$ & $01: 49.03$ & $00: 00.86$ & $\underline{0}$ & 27 \\
\hline 25 & 01:21.18 & $01: 22.24$ & $00: 01.06$ & 0 & 26 & $01: 38.26$ & $01: 39.27$ & $00: 01.01$ & 1 & 27 \\
\hline 25 & inaudible & $00: 00.00$ & $00: 00.00$ & 0 & 26 & $02: 18.18$ & $02: 19.00$ & $00: 00.82$ & 0 & 27 \\
\hline 25 & $02: 34.05$ & $02: 35.03$ & $00: 00.98$ & 0 & 26 & $03: 04.18$ & $03: 05.18$ & $00: 01.00$ & 0 & 27 \\
\hline 25 & $01: 14.21$ & $01: 15.08$ & $00: 00.87$ & 0 & 26 & $01: 31.20$ & $01: 32.13$ & $00: 00.93$ & 0 & 27 \\
\hline 25 & $01: 42.11$ & $01: 43.19$ & $00: 01.08$ & 0 & 26 & $02: 03.04$ & $02: 03.21$ & $00: 00.17$ & 0 & 27 \\
\hline 25 & $01: 02.22$ & $01: 03.12$ & $00: 00.90$ & 0 & 26 & $01: 18.15$ & $01: 19.00$ & $00: 00.85$ & 0 & 27 \\
\hline 25 & $02: 02.29$ & $02: 03.19$ & $00: 00.90$ & 0 & 26 & $02: 33.20$ & $02: 34.12$ & $00: 00.92$ & 0 & 27 \\
\hline
\end{tabular}




\begin{tabular}{|c|c|c|c|c|c|c|c|c|c|c|}
\hline Cue Time & Reaction time & RT & \begin{tabular}{|l|} 
Scoring \\
\end{tabular} & Item \# & Cue Time & Reaction time & RT & \begin{tabular}{|l|} 
Scoring \\
\end{tabular} & Item \# & Cue Time \\
\hline $02: 42.29$ & $02: 44.09$ & $00: 01.80$ & 0 & \begin{tabular}{|r|}
28 \\
\end{tabular} & \begin{tabular}{|c|}
$03: 05.10$ \\
\end{tabular} & 03:06.22 & $00: 01.12$ & $\begin{array}{r}0 \\
\end{array}$ & 29 & $03: 31.00$ \\
\hline $02: 21.24$ & $02: 23.16$ & $00: 01.92$ & 0 & 28 & $02: 41.24$ & $02: 42.19$ & $00: 00.95$ & 0 & 29 & $02: 53.21$ \\
\hline $02: 24.06$ & $02: 25.05$ & $00: 00.99$ & 0 & 28 & $02: 44.06$ & $02: 45.02$ & $00: 00.96$ & 0 & 29 & $03: 14.00$ \\
\hline $02: 48.05$ & $02: 49.03$ & $00: 00.98$ & 0 & 28 & $03: 56.17$ & $03: 57.15$ & $00: 00.98$ & 0 & 29 & $04: 05.03$ \\
\hline $02: 19.11$ & $02: 20.06$ & $00: 00.95$ & 0 & 28 & $02: 36.25$ & $02: 39.00$ & $00: 02.75$ & 0 & 29 & $02: 43.22$ \\
\hline $01: 57.16$ & $01: 59.24$ & $00: 02.08$ & 0 & 28 & $02: 20.05$ & $02: 22.20$ & $00: 02.15$ & 0 & 29 & $02: 32.03$ \\
\hline $02: 32.14$ & $02: 33.19$ & $00: 01.05$ & 0 & 28 & $03: 22.18$ & $03: 23.03$ & $00: 00.85$ & 0 & 29 & $03: 29.26$ \\
\hline $01: 48.27$ & $01: 49.25$ & $00: 00.98$ & 1 & 28 & $02: 07.29$ & $02: 09.11$ & $00: 01.82$ & 0 & 29 & $02: 15.07$ \\
\hline $01: 56.08$ & $01: 57.16$ & $00: 01.08$ & 0 & 28 & $02: 17.02$ & $02: 17.21$ & $00: 00.19$ & 0 & 29 & $02: 28.20$ \\
\hline $02: 50.20$ & $02: 51.12$ & $00: 00.92$ & 0 & 28 & $03: 17.27$ & $03: 18.16$ & $00: 00.89$ & 0 & 29 & $03: 32.08$ \\
\hline $02: 04.04$ & $02: 06.08$ & $00: 02.04$ & 0 & 28 & $02: 22.25$ & $02: 24.07$ & $00: 01.82$ & 0 & 29 & $02: 31.12$ \\
\hline $03: 16.08$ & $03: 17.18$ & $00: 01.10$ & 0 & 28 & $04: 26.06$ & $04: 28.03$ & $00: 01.97$ & 0 & 29 & $05: 24.26$ \\
\hline $02: 03.25$ & $02: 04.20$ & $00: 00.95$ & 0 & 28 & $02: 25.04$ & $02: 25.22$ & $00: 00.18$ & 0 & 29 & $02: 32.25$ \\
\hline $01: 39.27$ & $01: 40.21$ & $00: 00.94$ & 0 & 28 & $01: 57.03$ & $01: 58.02$ & $00: 00.99$ & 0 & 29 & $02: 03.19$ \\
\hline $02: 50.20$ & $02: 51.03$ & $00: 00.83$ & 0 & 28 & $03: 37.21$ & $03: 38.04$ & $00: 00.83$ & 0 & 29 & $03: 53.01$ \\
\hline $02: 17.14$ & $02: 17.22$ & $00: 00.08$ & 0 & 28 & $02: 50.18$ & $02: 52.16$ & $00: 01.98$ & 0 & 29 & $02: 58.15$ \\
\hline $03: 59.25$ & $04: 00.23$ & $00: 00.98$ & 0 & 28 & $04: 40.12$ & $04: 41.03$ & $00: 00.91$ & 0 & 29 & $04: 53.17$ \\
\hline $01: 47.12$ & $01: 47.20$ & $00: 00.08$ & 0 & 28 & $02: 15.05$ & $02: 15.13$ & $00: 00.08$ & 0 & 29 & $02: 24.12$ \\
\hline $06: 04.28$ & $06: 09.27$ & $00: 04.99$ & 0 & 28 & $08: 55.25$ & $08: 56.04$ & $00: 00.79$ & 0 & 29 & $09: 14.08$ \\
\hline $01: 30.29$ & $01: 31.19$ & $00: 00.90$ & 0 & 28 & $01: 48.02$ & $01: 48.18$ & $00: 00.16$ & 0 & 29 & $01: 54.27$ \\
\hline $04: 08.19$ & $04: 09.26$ & $00: 01.07$ & 0 & 28 & $04: 27.05$ & $04: 29.03$ & $00: 01.98$ & 0 & 29 & $04: 56.19$ \\
\hline $01: 51.20$ & $01: 52.08$ & $00: 00.88$ & 0 & 28 & $02: 10.09$ & $02: 10.17$ & $00: 00.08$ & 0 & 29 & $02: 17.02$ \\
\hline $01: 43.25$ & $01: 44.19$ & $00: 00.94$ & 0 & 28 & $02: 07.26$ & $02: 08.16$ & $00: 00.90$ & 0 & 29 & $02: 16.28$ \\
\hline $03: 19.08$ & $03: 21.13$ & $00: 02.05$ & 0 & 28 & $03: 46.12$ & $03: 46.22$ & $00: 00.10$ & 0 & 29 & $03: 52.19$ \\
\hline $02: 01.13$ & $02: 02.28$ & $00: 01.15$ & 1 & 28 & $02: 29.11$ & $02: 33.03$ & $00: 03.92$ & 0 & 29 & $02: 46.17$ \\
\hline $02: 35.18$ & $02: 36.07$ & $00: 00.89$ & 0 & 28 & $03: 02.05$ & $03: 02.21$ & $00: 00.16$ & 0 & 29 & $03: 14.01$ \\
\hline $03: 21.05$ & $03: 22.29$ & $00: 01.24$ & 0 & 28 & $04: 04.28$ & $04: 05.25$ & $00: 00.97$ & 0 & 29 & $04: 21.09$ \\
\hline $01: 46.28$ & $01: 47.13$ & $00: 00.85$ & 0 & 28 & $02: 07.12$ & $02: 07.21$ & $00: 00.09$ & 0 & 29 & $02: 15.27$ \\
\hline $02: 22.15$ & $02: 23.16$ & $00: 01.01$ & 0 & 28 & $02: 48.22$ & $02: 50.20$ & $00: 01.98$ & 0 & 29 & $02: 58.28$ \\
\hline $01: 34.16$ & $01: 35.05$ & $00: 00.89$ & 0 & 28 & $01: 52.24$ & $01: 53.09$ & $00: 00.85$ & 0 & 29 & $01: 58.19$ \\
\hline $03: 01.08$ & $03: 02.22$ & $00: 01.14$ & 0 & 28 & $03: 35.11$ & $03: 38.19$ & $00: 03.08$ & 0 & 29 & $03: 56.00$ \\
\hline
\end{tabular}

\begin{tabular}{|c|c|c|c|c|c|c|c|c|c|c|}
\hline Reaction time & RT & Scoring & Item \# & Cue Time & Reaction time & RT & Scoring & Item \# & Cue Time & Reaction time \\
\hline $03: 31.20$ & $00: 00.20$ & 0 & 30 & $03: 45.12$ & \begin{tabular}{|c|}
$03: 46.09$ \\
\end{tabular} & $00: 00.97$ & 0 & \begin{tabular}{|r|}
31 \\
\end{tabular} & $04: 15.03$ & $04: 15.21$ \\
\hline $02: 54.09$ & $00: 00.88$ & 0 & 30 & $03: 07.16$ & $03: 08.00$ & $00: 00.84$ & 0 & 31 & $03: 49.05$ & $03: 50.03$ \\
\hline $03: 14.22$ & $00: 00.22$ & 0 & 30 & $03: 28.16$ & $03: 29.17$ & $00: 01.01$ & 0 & 31 & $03: 54.15$ & $03: 54.28$ \\
\hline $04: 05.18$ & $00: 00.15$ & 0 & 30 & $04: 18.04$ & $04: 18.29$ & $00: 00.25$ & 0 & 31 & $04: 55.13$ & $04: 56.03$ \\
\hline $02: 46.11$ & $00: 02.89$ & 0 & 30 & $03: 05.19$ & $03: 07.29$ & $00: 02.10$ & 0 & 31 & $03: 30.18$ & $03: 31.24$ \\
\hline $02: 34.11$ & $00: 02.08$ & 0 & 30 & $02: 46.02$ & $02: 47.09$ & $00: 01.07$ & 0 & 31 & $03: 27.27$ & $03: 30.06$ \\
\hline $03: 30.11$ & $00: 00.85$ & 0 & 30 & $03: 47.07$ & $03: 47.21$ & $00: 00.14$ & 0 & 31 & $05: 05.00$ & $05: 05.15$ \\
\hline $02: 16.02$ & $00: 00.95$ & 0 & 30 & $02: 27.07$ & $02: 27.25$ & $00: 00.18$ & 0 & 31 & $02: 52.22$ & $02: 53.17$ \\
\hline $02: 30.22$ & $00: 02.02$ & 0 & 30 & $02: 45.02$ & $02: 45.20$ & $00: 00.18$ & 0 & 31 & $03: 08.25$ & $03: 09.15$ \\
\hline $03: 32.22$ & $00: 00.14$ & 0 & 30 & $03: 45.20$ & $03: 46.05$ & $00: 00.85$ & 0 & 31 & $04: 22.09$ & $04: 22.23$ \\
\hline $02: 32.02$ & $00: 00.90$ & 0 & 30 & $02: 41.25$ & $02: 42.10$ & $00: 00.85$ & 0 & 31 & $03: 17.09$ & 03:18.07 \\
\hline $05: 25.11$ & $00: 00.85$ & 0 & 30 & $06: 32.13$ & $06: 34.17$ & $00: 02.04$ & 0 & 31 & $06: 57.21$ & $06: 58.00$ \\
\hline $02: 34.06$ & $00: 01.81$ & 0 & 30 & $02: 46.15$ & $02: 47.01$ & $00: 00.86$ & 0 & 31 & $03: 14.04$ & $03: 14.11$ \\
\hline $02: 04.10$ & $00: 00.91$ & 0 & 30 & $02: 15.15$ & $02: 16.14$ & $00: 00.99$ & 0 & 31 & $02: 36.19$ & $02: 38.00$ \\
\hline $03: 53.10$ & $00: 00.09$ & 0 & 30 & $04: 27.17$ & $04: 27.23$ & $00: 00.06$ & 0 & 31 & $05: 06.00$ & $05: 06.03$ \\
\hline $02: 58.23$ & $00: 00.08$ & 0 & 30 & $03: 23.12$ & $03: 23.20$ & $00: 00.08$ & 0 & 31 & $03: 44.16$ & $03: 45.13$ \\
\hline $04: 54.11$ & $00: 00.94$ & 0 & 30 & $05: 31.20$ & $05: 33.04$ & $00: 01.84$ & 0 & 31 & $06: 20.25$ & $06: 21.12$ \\
\hline $02: 24.27$ & $00: 00.15$ & 0 & 30 & $02: 36.12$ & $02: 36.27$ & $00: 00.15$ & 0 & 31 & $03: 07.23$ & $03: 08.04$ \\
\hline $09: 14.26$ & $00: 00.18$ & 0 & 30 & $09: 27.20$ & $00: 00.00$ & $00: 00.00$ & 1 & 31 & $00: 59.08$ & $00: 59.13$ \\
\hline $01: 55.21$ & $00: 00.94$ & 0 & 30 & $02: 06.24$ & $02: 06.29$ & $00: 00.05$ & 0 & 31 & $02: 43.00$ & $02: 43.20$ \\
\hline $04: 57.07$ & $00: 00.88$ & 0 & 30 & $05: 07.11$ & $05: 08.14$ & $00: 01.03$ & 0 & 31 & $05: 26.19$ & $05: 27.00$ \\
\hline $02: 17.13$ & $00: 00.11$ & 0 & 30 & $02: 28.17$ & $02: 29.06$ & $00: 00.89$ & 0 & 31 & $02: 53.13$ & $02: 53.23$ \\
\hline $02: 17.11$ & $00: 00.83$ & 0 & 30 & $03: 02.14$ & $03: 03.05$ & $00: 00.91$ & 0 & 31 & $03: 28.13$ & $03: 29.07$ \\
\hline $03: 53.06$ & $00: 00.87$ & 0 & 30 & $04: 02.22$ & $04: 04.28$ & $00: 02.06$ & 0 & 31 & $04: 29.10$ & $04: 29.27$ \\
\hline $02: 48.21$ & $00: 02.04$ & 0 & 30 & $03: 02.19$ & $03: 04.15$ & $00: 01.96$ & 0 & 31 & $03: 28.10$ & $03: 29.02$ \\
\hline $03: 14.28$ & $00: 00.27$ & 0 & 30 & $03: 29.19$ & $03: 30.16$ & $00: 00.97$ & 0 & 31 & inaudible & $00: 00.00$ \\
\hline $04: 21.26$ & $00: 00.17$ & 0 & 30 & $05: 04.19$ & $05: 05.08$ & $00: 00.89$ & 0 & 31 & $05: 55.05$ & $05: 55.24$ \\
\hline $02: 16.05$ & $00: 00.78$ & 0 & 30 & $02: 33.24$ & $02: 34.26$ & $00: 01.02$ & 0 & 31 & $02: 57.08$ & $02: 57.24$ \\
\hline $02: 59.14$ & $00: 00.86$ & 0 & 30 & $03: 10.17$ & $03: 11.26$ & $00: 01.09$ & 0 & 31 & $03: 47.12$ & $00: 00.00$ \\
\hline $01: 59.03$ & $00: 00.84$ & 0 & 30 & $02: 12.06$ & $02: 13.04$ & $00: 00.98$ & 0 & 31 & $02: 35.28$ & $02: 36.09$ \\
\hline $03: 58.23$ & $00: 02.23$ & 0 & 30 & $04: 26.18$ & $04: 29.12$ & $00: 02.94$ & 0 & 31 & $05: 18.05$ & $05: 18.29$ \\
\hline
\end{tabular}




\begin{tabular}{|c|c|c|c|c|c|c|c|c|c|c|}
\hline RT & Scoring & Item \# & Cue Time & Reaction time & RT & Scoring & Item \# & Cue Time & Reaction time & RT \\
\hline $00: 00.18$ & $\begin{array}{l}0 \\
\end{array}$ & 32 & \begin{tabular}{|c|}
$04: 24.11$ \\
\end{tabular} & \begin{tabular}{|c|}
$04: 25.06$ \\
\end{tabular} & $00: 00.95$ & 0 & 33 & $04: 33.28$ & \begin{tabular}{|c|}
$04: 34.18$ \\
\end{tabular} & $00: 00.90$ \\
\hline $00: 00.98$ & 0 & 32 & $04: 03.10$ & $04: 04.10$ & $00: 01.00$ & 1 & 33 & $04: 20.11$ & $04: 21.18$ & $00: 01.07$ \\
\hline $00: 00.13$ & 0 & 32 & $04: 06.06$ & $04: 06.29$ & $00: 00.23$ & 1 & 33 & $04: 17.20$ & $04: 18.15$ & $00: 00.95$ \\
\hline $00: 00.90$ & 1 & 32 & $05: 06.24$ & $05: 07.24$ & $00: 01.00$ & 0 & 33 & $05: 18.07$ & $05: 18.23$ & $00: 00.16$ \\
\hline $00: 01.06$ & 0 & 32 & $03: 54.16$ & $03: 55.07$ & $00: 00.91$ & 1 & 33 & $04: 01.25$ & $04: 02.26$ & $00: 01.01$ \\
\hline $00: 02.79$ & 0 & 32 & $03: 41.09$ & $03: 42.07$ & $00: 00.98$ & 0 & 33 & $03: 57.16$ & $03: 58.15$ & $00: 00.99$ \\
\hline $00: 00.15$ & 0 & 32 & $05: 25.26$ & $05: 27.23$ & $00: 01.97$ & 0 & 33 & $07: 09.20$ & $07: 10.02$ & $00: 00.82$ \\
\hline $00: 00.95$ & 0 & 32 & $03: 01.12$ & $03: 02.26$ & $00: 01.14$ & 0 & 33 & $03: 09.28$ & $03: 10.26$ & $00: 00.98$ \\
\hline $00: 00.90$ & 0 & 32 & $03: 18.15$ & $03: 19.22$ & $00: 01.07$ & 0 & 33 & $03: 28.08$ & $03: 28.24$ & $00: 00.16$ \\
\hline $00: 00.14$ & 0 & 32 & $04: 33.12$ & $04: 34.01$ & $00: 00.89$ & 0 & 33 & $04: 58.29$ & $04: 59.19$ & $00: 00.90$ \\
\hline $00: 00.98$ & 1 & 32 & $03: 27.16$ & $03: 28.27$ & $00: 01.11$ & 1 & 33 & $03: 36.20$ & $03: 39.14$ & $00: 02.94$ \\
\hline $00: 00.79$ & 1 & 32 & $07: 25.14$ & $07: 26.05$ & $00: 00.91$ & 0 & 33 & $08: 08.17$ & $08: 09.05$ & $00: 00.88$ \\
\hline $00: 00.07$ & 0 & 32 & $03: 22.15$ & $03: 22.25$ & $00: 00.10$ & 1 & 33 & $03: 29.22$ & $03: 30.03$ & $00: 00.81$ \\
\hline $00: 01.81$ & 0 & 32 & $02: 44.28$ & $02: 45.27$ & $00: 00.99$ & 1 & 33 & $02: 52.14$ & $02: 53.08$ & $00: 00.94$ \\
\hline $00: 00.03$ & 0 & 32 & $05: 30.00$ & $05: 31.16$ & $00: 01.16$ & 0 & 33 & $05: 45.03$ & 46.08 & $00: 01.05$ \\
\hline $00: 00.97$ & 0 & 32 & $03: 56.06$ & $03: 57.16$ & $00: 01.10$ & 0 & 33 & $04: 06.26$ & $04: 07.13$ & $00: 00.87$ \\
\hline $00: 00.87$ & 1 & 32 & $06: 28.19$ & $06: 29.02$ & $00: 00.83$ & 0 & 33 & $07: 59.19$ & $08: 00.01$ & $00: 00.82$ \\
\hline $00: 00.81$ & 0 & 32 & $03: 16.27$ & $03: 17.10$ & $00: 00.83$ & 0 & 33 & $03: 24.23$ & $03: 25.07$ & $00: 00.84$ \\
\hline $00: 00.05$ & 0 & 32 & $01: 53.20$ & $01: 54.15$ & $00: 00.95$ & 1 & 33 & $02: 52.04$ & $02: 52.18$ & $00: 00.14$ \\
\hline $00: 00.20$ & 1 & 32 & $02: 51.27$ & $02: 53.01$ & $00: 01.74$ & 0 & 33 & $02: 59.11$ & $02: 59.18$ & $00: 00.07$ \\
\hline $00: 00.81$ & 0 & 32 & $05: 37.15$ & $05: 40.09$ & $00: 02.94$ & 0 & 33 & $06: 00.19$ & $06: 02.11$ & $00: 01.92$ \\
\hline $00: 00.10$ & 0 & 32 & $03: 02.17$ & 03.09 & $00: 00.92$ & 0 & 33 & 15.21 & 6.26 & $00: 01.05$ \\
\hline $00: 00.94$ & 0 & 32 & $03: 40.26$ & $03: 41.17$ & $00: 00.91$ & 1 & 33 & $03: 49.28$ & $03: 50.20$ & $00: 00.92$ \\
\hline $00: 00.17$ & 0 & 32 & $04: 36.02$ & $04: 36.13$ & $00: 00.11$ & 0 & 33 & $04: 43.11$ & $04: 44.02$ & $00: 00.91$ \\
\hline $00: 00.92$ & 0 & 32 & $03: 41.29$ & $03: 44.06$ & $00: 02.77$ & 0 & 33 & $03: 52.13$ & $03: 52.29$ & $00: 00.16$ \\
\hline $00: 00.00$ & 0 & 32 & $04: 24.08$ & $04: 25.01$ & $00: 00.93$ & 0 & 33 & $04: 35.13$ & $04: 35.27$ & $00: 00.14$ \\
\hline $00: 00.19$ & 0 & 32 & $06: 08.03$ & $06: 09.13$ & $00: 01.10$ & 0 & 33 & $06: 20.23$ & $06: 21.16$ & $00: 00.93$ \\
\hline $00: 00.16$ & 0 & 32 & $03: 08.01$ & $03: 08.17$ & $00: 00.16$ & 0 & 33 & $03: 15.14$ & $03: 16.00$ & $00: 00.86$ \\
\hline $00: 00.00$ & 0 & 32 & $03: 57.17$ & $03: 58.28$ & $00: 01.11$ & 1 & 33 & $04: 28.10$ & $04: 29.10$ & $00: 01.00$ \\
\hline $00: 00.81$ & 0 & 32 & $02: 44.09$ & $02: 44.17$ & $00: 00.08$ & 0 & 33 & $02: 50.21$ & $02: 51.09$ & $00: 00.88$ \\
\hline $00: 00.24$ & 0 & 32 & $05: 33.21$ & $05: 34.18$ & $00: 00.97$ & 0 & 33 & $05: 45.28$ & $05: 47.03$ & $00: 01.75$ \\
\hline
\end{tabular}

\begin{tabular}{|c|c|c|c|c|c|c|c|c|c|c|}
\hline Scoring & Item \# & Cue Time & Reaction time & RT & Scoring & Item \# & Cue Time & Reaction time & RT & Scoring \\
\hline 0 & 34 & $04: 43.12$ & \begin{tabular}{|r|}
$04: 44.05$ \\
\end{tabular} & $00: 00.93$ & 0 & 35 & $04: 54.08$ & $04: 54.29$ & $00: 00.21$ & 0 \\
\hline 0 & 34 & $04: 30.19$ & $04: 32.19$ & $00: 02.00$ & 0 & 35 & $04: 53.24$ & $04: 54.23$ & $00: 00.99$ & 0 \\
\hline 0 & 34 & $04: 39.04$ & $04: 40.17$ & $00: 01.13$ & 0 & 35 & $04: 59.05$ & 05:00.01 & $00: 00.96$ & 0 \\
\hline 0 & 34 & $05: 31.07$ & $05: 32.25$ & $00: 01.18$ & 1 & 35 & $05: 47.12$ & $05: 48.00$ & $00: 00.88$ & 1 \\
\hline 0 & 34 & $04: 10.27$ & $04: 13.09$ & $00: 02.82$ & 0 & 35 & $04: 23.18$ & $04: 26.05$ & $00: 02.87$ & 0 \\
\hline 0 & 34 & $04: 09.16$ & $04: 12.24$ & $00: 03.08$ & 0 & 35 & $04: 24.12$ & $04: 25.18$ & $00: 01.06$ & 0 \\
\hline 0 & 34 & $08: 39.28$ & $08: 41.04$ & $00: 01.76$ & 0 & 35 & $00: 37.05$ & $00: 37.24$ & $00: 00.19$ & 0 \\
\hline 0 & 34 & $03: 19.04$ & $03: 19.25$ & $00: 00.21$ & 0 & 35 & $03: 31.07$ & $03: 32.21$ & $00: 01.14$ & 0 \\
\hline 0 & 34 & $03: 40.25$ & $03: 41.10$ & $00: 00.85$ & 0 & 35 & $03: 56.14$ & $03: 57.05$ & $00: 00.91$ & 0 \\
\hline 0 & 34 & $05: 09.08$ & $05: 10.08$ & $00: 01.00$ & 0 & 35 & $05: 28.26$ & $05: 29.13$ & $00: 00.87$ & 1 \\
\hline 0 & 34 & 03:47.09 & $03: 49.22$ & $00: 02.13$ & 0 & 35 & $04: 00.29$ & $04: 01.12$ & $00: 00.83$ & 0 \\
\hline 0 & 34 & $08: 50.04$ & $08: 51.10$ & $00: 01.06$ & 0 & 35 & $00: 18.00$ & $00: 18.21$ & $00: 00.21$ & 1 \\
\hline 0 & 34 & $03: 38.28$ & $03: 39.24$ & $00: 00.96$ & 0 & 35 & $04: 01.08$ & $04: 02.21$ & $00: 01.13$ & 0 \\
\hline 0 & 34 & $03: 07.00$ & $03: 08.12$ & $00: 01.12$ & 0 & 35 & $03: 20.13$ & $03: 21.00$ & $00: 00.87$ & 0 \\
\hline 0 & 34 & $06: 02.01$ & $06: 02.13$ & $00: 00.12$ & 0 & 35 & $06: 27.14$ & $06: 27.28$ & $00: 00.14$ & 1 \\
\hline 0 & 34 & $04: 16.28$ & $04: 18.13$ & $00: 01.85$ & 1 & 35 & $04: 34.28$ & $04: 36.00$ & $00: 01.72$ & 1 \\
\hline 0 & 34 & $08: 29.05$ & $08: 29.28$ & $00: 00.23$ & 1 & 35 & $08: 55.00$ & $08: 55.22$ & $00: 00.22$ & 0 \\
\hline 0 & 34 & $03: 34.23$ & $03: 35.02$ & $00: 00.79$ & 0 & 35 & $03: 48.10$ & $03: 49.18$ & $00: 01.08$ & 0 \\
\hline 0 & 34 & $03: 01.21$ & $03: 02.22$ & $00: 01.01$ & 0 & 35 & $03: 45.29$ & $03: 46.19$ & $00: 00.90$ & 1 \\
\hline 0 & 34 & $03: 07.04$ & $03: 07.17$ & $00: 00.13$ & 0 & 35 & $03: 19.14$ & $03: 20.01$ & $00: 00.87$ & 0 \\
\hline 0 & 34 & $07: 49.01$ & $07: 49.28$ & $00: 00.27$ & 0 & 35 & $08: 03.08$ & $08: 03.18$ & $00: 00.10$ & 0 \\
\hline 0 & 34 & $03: 25.29$ & $03: 26.16$ & $00: 00.87$ & 0 & 35 & $03: 50.15$ & $03: 51.04$ & $00: 00.89$ & 0 \\
\hline 0 & 34 & $04: 58.07$ & $04: 59.06$ & $00: 00.99$ & 1 & 35 & $05: 35.23$ & $05: 36.08$ & $00: 00.85$ & 1 \\
\hline 0 & 34 & $04: 51.04$ & $04: 52.28$ & $00: 01.24$ & 0 & 35 & $05: 18.26$ & $05: 19.11$ & $00: 00.85$ & 0 \\
\hline 0 & 34 & $04: 04.04$ & $04: 04.28$ & $00: 00.24$ & 0 & 35 & $04: 18.26$ & $04: 20.25$ & $00: 01.99$ & 1 \\
\hline 0 & 34 & $04: 47.22$ & $04: 48.13$ & $00: 00.91$ & 0 & 35 & inaudible & $00: 00.00$ & $00: 00.00$ & 0 \\
\hline 0 & 34 & $06: 41.11$ & $06: 42.17$ & $00: 01.06$ & 0 & 35 & $06: 55.21$ & $06: 56.18$ & $00: 00.97$ & 1 \\
\hline 0 & 34 & $03: 25.10$ & $03: 26.01$ & $00: 00.91$ & 0 & 35 & $03: 38.16$ & $03: 39.00$ & $00: 00.84$ & 1 \\
\hline 0 & 34 & $04: 42.20$ & $04: 44.15$ & $00: 01.95$ & 1 & 35 & $05: 01.17$ & $05: 02.03$ & $00: 00.86$ & 0 \\
\hline 0 & 34 & $03: 01.05$ & $03: 01.22$ & $00: 00.17$ & 0 & 35 & $03: 15.04$ & $03: 15.14$ & $00: 00.10$ & 0 \\
\hline 0 & 34 & $06: 06.03$ & $06: 09.01$ & $00: 02.98$ & 0 & 35 & $06: 26.13$ & $06: 26.26$ & $00: 00.13$ & 0 \\
\hline
\end{tabular}




\begin{tabular}{|c|c|c|c|c|c|c|c|c|c|c|}
\hline Item \# & Cue Time & Reaction time & $\mathbf{R T}$ & Scoring & Item \# & Cue Time & Reaction time & RT & Scoring & Item \# \\
\hline 36 & 05:02.00 & $\begin{array}{r}05: 02.28 \\
\end{array}$ & $00: 00.28$ & 0 & 37 & $05: 25.01$ & $05: 26.00$ & $00: 00.99$ & 1 & \begin{tabular}{|r|}
38 \\
\end{tabular} \\
\hline 36 & $05: 03.16$ & $05: 04.20$ & $00: 01.04$ & 0 & 37 & $05: 22.01$ & $05: 22.28$ & $00: 00.27$ & 1 & 38 \\
\hline 36 & $05: 21.03$ & $05: 21.23$ & $00: 00.20$ & 0 & 37 & $05: 45.03$ & $05: 45.20$ & $00: 00.17$ & 1 & 38 \\
\hline 36 & $06: 28.24$ & $06: 29.09$ & $00: 00.85$ & 0 & 37 & $06: 40.05$ & $06: 40.22$ & $00: 00.17$ & 1 & 38 \\
\hline 36 & $04: 34.07$ & $04: 34.28$ & $00: 00.21$ & 0 & 37 & $04: 44.18$ & $04: 45.07$ & $00: 00.89$ & 1 & 38 \\
\hline 36 & $04: 35.27$ & $04: 36.23$ & $00: 00.96$ & 0 & 37 & $04: 48.00$ & $04: 49.04$ & $00: 01.04$ & 1 & 38 \\
\hline 36 & $07: 33.26$ & $07: 35.19$ & $00: 01.93$ & 0 & 37 & $08: 32.05$ & $08: 32.19$ & $00: 00.14$ & 1 & 38 \\
\hline 36 & $03: 38.25$ & $03: 39.19$ & $00: 00.94$ & 0 & 37 & $03: 54.20$ & $03: 55.16$ & $00: 00.96$ & 0 & 38 \\
\hline 36 & $04: 04.15$ & $04: 05.08$ & $00: 00.93$ & 0 & 37 & $04: 15.05$ & $04: 15.19$ & $00: 00.14$ & 1 & 38 \\
\hline 36 & $05: 38.11$ & $05: 39.15$ & $00: 01.04$ & 0 & 37 & $05: 56.19$ & $05: 57.02$ & $00: 00.83$ & 1 & 38 \\
\hline 36 & $04: 24.28$ & $04: 28.02$ & $00: 03.74$ & 0 & 37 & $04: 41.13$ & $04: 42.00$ & $00: 00.87$ & 1 & 38 \\
\hline 36 & $01: 56.07$ & $01: 56.22$ & $00: 00.15$ & 0 & 37 & $03: 08.27$ & $03: 09.13$ & $00: 00.86$ & 1 & 38 \\
\hline 36 & $04: 11.08$ & $04: 12.00$ & $00: 00.92$ & 0 & 37 & $04: 22.25$ & $00: 00.00$ & $00: 00.00$ & 1 & 38 \\
\hline 36 & $03: 29.14$ & $03: 30.01$ & $00: 00.87$ & 0 & 37 & $03: 42.03$ & $03: 42.21$ & $00: 00.18$ & 1 & 38 \\
\hline 36 & $06: 54.11$ & $06: 54.20$ & $00: 00.09$ & 0 & 37 & $07: 15.06$ & $07: 15.19$ & $00: 00.13$ & 0 & 38 \\
\hline 36 & $04: 45.20$ & $04: 48.21$ & $00: 03.01$ & 0 & 37 & $05: 05.21$ & $05: 05.28$ & $00: 00.07$ & 1 & 38 \\
\hline 36 & $09: 18.28$ & $09: 19.07$ & $00: 00.79$ & 0 & 37 & $00: 14.25$ & $00: 16.03$ & $00: 01.78$ & 1 & 38 \\
\hline 36 & $03: 56.14$ & $03: 56.25$ & $00: 00.11$ & 0 & 37 & $04: 09.22$ & $04: 10.12$ & $00: 00.90$ & 1 & 38 \\
\hline 36 & $06: 55.28$ & $06: 56.04$ & $00: 00.76$ & 0 & 37 & $07: 20.02$ & $07: 19.27$ & $-00: 00.75$ & 0 & 38 \\
\hline 36 & $03: 29.10$ & $03: 29.17$ & $00: 00.07$ & 0 & 37 & $03: 38.28$ & $03: 39.10$ & $00: 00.82$ & 1 & 38 \\
\hline 36 & $08: 12.25$ & $08: 13.21$ & $00: 00.96$ & 0 & 37 & $08: 24.27$ & $08: 25.10$ & $00: 00.83$ & 1 & 38 \\
\hline 36 & $04: 06.01$ & $04: 06.19$ & $00: 00.18$ & 0 & 37 & $04: 19.08$ & $04: 19.18$ & $00: 00.10$ & 1 & 38 \\
\hline 36 & $06: 07.10$ & $06: 07.29$ & $00: 00.19$ & 0 & 37 & $06: 19.12$ & $06: 20.05$ & $00: 00.93$ & 0 & 38 \\
\hline 36 & $05: 54.14$ & $05: 55.08$ & $00: 00.94$ & 0 & 37 & $06: 17.02$ & $06: 17.29$ & $00: 00.27$ & 1 & 38 \\
\hline 36 & $04: 31.15$ & $04: 34.02$ & $00: 02.87$ & 0 & 37 & $04: 52.20$ & $04: 54.18$ & $00: 01.98$ & 0 & 38 \\
\hline 36 & $05: 15.08$ & $05: 16.12$ & $00: 01.04$ & 0 & 37 & $05: 28.09$ & $05: 28.20$ & $00: 00.11$ & 1 & 38 \\
\hline 36 & $07: 07.26$ & $07: 08.28$ & $00: 01.02$ & 0 & 37 & $07: 45.20$ & $07: 46.02$ & $00: 00.82$ & 1 & 38 \\
\hline 36 & $03: 54.16$ & $03: 54.21$ & $00: 00.05$ & 0 & 37 & $04: 06.01$ & $04: 06.13$ & $00: 00.12$ & 1 & 38 \\
\hline 36 & $05: 21.25$ & $05: 23.13$ & $00: 01.88$ & 0 & 37 & $05: 36.13$ & $05: 37.20$ & $00: 01.07$ & 1 & 38 \\
\hline 36 & $03: 25.01$ & $03: 25.11$ & $00: 00.10$ & 0 & 37 & $03: 34.02$ & $03: 34.17$ & $00: 00.15$ & 1 & 38 \\
\hline 36 & $06: 38.10$ & $06: 40.12$ & $00: 02.02$ & 0 & 37 & $06: 55.18$ & $06: 56.05$ & $00: 00.87$ & 1 & 38 \\
\hline
\end{tabular}

\begin{tabular}{|c|c|c|c|c|c|c|c|c|c|c|}
\hline Cue Time & Reaction time & RT & Scoring & Item \# & Cue Time & Reaction time & RT & Scoring & Item \# & Cue Time \\
\hline $05: 30.21$ & \begin{tabular}{|c|}
$05: 31.14$ \\
\end{tabular} & $00: 00.93$ & \begin{tabular}{|l|}
1 \\
\end{tabular} & \begin{tabular}{|r|}
39 \\
\end{tabular} & 05:38.09 & $05: 39.19$ & $00: 01.10$ & \begin{tabular}{|r|}
0 \\
\end{tabular} & $\begin{array}{r}40 \\
\end{array}$ & 05:56.21 \\
\hline $05: 32.14$ & $05: 32.29$ & $00: 00.15$ & 1 & 39 & $05: 49.24$ & $05: 51.04$ & $00: 01.80$ & 0 & 40 & $06: 26.19$ \\
\hline $05: 57.26$ & $05: 58.22$ & $00: 00.96$ & 1 & 39 & $06: 06.23$ & $06: 07.11$ & $00: 00.88$ & 0 & 40 & $06: 21.05$ \\
\hline $07: 09.11$ & $07: 09.28$ & $00: 00.17$ & 1 & 39 & $07: 21.29$ & $07: 23.05$ & $00: 01.76$ & 1 & 40 & $07: 41.21$ \\
\hline $04: 53.07$ & $04: 53.25$ & $00: 00.18$ & 1 & 39 & $05: 02.01$ & $05: 04.06$ & $00: 02.05$ & 0 & 40 & $05: 14.29$ \\
\hline $04: 57.00$ & $04: 58.20$ & $00: 01.20$ & 1 & 39 & $05: 06.18$ & $05: 07.20$ & $00: 01.02$ & 1 & 40 & $05: 21.11$ \\
\hline $00: 04.04$ & $00: 04.28$ & $00: 00.24$ & 1 & 39 & $00: 17.22$ & $00: 18.11$ & $00: 00.89$ & 1 & 40 & $07: 57.27$ \\
\hline $04: 02.12$ & $04: 02.29$ & $00: 00.17$ & 1 & 39 & $04: 12.03$ & $04: 12.26$ & $00: 00.23$ & 0 & 40 & $04: 26.24$ \\
\hline $04: 24.27$ & $04: 25.16$ & $00: 00.89$ & 1 & 39 & $04: 35.18$ & $04: 37.22$ & $00: 02.04$ & 0 & 40 & $04: 53.17$ \\
\hline $06: 07.18$ & $06: 08.03$ & $00: 00.85$ & 1 & 39 & $06: 21.13$ & $06: 21.28$ & $00: 00.15$ & 0 & 40 & $06: 37.25$ \\
\hline $04: 50.15$ & $04: 51.00$ & $00: 00.85$ & 1 & 39 & $05: 01.26$ & $05: 03.15$ & $00: 01.89$ & 0 & 40 & $05: 18.14$ \\
\hline $03: 15.25$ & $03: 16.04$ & $00: 00.79$ & 1 & 39 & $03: 52.07$ & $03: 53.00$ & $00: 00.93$ & 0 & 40 & $04: 15.07$ \\
\hline $04: 30.21$ & $04: 31.01$ & $00: 00.80$ & 1 & 39 & $04: 39.18$ & $04: 40.07$ & $00: 00.89$ & 1 & 40 & $04: 52.28$ \\
\hline $03: 50.02$ & $03: 50.17$ & $00: 00.15$ & 1 & 39 & $03: 58.08$ & $03: 58.29$ & $00: 00.21$ & 0 & 40 & $04: 14.08$ \\
\hline $07: 28.04$ & $07: 28.12$ & $00: 00.08$ & 1 & 39 & $07: 41.17$ & $07: 41.26$ & $00: 00.09$ & 0 & 40 & $09: 19.15$ \\
\hline $05: 13.28$ & $05: 14.08$ & $00: 00.80$ & 1 & 39 & $05: 24.00$ & $05: 24.15$ & $00: 00.15$ & 0 & 40 & $05: 40.12$ \\
\hline $00: 25.23$ & $00: 26.12$ & $00: 00.89$ & 1 & 39 & $01: 20.05$ & $01: 21.22$ & $00: 01.17$ & 0 & 40 & $02: 19.07$ \\
\hline $04: 16.26$ & $04: 17.07$ & $00: 00.81$ & 1 & 39 & $04: 27.04$ & $04: 27.14$ & $00: 00.10$ & 0 & 40 & $04: 43.18$ \\
\hline $07: 30.28$ & $07: 31.06$ & $00: 00.78$ & 0 & 39 & $07: 41.21$ & $07: 42.25$ & $00: 01.04$ & 0 & 40 & $08: 16.25$ \\
\hline $03: 48.20$ & $03: 49.24$ & $00: 01.04$ & 1 & 39 & 04:01.07 & $04: 01.22$ & $00: 00.15$ & 0 & 40 & $04: 16.05$ \\
\hline $08: 59.18$ & $09: 00.03$ & $00: 00.85$ & 1 & 39 & $00: 00.09$ & $00: 00.21$ & $00: 00.12$ & 0 & 40 & $00: 19.25$ \\
\hline $04: 32.14$ & $04: 32.16$ & $00: 00.02$ & 1 & 39 & $04: 42.02$ & $04: 42.16$ & $00: 00.14$ & 0 & 40 & $04: 59.20$ \\
\hline $06: 37.00$ & $06: 37.20$ & $00: 00.20$ & 1 & 39 & $08: 24.24$ & $08: 25.05$ & $00: 00.81$ & 0 & 40 & $08: 54.28$ \\
\hline $06: 25.14$ & $06: 25.25$ & $00: 00.11$ & 1 & 39 & $06: 33.27$ & $06: 34.06$ & $00: 00.79$ & 0 & 40 & $07: 29.17$ \\
\hline $05: 05.21$ & $05: 07.00$ & $00: 01.79$ & 1 & 39 & $05: 19.06$ & $05: 20.03$ & $00: 00.97$ & 0 & 40 & $05: 35.19$ \\
\hline $05: 40.00$ & $05: 40.07$ & $00: 00.07$ & 1 & 39 & $05: 49.28$ & $05: 50.14$ & $00: 00.86$ & 0 & 40 & $06: 16.02$ \\
\hline $07: 56.20$ & $07: 57.27$ & $00: 01.07$ & 0 & 39 & $08: 25.15$ & $08: 26.10$ & $00: 00.95$ & 0 & 40 & $09: 05.09$ \\
\hline $04: 14.21$ & $04: 14.28$ & $00: 00.07$ & 1 & 39 & $04: 23.22$ & $04: 24.07$ & $00: 00.85$ & 1 & 40 & $04: 27.03$ \\
\hline $06: 07.24$ & $06: 08.19$ & $00: 00.95$ & 1 & 39 & $06: 22.15$ & $06: 25.08$ & $00: 02.93$ & 0 & 40 & $06: 40.00$ \\
\hline $03: 42.24$ & $03: 43.08$ & $00: 00.84$ & 1 & 39 & $03: 51.07$ & $03: 51.20$ & $00: 00.13$ & 0 & 40 & $04: 02.16$ \\
\hline $07: 09.27$ & $07: 10.14$ & $00: 00.87$ & 1 & 39 & $07: 24.06$ & $07: 24.26$ & $00: 00.20$ & 0 & 40 & $07: 41.03$ \\
\hline
\end{tabular}




\begin{tabular}{|c|c|c|c|c|c|c|c|}
\hline Reaction time & RT & Scoring & Block 1 RT & Block 1 (sec) & Block 1 Accuracy & Block 2 RT & Block 2 (sec) \\
\hline $05: 57.18$ & $00: 00.97$ & \begin{tabular}{|l|}
0 \\
\end{tabular} & $00: 01.99$ & \begin{tabular}{|r|}
1.99 \\
\end{tabular} & 0.3 & $00: 01.45$ & 1.45 \\
\hline $06: 27.14$ & $00: 00.95$ & 0 & $00: 01.49$ & 1.49 & 0.1 & $00: 01.32$ & 1.32 \\
\hline $06: 22.17$ & $00: 01.12$ & 1 & 00:01.09 & 1.09 & 0.3 & $00: 00.50$ & 0.5 \\
\hline $07: 42.14$ & $00: 00.93$ & 0 & $00: 01.31$ & 1.31 & 0.2 & $00: 01.01$ & 1.01 \\
\hline $05: 16.01$ & $00: 01.72$ & 0 & $00: 01.54$ & 1.54 & 0.3 & $00: 01.11$ & 1.11 \\
\hline $05: 22.27$ & $00: 01.16$ & 0 & $00: 02.01$ & 2.01 & 0.2 & $00: 01.79$ & 1.79 \\
\hline $07: 58.29$ & $00: 01.02$ & 0 & $00: 01.39$ & 1.39 & 0.3 & $00: 00.91$ & 0.91 \\
\hline $04: 28.09$ & $00: 01.85$ & 0 & $00: 01.97$ & 1.97 & 0.3 & $00: 01.61$ & 1.61 \\
\hline $04: 55.02$ & $00: 01.85$ & 0 & $00: 02.40$ & 2.4 & 0.3 & $00: 02.06$ & 2.06 \\
\hline $06: 38.22$ & $00: 00.97$ & 0 & $00: 01.19$ & 1.19 & 0.2 & $00: 00.90$ & 0.9 \\
\hline $05: 19.12$ & $00: 00.98$ & 0 & $00: 02.62$ & 2.62 & 0.1 & $00: 01.79$ & 1.79 \\
\hline $04: 16.18$ & $00: 01.11$ & 0 & $00: 01.07$ & 1.07 & 0.2 & $00: 00.63$ & 0.63 \\
\hline $04: 53.20$ & $00: 00.92$ & 0 & $00: 01.49$ & 1.49 & 0.2 & $00: 01.36$ & 1.36 \\
\hline $04: 15.04$ & $00: 00.96$ & 1 & $00: 01.74$ & 1.74 & 0.2 & $00: 01.29$ & 1.29 \\
\hline $09: 20.01$ & $00: 00.86$ & 0 & $00: 00.23$ & 0.23 & 0 & $00: 00.53$ & 0.53 \\
\hline $05: 42.19$ & $00: 02.07$ & 0 & $00: 02.15$ & 2.15 & 0.3 & $00: 01.45$ & 1.45 \\
\hline $02: 19.20$ & $00: 00.13$ & 1 & $00: 00.88$ & 0.88 & 0.3 & $00: 00.94$ & 0.94 \\
\hline $04: 44.00$ & $00: 00.82$ & 0 & $00: 01.00$ & 1 & 0.3 & $00: 01.16$ & 1.16 \\
\hline $08: 17.03$ & $00: 00.78$ & 0 & $00: 01.77$ & 1.77 & 0.3 & $00: 01.05$ & 1.05 \\
\hline $04: 16.14$ & $00: 00.09$ & 0 & $00: 01.69$ & 1.69 & 0.2 & $00: 02.24$ & 2.24 \\
\hline $00: 20.23$ & $00: 00.98$ & 0 & $00: 01.31$ & 1.31 & 0.2 & $00: 00.81$ & 0.81 \\
\hline $05: 00.06$ & $00: 00.86$ & 0 & $00: 01.14$ & 1.14 & 0.4 & $00: 00.69$ & 0.69 \\
\hline $08: 55.19$ & $00: 00.91$ & 0 & $00: 00.76$ & 0.76 & 0.3 & $00: 01.00$ & \\
\hline $07: 30.13$ & $00: 00.96$ & 0 & $00: 01.85$ & 1.85 & 0.2 & $00: 01.47$ & 1.47 \\
\hline $05: 37.01$ & $00: 01.82$ & 0 & $00: 01.38$ & 1.38 & 0.2 & $00: 01.20$ & 1.2 \\
\hline $06: 17.02$ & $00: 01.00$ & 0 & $00: 01.74$ & 1.74 & 0.3 & $00: 01.27$ & 1.27 \\
\hline $09: 06.06$ & $00: 00.97$ & 0 & $00: 00.90$ & 0.9 & 0.2 & $00: 01.22$ & 1.22 \\
\hline $04: 37.21$ & $00: 10.18$ & 0 & $00: 01.00$ & 1 & 0.3 & $00: 00.97$ & 0.97 \\
\hline $06: 40.29$ & $00: 00.29$ & 1 & $00: 02.16$ & 2.16 & 0.2 & $00: 01.71$ & 1.71 \\
\hline $04: 03.08$ & $00: 00.92$ & 0 & $00: 00.65$ & 0.65 & 0.3 & $00: 00.42$ & 0.42 \\
\hline $07: 41.24$ & $00: 00.21$ & 0 & $00: 01.49$ & 1.49 & 0.3 & $00: 01.51$ & 1.51 \\
\hline
\end{tabular}

\begin{tabular}{|c|c|c|c|c|c|c|}
\hline Block 2 Accuracy & Block 3 RT & Block $3(\mathrm{sec})$ & Block 3 Accuracy & Block 4 RT & Block 4 (sec) & Block 4 Accuracy \\
\hline 0.3 & $00: 01.08$ & \begin{tabular}{|r|}
1.08 \\
\end{tabular} & 0.1 & $00: 00.74$ & 0.74 & 0.2 \\
\hline 0.3 & $00: 01.11$ & 1.11 & 0.2 & $00: 01.03$ & 1.03 & 0.3 \\
\hline 0.3 & $00: 00.73$ & 0.73 & 0.2 & $00: 00.67$ & 0.67 & 0.4 \\
\hline 0.2 & $00: 00.46$ & 0.46 & 0.2 & $00: 00.80$ & 0.8 & 0.6 \\
\hline 0.5 & $00: 01.44$ & 1.44 & 0.1 & $00: 01.37$ & 1.37 & 0.3 \\
\hline 0.4 & $00: 01.70$ & 1.7 & 0 & $00: 01.43$ & 1.43 & 0.3 \\
\hline 0.3 & $00: 00.79$ & 0.79 & 0.2 & $00: 00.91$ & 0.91 & 0.3 \\
\hline 0.3 & $00: 01.04$ & 1.04 & 0.1 & $00: 00.86$ & 0.86 & 0.1 \\
\hline 0.3 & $00: 00.68$ & 0.68 & 0.2 & $00: 00.97$ & 0.97 & 0.2 \\
\hline 0.3 & $00: 00.60$ & 0.68 & 0.1 & $00: 00.76$ & 0.76 & 0.3 \\
\hline 0.5 & $00: 01.17$ & 1.17 & 0.1 & $00: 01.63$ & 1.63 & 0.4 \\
\hline 0.3 & $00: 00.89$ & 0.89 & 0.2 & $00: 00.77$ & 0.77 & 0.4 \\
\hline 0.2 & $00: 00.78$ & 0.78 & 0.1 & $00: 00.73$ & 0.73 & 0.4 \\
\hline 0.2 & $00: 00.91$ & 0.91 & 0.2 & $00: 00.81$ & 0.81 & 0.4 \\
\hline 0.2 & $00: 00.33$ & 0.33 & 0 & $00: 00.38$ & 0.38 & 0.2 \\
\hline 0.2 & $00: 00.59$ & 0.59 & 0.1 & $00: 01.26$ & 1.26 & 0.4 \\
\hline 0.4 & $00: 00.77$ & 0.77 & 0.1 & $00: 00.77$ & 0.77 & 0.5 \\
\hline 0.4 & $00: 00.26$ & 0.26 & 0.1 & $00: 00.71$ & 0.71 & 0.222222222 \\
\hline 0.2 & 00:01.13 & 1.13 & 0.3 & $00: 00.57$ & 0.57 & 0.2 \\
\hline 0.4 & $00: 00.52$ & 0.52 & 0.2 & $00: 00.52$ & 0.52 & 0.3 \\
\hline 0.4 & $00: 01.06$ & 1.06 & 0.2 & $00: 00.98$ & 0.98 & 0.2 \\
\hline 0.2 & $00: 00.56$ & 0.56 & 0.2 & $00: 00.51$ & 0.51 & 0.2 \\
\hline 0.3 & $00: 00.60$ & 0.6 & 0.2 & $00: 00.76$ & 0.76 & 0.4 \\
\hline 0.2 & $00: 00.97$ & 0.97 & 0.1 & $00: 00.63$ & 0.63 & 0.2 \\
\hline 0.2 & $00: 01.52$ & 1.52 & 0.3 & $00: 01.55$ & 1.55 & 0.2 \\
\hline 0.4 & 00:00.59 & 0.59 & 0.1 & $00: 00.63$ & 0.63 & 0.2 \\
\hline 0.3 & $00: 00.91$ & 0.91 & 0.1 & $00: 00.91$ & 0.91 & 0.2 \\
\hline 0.3 & $00: 00.73$ & 0.73 & 0.2 & $00: 01.42$ & 1.42 & 0.4 \\
\hline 0.3 & $00: 01.20$ & 1.2 & 0.1 & $00: 01.34$ & 1.34 & 0.5 \\
\hline 0.4 & $00: 00.76$ & 0.76 & 0.1 & $00: 00.42$ & 0.42 & 0.2 \\
\hline 0.3 & $00: 01.50$ & 1.5 & 0.1 & $00: 01.02$ & 1.02 & 0.2 \\
\hline
\end{tabular}




\section{APPENDIX C}

TLX DATA

\begin{tabular}{|l|l|l|}
\hline Scale & Value & Weight \\
\hline Subject 4 & & \\
\hline SWAN single task & & \\
\hline Mental Demand & 15 & 0.2 \\
\hline Physical Demand & 15 & 0 \\
\hline Temporal Demand & 15 & 0.2 \\
\hline Performance & 10 & 0.266667 \\
\hline Effort & 15 & 0.0666667 \\
\hline Frustration & 20 & 0.266667 \\
\hline Total Workload & 15 & \\
\hline & & \\
\hline $\begin{array}{l}\text { Speech } \\
\text { discrimination } \\
\text { single task }\end{array}$ & & \\
\hline Mental Demand & 85 & \\
\hline Physical Demand & 5 & 0.333333 \\
\hline Temporal Demand & 70 & 0 \\
\hline Performance & 55 & 0.0666667 \\
\hline Effort & 80 & 0.133333 \\
\hline Frustration & 70 & 0.2 \\
\hline Total Workload & 75 & 0.266667 \\
\hline & & \\
\hline Dual task & & \\
\hline Mental Demand & 90 & 0.333333 \\
\hline Physical Demand & 75 & 0 \\
\hline Temporal Demand & 80 & 0.133333 \\
\hline Performance & 70 & 0.0666667 \\
\hline Effort & 80 & 0.2 \\
\hline Frustration & 80 & 0.266667 \\
\hline Total Workload & 82.6667 & \\
\hline & & \\
\hline Subject 5 & & 0.266667 \\
\hline SWAN single task & & 0.2 \\
\hline Mental Demand & 75 & 0.3333333 \\
\hline Physical Demand & 25 & \\
\hline Temporal Demand & 75 & \\
\hline Performance & 20 & \\
\hline Effort & 25 & \\
\hline Frustration & 35 & \\
\hline & & \\
\hline
\end{tabular}




\begin{tabular}{|l|l|l|}
\hline Total Workload & 48.3333 & \\
\hline & & \\
\hline $\begin{array}{l}\text { Speech } \\
\text { discrimination } \\
\text { single task }\end{array}$ & & \\
\hline Mental Demand & 85 & 0.2 \\
\hline Physical Demand & 35 & 0 \\
\hline Temporal Demand & 80 & 0.266667 \\
\hline Performance & 85 & 0.133333 \\
\hline Effort & 90 & 0.0666667 \\
\hline Frustration & 90 & 0.333333 \\
\hline Total Workload & 85.6667 & \\
\hline & & \\
\hline Dual task & & 0.333333 \\
\hline Mental Demand & 80 & 0.133333 \\
\hline Physical Demand & 80 & 0.133333 \\
\hline Temporal Demand & 75 & 0.2 \\
\hline Performance & 90 & 0.0666667 \\
\hline Effort & 100 & 0.133333 \\
\hline Frustration & 85 & \\
\hline Total Workload & 83.3333 & \\
\hline & & 0.333333 \\
\hline Subject 6 & & \\
\hline SWAN single task & & 0.2 \\
\hline Mental Demand & 25 & 0.133333 \\
\hline Physical Demand & 15 & 0.333333 \\
\hline Temporal Demand & 15 & 0.233333 \\
\hline Performance & 30 & 0.266667 \\
\hline Effort & 35 & \\
\hline Frustration & 10 & \\
\hline Total Workload & 25.3333 & \\
\hline & & \\
\hline $\begin{array}{l}\text { Speech } \\
\text { discrimination } \\
\text { single task }\end{array}$ & & \\
\hline Mental Demand & 25 & \\
\hline Physical Demand & 20 & \\
\hline Temporal Demand & 20 & \\
\hline Performance & 40 & 40666667 \\
\hline Effort & 50 & \\
\hline Frustration & 37.3333 & \\
\hline Total Workload & & \\
\hline Dual task & & \\
\hline Mental Demand & 35 & \\
\hline & & \\
\hline & & \\
\hline
\end{tabular}




\begin{tabular}{|l|l|l|}
\hline Physical Demand & 20 & 0 \\
\hline Temporal Demand & 25 & 0.0666667 \\
\hline Performance & 30 & 0.266667 \\
\hline Effort & 30 & 0.133333 \\
\hline Frustration & 30 & 0.2 \\
\hline Total Workload & 31.3333 & \\
\hline & & \\
\hline Subject 7 & & \\
\hline SWAN single task & & 0.333333 \\
\hline Mental Demand & 30 & 0 \\
\hline Physical Demand & 15 & 0.133333 \\
\hline Temporal Demand & 25 & 0.2 \\
\hline Performance & 5 & 0.266667 \\
\hline Effort & 20 & 0.0666667 \\
\hline Frustration & 20 & \\
\hline Total Workload & 21 & \\
\hline & & \\
\hline $\begin{array}{l}\text { Speech } \\
\text { discrimination } \\
\text { single task }\end{array}$ & & \\
\hline Mental Demand & 60 & 0.266667 \\
\hline Physical Demand & 10 & 0 \\
\hline Temporal Demand & 20 & 0.0666667 \\
\hline Performance & 65 & 0.133333 \\
\hline Effort & 70 & 0.333333 \\
\hline Frustration & 75 & 0.2 \\
\hline Total Workload & 64.3333 & \\
\hline & & 0.333333 \\
\hline Dual task & & \\
\hline Mental Demand & 75 & 0.333333 \\
\hline Physical Demand & 15 & 0.2 \\
\hline Temporal Demand & 30 & 0.2666667 \\
\hline Performance & 45 & \\
\hline Effort & 70 & \\
\hline Frustration & 55 & \\
\hline Total Workload & 61 & \\
\hline & & 0.266667 \\
\hline Subject 9 & & \\
\hline SWAN single task & & \\
\hline Mental Demand & 40 & \\
\hline Physical Demand & 15 & \\
\hline Temporal Demand & 40 & \\
\hline Performance & 65 & \\
\hline Effort & & \\
\hline Frustration & & \\
\hline & & \\
\hline
\end{tabular}




\begin{tabular}{|c|c|c|}
\hline Total Workload & 44.6667 & \\
\hline \multicolumn{3}{|l|}{$\begin{array}{l}\text { Speech } \\
\text { discrimination } \\
\text { single task }\end{array}$} \\
\hline Mental Demand & 85 & 0.333333 \\
\hline Physical Demand & 10 & 0 \\
\hline Temporal Demand & 10 & 0.0666667 \\
\hline Performance & 25 & 0.2 \\
\hline Effort & 80 & 0.133333 \\
\hline Frustration & 70 & 0.266667 \\
\hline Total Workload & 63.3333 & \\
\hline \multicolumn{3}{|l|}{ Dual task } \\
\hline Mental Demand & 95 & 0.333333 \\
\hline Physical Demand & 25 & 0 \\
\hline Temporal Demand & 50 & 0.0666667 \\
\hline Performance & 75 & 0.133333 \\
\hline Effort & 80 & 0.2 \\
\hline Frustration & 90 & 0.266667 \\
\hline Total Workload & 85 & \\
\hline \multicolumn{3}{|l|}{ Subject 10} \\
\hline \multicolumn{3}{|l|}{ SWAN single task } \\
\hline Mental Demand & 5 & 0.0666667 \\
\hline Physical Demand & 10 & 0 \\
\hline Temporal Demand & 25 & 0.333333 \\
\hline Performance & 40 & 0.266667 \\
\hline Effort & 30 & 0.133333 \\
\hline Frustration & 45 & 0.2 \\
\hline Total Workload & 32.3333 & \\
\hline \multicolumn{3}{|l|}{$\begin{array}{l}\text { Speech } \\
\text { discrimination } \\
\text { single task }\end{array}$} \\
\hline Mental Demand & 20 & 0.133333 \\
\hline Physical Demand & 5 & 0 \\
\hline Temporal Demand & 20 & 0.2 \\
\hline Performance & 50 & 0.333333 \\
\hline Effort & 25 & 0.266667 \\
\hline Frustration & 10 & 0.0666667 \\
\hline Total Workload & 30.6667 & \\
\hline \multicolumn{3}{|l|}{ Dual task } \\
\hline Mental Demand & 30 & 0.0666667 \\
\hline
\end{tabular}




\begin{tabular}{|c|c|c|}
\hline Physical Demand & 5 & 0 \\
\hline Temporal Demand & 50 & 0.2 \\
\hline Performance & 35 & 0.266667 \\
\hline Effort & 55 & 0.133333 \\
\hline Frustration & 70 & 0.333333 \\
\hline Total Workload & 52 & \\
\hline \multicolumn{3}{|l|}{ Subject 11} \\
\hline \multicolumn{3}{|l|}{ SWAN single task } \\
\hline Mental Demand & 85 & 0.266667 \\
\hline Physical Demand & 55 & 0.133333 \\
\hline Temporal Demand & 55 & 0.266667 \\
\hline Performance & 25 & 0.0666667 \\
\hline Effort & 35 & 0.266667 \\
\hline Frustration & 10 & 0 \\
\hline Total Workload & 55.6667 & \\
\hline \multicolumn{3}{|l|}{$\begin{array}{l}\text { Speech } \\
\text { discrimination } \\
\text { single task }\end{array}$} \\
\hline Mental Demand & 90 & 0.333333 \\
\hline Physical Demand & 65 & 0.0666667 \\
\hline Temporal Demand & 85 & 0.266667 \\
\hline Performance & 70 & 0 \\
\hline Effort & 100 & 0.2 \\
\hline Frustration & 55 & 0.133333 \\
\hline Total Workload & 84.3333 & \\
\hline \multicolumn{3}{|l|}{ Dual task } \\
\hline Mental Demand & 100 & 0.333333 \\
\hline Physical Demand & 80 & 0.2 \\
\hline Temporal Demand & 100 & 0.266667 \\
\hline Performance & 65 & 0 \\
\hline Effort & 100 & 0.133333 \\
\hline Frustration & 60 & 0.0666667 \\
\hline Total Workload & 93.3333 & \\
\hline \multicolumn{3}{|l|}{ Subject 12} \\
\hline \multicolumn{3}{|l|}{ SWAN single task } \\
\hline Mental Demand & 65 & 0.2 \\
\hline Physical Demand & 5 & 0.0666667 \\
\hline Temporal Demand & 70 & 0.133333 \\
\hline Performance & 15 & 0.333333 \\
\hline Effort & 80 & 0.266667 \\
\hline Frustration & 15 & 0 \\
\hline
\end{tabular}




\begin{tabular}{|l|l|l|}
\hline Total Workload & 49 & \\
\hline & & \\
\hline $\begin{array}{l}\text { Speech } \\
\text { discrimination } \\
\text { single task }\end{array}$ & & \\
\hline Mental Demand & 95 & 0.266667 \\
\hline Physical Demand & 5 & 0 \\
\hline Temporal Demand & 100 & 0.266667 \\
\hline Performance & 70 & 0.0666667 \\
\hline Effort & 95 & 0.133333 \\
\hline Frustration & 70 & 0.266667 \\
\hline Total Workload & 88 & \\
\hline & & \\
\hline Dual task & & \\
\hline Mental Demand & 95 & 0.3333333 \\
\hline Physical Demand & 35 & 0 \\
\hline Temporal Demand & 90 & 0.1333333 \\
\hline Performance & 40 & 0.2 \\
\hline Effort & 85 & 0.2 \\
\hline Frustration & 80 & 0.133333 \\
\hline Total Workload & 79.3333 & \\
\hline & & \\
\hline Subject 13 & & \\
\hline SWAN single task & & 0.266667 \\
\hline Mental Demand & 60 & \\
\hline Physical Demand & 50 & 0.133333 \\
\hline Temporal Demand & 55 & 0.2 \\
\hline Performance & 40 & 0.2 \\
\hline Effort & 60 & 0.133333 \\
\hline Frustration & 65 & 0.266667 \\
\hline Total Workload & 55.6667 & \\
\hline & & 0.2666733 \\
\hline $\begin{array}{l}\text { Speech } \\
\text { discrimination } \\
\text { single task }\end{array}$ & & \\
\hline Mental Demand & 85 & \\
\hline Physical Demand & 30 & \\
\hline Temporal Demand & 10 & \\
\hline Performance & 70 & 75 \\
\hline Effort & 75 & \\
\hline Frustration & 74.6667 & \\
\hline Total Workload & & \\
\hline Dual task & & \\
\hline Mental Demand & 85 & \\
\hline & & \\
\hline & & \\
\hline
\end{tabular}




\begin{tabular}{|c|c|c|}
\hline Physical Demand & 50 & 0 \\
\hline Temporal Demand & 45 & 0.0666667 \\
\hline Performance & 65 & 0.133333 \\
\hline Effort & 80 & 0.333333 \\
\hline Frustration & 70 & 0.2 \\
\hline Total Workload & 75 & \\
\hline \multicolumn{3}{|l|}{ Subject 14} \\
\hline \multicolumn{3}{|l|}{ SWAN single task } \\
\hline Mental Demand & 30 & 0.266667 \\
\hline Physical Demand & 15 & 0 \\
\hline Temporal Demand & 20 & 0.133333 \\
\hline Performance & 20 & 0.333333 \\
\hline Effort & 45 & 0.2 \\
\hline Frustration & 10 & 0.0666667 \\
\hline Total Workload & 27 & \\
\hline \multicolumn{3}{|l|}{$\begin{array}{l}\text { Speech } \\
\text { discrimination } \\
\text { single task }\end{array}$} \\
\hline Mental Demand & 85 & 0.266667 \\
\hline Physical Demand & 5 & 0 \\
\hline Temporal Demand & 75 & 0.2 \\
\hline Performance & 85 & 0.266667 \\
\hline Effort & 85 & 0.0666667 \\
\hline Frustration & 75 & 0.2 \\
\hline Total Workload & 81 & \\
\hline \multicolumn{3}{|l|}{ Dual task } \\
\hline Mental Demand & 90 & 0.2 \\
\hline Physical Demand & 10 & 0.0666667 \\
\hline Temporal Demand & 60 & 0.333333 \\
\hline Performance & 65 & 0.266667 \\
\hline Effort & 85 & 0.0666667 \\
\hline Frustration & 55 & 0.0666667 \\
\hline Total Workload & 65.3333 & \\
\hline \multicolumn{3}{|l|}{ Subject 15} \\
\hline \multicolumn{3}{|l|}{ SWAN single task } \\
\hline Mental Demand & 20 & 0.0666667 \\
\hline Physical Demand & 15 & 0 \\
\hline Temporal Demand & 50 & 0.266667 \\
\hline Performance & 50 & 0.333333 \\
\hline Effort & 65 & 0.133333 \\
\hline Frustration & 55 & 0.2 \\
\hline
\end{tabular}




\begin{tabular}{|l|l|l|}
\hline Total Workload & 51 & \\
\hline & & \\
\hline $\begin{array}{l}\text { Speech } \\
\text { discrimination } \\
\text { single task }\end{array}$ & & \\
\hline Mental Demand & 50 & 0.2 \\
\hline Physical Demand & 5 & 0 \\
\hline Temporal Demand & 5 & 0.0666667 \\
\hline Performance & 5 & 0.333333 \\
\hline Effort & 50 & 0.266667 \\
\hline Frustration & 55 & 0.133333 \\
\hline Total Workload & 32.6667 & \\
\hline & & \\
\hline Dual task & & \\
\hline Mental Demand & 60 & 0.2 \\
\hline Physical Demand & 45 & 0.0666667 \\
\hline Temporal Demand & 70 & 0.0666667 \\
\hline Performance & 5 & 0.333333 \\
\hline Effort & 50 & 0.266667 \\
\hline Frustration & 35 & 0.0666667 \\
\hline Total Workload & 37 & \\
\hline & & \\
\hline Subject 16 & & 0.333333 \\
\hline SWAN single task & & \\
\hline Mental Demand & 50 & 0.266667 \\
\hline Physical Demand & 40 & 0.266667 \\
\hline Temporal Demand & 35 & 0.133333 \\
\hline Performance & 20 & 0.266667 \\
\hline Effort & 15 & 0.0666667 \\
\hline Frustration & 5 & \\
\hline Total Workload & 29.6667 & 0.333333 \\
\hline & & \\
\hline $\begin{array}{l}\text { Speech } \\
\text { discrimination } \\
\text { single task }\end{array}$ & & \\
\hline Mental Demand & 10 & \\
\hline Physical Demand & 10 & \\
\hline Temporal Demand & 10 & \\
\hline Performance & 25 & \\
\hline Effort & 30 & \\
\hline Frustration & 15 & \\
\hline Total Workload & 16 & \\
\hline & & \\
\hline Dual task & & \\
\hline Mental Demand & 10 & \\
\hline & & \\
\hline & & \\
\hline
\end{tabular}




\begin{tabular}{|l|l|l|}
\hline Physical Demand & 10 & 0.133333 \\
\hline Temporal Demand & 10 & 0.133333 \\
\hline Performance & 25 & 0.2 \\
\hline Effort & 15 & 0.133333 \\
\hline Frustration & 10 & 0.0666667 \\
\hline Total Workload & 13.6667 & \\
\hline & & \\
\hline Subject 17 & & \\
\hline SWAN single task & & 0.2 \\
\hline Mental Demand & 15 & 0.0666667 \\
\hline Physical Demand & 15 & 0.333333 \\
\hline Temporal Demand & 30 & 0.133333 \\
\hline Performance & 15 & 0.266667 \\
\hline Effort & 20 & 0 \\
\hline Frustration & 10 & \\
\hline Total Workload & 21.3333 & \\
\hline & & \\
\hline $\begin{array}{l}\text { Speech } \\
\text { discrimination } \\
\text { single task }\end{array}$ & & \\
\hline Mental Demand & 65 & 0.333333 \\
\hline Physical Demand & 10 & 0 \\
\hline Temporal Demand & 50 & 0.266667 \\
\hline Performance & 50 & 0.133333 \\
\hline Effort & 40 & 0.0666667 \\
\hline Frustration & 50 & 0.2 \\
\hline Total Workload & 54.3333 & \\
\hline & & 0.3333333 \\
\hline Dual task & & 0.263333 \\
\hline Mental Demand & 70 & \\
\hline Physical Demand & 25 & 0.2666667 \\
\hline Temporal Demand & 65 & \\
\hline Performance & 55 & \\
\hline Effort & 45 & \\
\hline Frustration & 45 & \\
\hline Total Workload & 60.6667 & \\
\hline & & \\
\hline Subject 18 & & \\
\hline SWAN single task & & \\
\hline Mental Demand & 45 & \\
\hline Physical Demand & 15 & \\
\hline Temporal Demand & 35 & \\
\hline Performance & 70 & \\
\hline Effort & 20 & \\
\hline Frustration & & \\
\hline & & \\
\hline
\end{tabular}




\begin{tabular}{|l|l|l|}
\hline Total Workload & 57 & \\
\hline & & \\
\hline $\begin{array}{l}\text { Speech } \\
\text { discrimination } \\
\text { single task }\end{array}$ & & \\
\hline Mental Demand & 90 & 0.333333 \\
\hline Physical Demand & 5 & 0 \\
\hline Temporal Demand & 75 & 0.133333 \\
\hline Performance & 75 & 0.2 \\
\hline Effort & 80 & 0.266667 \\
\hline Frustration & 65 & 0.0666667 \\
\hline Total Workload & 80.6667 & \\
\hline & & \\
\hline Dual task & & 0.333333 \\
\hline Mental Demand & 95 & 0 \\
\hline Physical Demand & 30 & 0.133333 \\
\hline Temporal Demand & 70 & 0.2 \\
\hline Performance & 50 & 0.266667 \\
\hline Effort & 95 & 0.0666667 \\
\hline Frustration & 60 & \\
\hline Total Workload & 80.3333 & \\
\hline & & 0.333333 \\
\hline Subject 20 & & \\
\hline SWAN single task & & 0.333333 \\
\hline Mental Demand & 25 & 0.133333 \\
\hline Physical Demand & 10 & 0.2 \\
\hline Temporal Demand & 15 & 0.0666667 \\
\hline Performance & 20 & 0.266667 \\
\hline Effort & 25 & \\
\hline Frustration & 25 & 0.133333 \\
\hline Total Workload & 22.6667 & \\
\hline & & \\
\hline $\begin{array}{l}\text { Speech } \\
\text { discrimination } \\
\text { single task }\end{array}$ & & \\
\hline Mental Demand & 55 & \\
\hline Physical Demand & 20 & \\
\hline Temporal Demand & 15 & \\
\hline Performance & 35 & 5366667 \\
\hline Effort & 25 & \\
\hline Frustration & & \\
\hline Total Workload & 43.3333 & \\
\hline Dual task & & \\
\hline Mental Demand & 50 & \\
\hline & & \\
\hline & & \\
\hline
\end{tabular}




\begin{tabular}{|l|l|l|}
\hline Physical Demand & 20 & 0 \\
\hline Temporal Demand & 20 & 0.266667 \\
\hline Performance & 45 & 0.133333 \\
\hline Effort & 55 & 0.2 \\
\hline Frustration & 50 & 0.0666667 \\
\hline Total Workload & 42.3333 & \\
\hline & & \\
\hline Subject 21 & & \\
\hline SWAN single task & & 0.266667 \\
\hline Mental Demand & 70 & 0.0666667 \\
\hline Physical Demand & 60 & 0.2 \\
\hline Temporal Demand & 65 & 0.133333 \\
\hline Performance & 70 & 0.333333 \\
\hline Effort & 65 & 0 \\
\hline Frustration & 25 & \\
\hline Total Workload & 66.6667 & \\
\hline & & \\
\hline $\begin{array}{l}\text { Speech } \\
\text { discrimination } \\
\text { single task }\end{array}$ & & \\
\hline Mental Demand & 95 & 0.333333 \\
\hline Physical Demand & 15 & 0 \\
\hline Temporal Demand & 80 & 0.2 \\
\hline Performance & 80 & 0.0666667 \\
\hline Effort & 95 & 0.2 \\
\hline Frustration & 95 & 0.2 \\
\hline Total Workload & 91 & \\
\hline & & 0.133333 \\
\hline Dual task & & \\
\hline Mental Demand & 95 & 0.13333333 \\
\hline Physical Demand & 95 & \\
\hline Temporal Demand & 95 & 906667 \\
\hline Performance & 90 & \\
\hline Effort & 95 & \\
\hline Frustration & 100 & \\
\hline Total Workload & 96.6667 & \\
\hline & & \\
\hline Subject 22 & & \\
\hline SWAN single task & & \\
\hline Mental Demand & 75 & \\
\hline Physical Demand & 25 & \\
\hline Temporal Demand & 75 & \\
\hline Performance & 70 & \\
\hline Effort & 70 & \\
\hline Frustration & & \\
\hline & & \\
\hline
\end{tabular}




\begin{tabular}{|l|l|l|}
\hline Total Workload & 72 & \\
\hline & & \\
\hline $\begin{array}{l}\text { Speech } \\
\text { discrimination } \\
\text { single task }\end{array}$ & & \\
\hline Mental Demand & 90 & 0.266667 \\
\hline Physical Demand & 10 & 0 \\
\hline Temporal Demand & 75 & 0.266667 \\
\hline Performance & 75 & 0.0666667 \\
\hline Effort & 70 & 0.2 \\
\hline Frustration & 75 & 0.2 \\
\hline Total Workload & 78 & \\
\hline & & \\
\hline Dual task & & 0.333333 \\
\hline Mental Demand & 90 & 0.0666667 \\
\hline Physical Demand & 15 & 0.2 \\
\hline Temporal Demand & 90 & 0.266667 \\
\hline Performance & 75 & 0.133333 \\
\hline Effort & 80 & 0 \\
\hline Frustration & 70 & \\
\hline Total Workload & 79.6667 & \\
\hline & & 0.266667 \\
\hline Subject 23 & & \\
\hline SWAN single task & & 0.266667 \\
\hline Mental Demand & 50 & 0.0666667 \\
\hline Physical Demand & 35 & 0.2 \\
\hline Temporal Demand & 40 & 0.133333 \\
\hline Performance & 20 & 0 \\
\hline Effort & 35 & 0.333333 \\
\hline Frustration & 25 & \\
\hline Total Workload & 38 & \\
\hline & & 0.266667 \\
\hline $\begin{array}{l}\text { Speech } \\
\text { discrimination } \\
\text { single task }\end{array}$ & & \\
\hline Mental Demand & 95 & \\
\hline Physical Demand & 15 & \\
\hline Temporal Demand & 50 & \\
\hline Performance & 60 & \\
\hline Effort & 100 & \\
\hline Frustration & 95 & \\
\hline Total Workload & 77.3333 & \\
\hline Dual task & & \\
\hline Mental Demand & 100 & \\
\hline & & \\
\hline & & \\
\hline
\end{tabular}




\begin{tabular}{|l|l|l|}
\hline Physical Demand & 100 & 0.2 \\
\hline Temporal Demand & 90 & 0.133333 \\
\hline Performance & 45 & 0.0666667 \\
\hline Effort & 100 & 0.333333 \\
\hline Frustration & 100 & 0 \\
\hline Total Workload & 95 & \\
\hline & & \\
\hline Subject 24 & & \\
\hline SWAN single task & & 0.133333 \\
\hline Mental Demand & 15 & 0.0666667 \\
\hline Physical Demand & 25 & 0.266667 \\
\hline Temporal Demand & 50 & 0.133333 \\
\hline Performance & 30 & 0.0666667 \\
\hline Effort & 15 & 0.333333 \\
\hline Frustration & 15 & \\
\hline Total Workload & 27 & \\
\hline & & \\
\hline $\begin{array}{l}\text { Speech } \\
\text { discrimination } \\
\text { single task }\end{array}$ & & \\
\hline Mental Demand & 85 & 0.333333 \\
\hline Physical Demand & 30 & 0 \\
\hline Temporal Demand & 15 & 0.0666667 \\
\hline Performance & 55 & 0.133333 \\
\hline Effort & 75 & 0.2 \\
\hline Frustration & 75 & 0.266667 \\
\hline Total Workload & 71.6667 & \\
\hline & & 0.333333 \\
\hline Dual task & & \\
\hline Mental Demand & 80 & 0.266667 \\
\hline Physical Demand & 25 & 0.3333333 \\
\hline Temporal Demand & 60 & \\
\hline Performance & 45 & \\
\hline Effort & 60 & \\
\hline Frustration & 55 & 0.2 \\
\hline Total Workload & 63.3333 & \\
\hline & & \\
\hline Subject 25 & & \\
\hline SWAN single task & & \\
\hline Mental Demand & 50 & \\
\hline Physical Demand & 10 & \\
\hline Temporal Demand & 75 & \\
\hline Performance & 60 & \\
\hline Effort & 35 & \\
\hline Frustration & & \\
\hline & & \\
\hline
\end{tabular}




\begin{tabular}{|c|c|c|}
\hline Total Workload & 58 & \\
\hline \multicolumn{3}{|l|}{$\begin{array}{l}\text { Speech } \\
\text { discrimination } \\
\text { single task }\end{array}$} \\
\hline Mental Demand & 85 & 0.266667 \\
\hline Physical Demand & 10 & 0 \\
\hline Temporal Demand & 90 & 0.333333 \\
\hline Performance & 95 & 0.0666667 \\
\hline Effort & 65 & 0.133333 \\
\hline Frustration & 85 & 0.2 \\
\hline Total Workload & 84.6667 & \\
\hline \multicolumn{3}{|l|}{ Dual task } \\
\hline Mental Demand & 90 & 0.333333 \\
\hline Physical Demand & 15 & 0 \\
\hline Temporal Demand & 90 & 0.266667 \\
\hline Performance & 100 & 0.133333 \\
\hline Effort & 85 & 0.0666667 \\
\hline Frustration & 95 & 0.2 \\
\hline Total Workload & 92 & \\
\hline \multicolumn{3}{|l|}{ Subject 26} \\
\hline \multicolumn{3}{|l|}{ SWAN single task } \\
\hline Mental Demand & 30 & 0.133333 \\
\hline Physical Demand & 10 & 0 \\
\hline Temporal Demand & 45 & 0.333333 \\
\hline Performance & 20 & 0.2 \\
\hline Effort & 20 & 0.266667 \\
\hline Frustration & 20 & 0.0666667 \\
\hline Total Workload & 29.6667 & \\
\hline \multicolumn{3}{|l|}{$\begin{array}{l}\text { Speech } \\
\text { discrimination } \\
\text { single task }\end{array}$} \\
\hline Mental Demand & 85 & 0.2 \\
\hline Physical Demand & 5 & 0 \\
\hline Temporal Demand & 20 & 0.0666667 \\
\hline Performance & 90 & 0.266667 \\
\hline Effort & 75 & 0.133333 \\
\hline Frustration & 75 & 0.333333 \\
\hline Total Workload & 77.3333 & \\
\hline \multicolumn{3}{|l|}{ Dual task } \\
\hline Mental Demand & 90 & 0.333333 \\
\hline
\end{tabular}




\begin{tabular}{|l|l|l|}
\hline Physical Demand & 20 & 0 \\
\hline Temporal Demand & 35 & 0.133333 \\
\hline Performance & 75 & 0.2 \\
\hline Effort & 85 & 0.266667 \\
\hline Frustration & 60 & 0.0666667 \\
\hline Total Workload & 76.3333 & \\
\hline & & \\
\hline Subject 27 & & \\
\hline SWAN single task & & 0.333333 \\
\hline Mental Demand & 60 & 0.0666667 \\
\hline Physical Demand & 35 & 0.2 \\
\hline Temporal Demand & 55 & 0.266667 \\
\hline Performance & 35 & 0.133333 \\
\hline Effort & 45 & 0 \\
\hline Frustration & 25 & \\
\hline Total Workload & 48.6667 & \\
\hline & & \\
\hline $\begin{array}{l}\text { Speech } \\
\text { discrimination } \\
\text { single task }\end{array}$ & & \\
\hline Mental Demand & 80 & 0.333333 \\
\hline Physical Demand & 65 & 0.0666667 \\
\hline Temporal Demand & 80 & 0.266667 \\
\hline Performance & 35 & 0 \\
\hline Effort & 70 & 0.133333 \\
\hline Frustration & 65 & 0.2 \\
\hline Total Workload & 74.6667 & \\
\hline & & 0.0666667 \\
\hline Dual task & & \\
\hline Mental Demand & 85 & 0.3333333 \\
\hline Physical Demand & 70 & 0.266667 \\
\hline Temporal Demand & 80 & \\
\hline Performance & 40 & \\
\hline Effort & 80 & \\
\hline Frustration & 85 & \\
\hline Total Workload & 78.6667 & \\
\hline & & \\
\hline Subject 28 & & \\
\hline SWAN single task & & \\
\hline Mental Demand & 90 & \\
\hline Physical Demand & 10 & \\
\hline Temporal Demand & 10 & \\
\hline Performance & 20 & \\
\hline Effort & 30 & \\
\hline Frustration & & \\
\hline & & \\
\hline
\end{tabular}




\begin{tabular}{|l|l|l|}
\hline Total Workload & 53 & \\
\hline & & \\
\hline $\begin{array}{l}\text { Speech } \\
\text { discrimination } \\
\text { single task }\end{array}$ & & \\
\hline Mental Demand & 95 & 0.266667 \\
\hline Physical Demand & 5 & 0 \\
\hline Temporal Demand & 90 & 0.133333 \\
\hline Performance & 40 & 0.333333 \\
\hline Effort & 95 & 0.2 \\
\hline Frustration & 60 & 0.0666667 \\
\hline Total Workload & 73.6667 & \\
\hline & & \\
\hline Dual task & & \\
\hline Mental Demand & 100 & 0.333333 \\
\hline Physical Demand & 5 & 0 \\
\hline Temporal Demand & 95 & 0.133333 \\
\hline Performance & 50 & 0.2 \\
\hline Effort & 90 & 0.266667 \\
\hline Frustration & 55 & 0.0666667 \\
\hline Total Workload & 83.6667 & \\
\hline & & \\
\hline Subject 29 & & 0.333333 \\
\hline SWAN single task & & \\
\hline Mental Demand & 15 & 0.133333 \\
\hline Physical Demand & 25 & 0.266667 \\
\hline Temporal Demand & 5 & 0.0666667 \\
\hline Performance & 15 & 0.333333 \\
\hline Effort & 25 & 0.2 \\
\hline Frustration & 5 & 0.133333 \\
\hline Total Workload & 19 & \\
\hline & & \\
\hline $\begin{array}{l}\text { Speech } \\
\text { discrimination } \\
\text { single task }\end{array}$ & & \\
\hline Mental Demand & 75 & 0.0666667 \\
\hline Physical Demand & 15 & \\
\hline Temporal Demand & 30 & \\
\hline Performance & 75 & 866667 \\
\hline Effort & 80 & \\
\hline Frustration & 70 & \\
\hline Total Workload & & \\
\hline Dual task & & \\
\hline Mental Demand & 100 & \\
\hline & & \\
\hline & & \\
\hline
\end{tabular}




\begin{tabular}{|l|l|l|}
\hline Physical Demand & 25 & 0 \\
\hline Temporal Demand & 25 & 0.2 \\
\hline Performance & 75 & 0.133333 \\
\hline Effort & 90 & 0.266667 \\
\hline Frustration & 60 & 0.0666667 \\
\hline Total Workload & 76.3333 & \\
\hline & & \\
\hline Subject 30 & & \\
\hline SWAN single task & & 0.266667 \\
\hline Mental Demand & 30 & 0.0666667 \\
\hline Physical Demand & 10 & 0.133333 \\
\hline Temporal Demand & 15 & 0.2 \\
\hline Performance & 15 & 0.333333 \\
\hline Effort & 25 & 0 \\
\hline Frustration & 5 & \\
\hline Total Workload & 22 & \\
\hline & & \\
\hline $\begin{array}{l}\text { Speech } \\
\text { discrimination } \\
\text { single task }\end{array}$ & & \\
\hline Mental Demand & 45 & 0.333333 \\
\hline Physical Demand & 5 & 0 \\
\hline Temporal Demand & 15 & 0.0666667 \\
\hline Performance & 80 & 0.133333 \\
\hline Effort & 65 & 0.266667 \\
\hline Frustration & 35 & 0.2 \\
\hline Total Workload & 51 & \\
\hline & & 0.266667 \\
\hline Dual task & & \\
\hline Mental Demand & 45 & 0.2 \\
\hline Physical Demand & 10 & 0.23333 \\
\hline Temporal Demand & 50 & \\
\hline Performance & 50 & \\
\hline Effort & 45 & \\
\hline Frustration & 15 & 0.3333333 \\
\hline Total Workload & 45.6667 & \\
\hline & & \\
\hline Subject 31 & & \\
\hline SWAN single task & & \\
\hline Mental Demand & 55 & \\
\hline Physical Demand & 20 & \\
\hline Temporal Demand & 20 & \\
\hline Performance & 20 & \\
\hline Effort & & \\
\hline Frustration & & \\
\hline & & \\
\hline & & \\
\hline
\end{tabular}




\begin{tabular}{|l|l|l|}
\hline Total Workload & 40.3333 & \\
\hline & & \\
\hline $\begin{array}{l}\text { Speech } \\
\text { discrimination } \\
\text { single task }\end{array}$ & & \\
\hline Mental Demand & 60 & 0.2 \\
\hline Physical Demand & 5 & 0 \\
\hline Temporal Demand & 100 & 0.333333 \\
\hline Performance & 60 & 0.0666667 \\
\hline Effort & 85 & 0.2 \\
\hline Frustration & 65 & 0.2 \\
\hline Total Workload & 79.3333 & \\
\hline & & \\
\hline Dual task & & \\
\hline Mental Demand & 90 & 0.266667 \\
\hline Physical Demand & 25 & 0 \\
\hline Temporal Demand & 90 & 0.3333333 \\
\hline Performance & 70 & 0.0666667 \\
\hline Effort & 85 & 0.2 \\
\hline Frustration & 65 & 0.133333 \\
\hline Total Workload & 84.3333 & \\
\hline & & \\
\hline Subject 32 & & 0.333333 \\
\hline Mental Demand & 30 & 0.333333 \\
\hline Physical Demand & 15 & 0.0666667 \\
\hline Temporal Demand & 45 & 0.2 \\
\hline Performance & 25 & 0 \\
\hline Effort & 40 & 0.266667 \\
\hline Frustration & 15 & 0.133333 \\
\hline Total Workload & 32.6667 & \\
\hline & & 0.333333 \\
\hline $\begin{array}{l}\text { Speech } \\
\text { discrimination } \\
\text { single task }\end{array}$ & & 0.2 \\
\hline Mental Demand & 80 & 0.133333 \\
\hline Physical Demand & 10 & \\
\hline Temporal Demand & 85 & \\
\hline Performance & 90 & \\
\hline Effort & 90 & \\
\hline Frustration & 65 & \\
\hline Total Workload & 77 & \\
\hline & & \\
\hline Dual task & & \\
\hline Mental Demand & 90 & \\
\hline Physical Demand & 20 & \\
\hline & & \\
\hline & & \\
\hline
\end{tabular}




\begin{tabular}{|l|l|l|}
\hline Temporal Demand & 95 & 0.2 \\
\hline Performance & 40 & 0 \\
\hline Effort & 95 & 0.266667 \\
\hline Frustration & 65 & 0.133333 \\
\hline Total Workload & 84.3333 & \\
\hline & & \\
\hline Subject 33 & & \\
\hline SWAN single task & & 0.0666667 \\
\hline Mental Demand & 60 & 0 \\
\hline Physical Demand & 20 & 0.133333 \\
\hline Temporal Demand & 50 & 0.266667 \\
\hline Performance & 50 & 0.2 \\
\hline Effort & 40 & 0.333333 \\
\hline Frustration & 55 & \\
\hline Total Workload & 50.3333 & \\
\hline & & \\
\hline $\begin{array}{l}\text { Speech } \\
\text { discrimination } \\
\text { single task }\end{array}$ & & \\
\hline Mental Demand & 75 & 0.133333 \\
\hline Physical Demand & 5 & 0 \\
\hline Temporal Demand & 65 & 0.133333 \\
\hline Performance & 75 & 0.266667 \\
\hline Effort & 70 & 0.2 \\
\hline Frustration & 95 & 0.266667 \\
\hline Total Workload & 78 & \\
\hline & & 0.133333 \\
\hline Dual task & & 0.333333 \\
\hline Mental Demand & 65 & \\
\hline Physical Demand & 10 & 0.0666667 \\
\hline Temporal Demand & 50 & \\
\hline Performance & 40 & 0.2 \\
\hline Effort & 60 & \\
\hline Frustration & 65 & \\
\hline Total Workload & 57.6667 & \\
\hline & & \\
\hline Subject 35 & & \\
\hline SWAN single task & & 0.333333 \\
\hline Mental Demand & 10 & \\
\hline Physical Demand & 15 & \\
\hline Temporal Demand & 20 & \\
\hline Performance & 10 & \\
\hline Effort & 14.3333 & \\
\hline Frustration & & \\
\hline Total Workload & & \\
\hline & & \\
\hline
\end{tabular}




\begin{tabular}{|l|l|l|}
\hline & & \\
\hline $\begin{array}{l}\text { Speech } \\
\text { discrimination } \\
\text { single task }\end{array}$ & & \\
\hline Mental Demand & 65 & \\
\hline Physical Demand & 10 & 0.333333 \\
\hline Temporal Demand & 45 & 0 \\
\hline Performance & 70 & 0.133333 \\
\hline Effort & 60 & 0.0666667 \\
\hline Frustration & 45 & 0.266667 \\
\hline Total Workload & 57.3333 & 0.2 \\
\hline & & \\
\hline Dual task & & \\
\hline Mental Demand & 45 & \\
\hline Physical Demand & 20 & 0.266667 \\
\hline Temporal Demand & 45 & 0 \\
\hline Performance & 80 & 0.2 \\
\hline Effort & 65 & 0.0666667 \\
\hline Frustration & 55 & 0.333333 \\
\hline Total Workload & 55.3333 & 0.133333 \\
\hline & & \\
\hline Subject 36 & & \\
\hline SWAN single task & & \\
\hline Mental Demand & 70 & 0.266667 \\
\hline Physical Demand & 15 & 0 \\
\hline Temporal Demand & 80 & 0.266667 \\
\hline Performance & 15 & 0.266667 \\
\hline Effort & 70 & 0.266667 \\
\hline Frustration & 30 & 0.133333 \\
\hline Total Workload & 55.3333 & 0.0666667 \\
\hline & & \\
\hline $\begin{array}{l}\text { Speech } \\
\text { discrimination } \\
\text { single task }\end{array}$ & & 0.0666667 \\
\hline Mental Demand & 100 & 0.266667 \\
\hline Physical Demand & 5 & \\
\hline Temporal Demand & 30 & \\
\hline Performance & 90 & 95 \\
\hline Effort & 80 & \\
\hline Frustration & 87.3333 & \\
\hline Total Workload & & \\
\hline Dual task & 55 & \\
\hline Mental Demand & & \\
\hline Physical Demand & & \\
\hline & & \\
\hline
\end{tabular}




\begin{tabular}{|l|l|l|}
\hline Temporal Demand & 30 & 0.2 \\
\hline Performance & 40 & 0.133333 \\
\hline Effort & 70 & 0.333333 \\
\hline Frustration & 40 & 0.0666667 \\
\hline Total Workload & 54.6667 & \\
\hline
\end{tabular}




\section{APPENDIX D}

DEMOGRAPHIC DATA

\begin{tabular}{|c|c|c|}
\hline Subject \# & Gender & Age \\
\hline 4 & male & 22 \\
\hline 5 & female & 19 \\
\hline 6 & male & 19 \\
\hline 7 & female & 22 \\
\hline 9 & male & 18 \\
\hline 10 & female & 19 \\
\hline 11 & male & 20 \\
\hline 12 & female & 20 \\
\hline 13 & female & 18 \\
\hline 14 & male & 20 \\
\hline 15 & male & 19 \\
\hline 16 & male & 20 \\
\hline 17 & male & 21 \\
\hline 18 & female & 20 \\
\hline 20 & female & 19 \\
\hline 21 & male & 19 \\
\hline 22 & female & 20 \\
\hline 23 & male & 25 \\
\hline 24 & male & 25 \\
\hline 25 & female & 25 \\
\hline 26 & male & 26 \\
\hline 27 & female & 26 \\
\hline 28 & female & 19 \\
\hline 29 & male & 25 \\
\hline 30 & female & 25 \\
\hline 31 & female & 19 \\
\hline 32 & female & 26 \\
\hline 33 & female & 26 \\
\hline 35 & male & 20 \\
\hline \multirow[t]{2}{*}{36} & male & 24 \\
\hline & Mean age & 21.53333333 \\
\hline
\end{tabular}




\section{REFERENCES}

Bolia, R. S., Nelson, W. T., Ericson, M. A., \& Simpson, B. D. (2000). A speech corpus for multitalker communications research. Journal of the Acoustical Society of America, 107(2), 1065-1066.

Bregman, A. S. (1990). Auditory scene analysis: The perceptual organization of sound. Cambridge, MA: MIT Press.

Bregman, A. S. (1993). Auditory scene analysis: Hearing in complex environments. In S. McAdams \& E. Bigand (Eds.), Thinking in Sound: The cognitive psychology of human audition (pp. 10-37). Oxford: Oxford Science Publications.

Brungart, D. S., Simpson B. D., Ericson, M. A., \& Scott, K. R. (2001). Informational and energetic masking effects in the perception of multiple simultaneous talkers. Journal of the Acoustical Society of America, 110(5), 2527-2538.

Cherry, E. C. (1953). Some experiments on the recognition of speech, with one and two ears. Journal of the Acoustical Society of America, 25(5), 975-979.

Corteen, R. S. W., B. (1972). Autonomic responses to shock-associated words in an unattended channel. Journal of Experimental Psychology, 94(3), 308-313.

De l'Aune, W. (2002). Legal Blindness and Visual Impairment in the Veteran Population 1990-2025. Decatur, GA: VA Rehabilitation R\&D Center.

Hart, S. G., \& Staveland, L. E. (1988). Development of NASA-TLX (Task Load Index): Results of empirical and theoretical research. In P. A. Hancock \& N. Meshkati (Eds.), Human Mental Workload (pp. 139-183). Oxford, England: North-Holland.

Helal, A., Moore, S., \& Ramachandran, B. (2001). Drishti: An Integrated Navigation System for Visually Impaired and Disabled. Proceedings of the Fifth International Symposium on Wearable Computers (ISWC'01), Zurich, Germany.

Kessler, D., Kooper, R., \& Hodges, L. (1998). Simple Virtual Environment Library: Version 2.0 User's Guide (Version 2.0): GVU Virtual Environments Group.

Loomis, J. M., Golledge, R. G., Klatzky, R. L., Speigle, J. M., \& Tietz, J. (1994). Personal guidance system for the visually impaired. Proceedings of the First Annual International ACM/SIGCAPH Conference on Assistive Technologies Marina del Rey, CA.

Loomis, J. M., Herbert, C., \& Cicinelli, J. G. (1990). Active localization of virtual sounds. Journal of the Acoustical Society of America, 88, 1757-1764. 
Moore, T. J. (1981). Voice communication jamming research. Proceedings of the AGARD Conference 311: Aural Communication in Aviation (pp. 2:1-2:6), Neuilly-sur-Seine, France.

Moray, N. (1959). Attention in dichotic listening: Affective cues and the influence of instructions. Quarterly Journal of Experimental Psychology, 11, 56-60.

Resnikoff, S., Pascolini, D., Etya'ale, D., Kocur, I., Pararajasegaram, R., Pokharel, G. P., et al. (2004). Global data on visual impairment in the year 2002. Bulletin of the World Health Organization, 82(11), 844-851.

Rubio, S., Diaz, E., Martin, J., \& Puente, J. M. (2004). Evaluation of subjective mental workload: A comparison of SWAT, NASA-TLX, and Workload Profile methods. Applied Psychology: An international review, 53(1), 61-86.

Salvendy, G. (1997). Handbook of human factors and ergonomics (2nd ed.). New York: Wiley.

Swets, J. A., Tanner, W. P., \& Birdsall, T. G. (1961). Decision processes in perception. Psychological Review, 68, 301-340.

Tran, T. V., Letowski, T., \& Abouchacra, K. S. (2000). Evaluation of acoustic beacon characteristics for navigation tasks. Ergonomics, 43(6), 807-827.

Triesman, A. M. (1960). Contextual cues in selective listening. Quarterly Journal of Experimental Psychology, 12, 242-248.

Walker, B. N., \& Lindsay, J. (2003). Effect of beacon sounds on navigation performance in a virtual reality environment. Proceedings of the Ninth International Conference on Auditory Display (ICAD2003) (pp. 204-207), Boston, MA.

Walker, B. N., \& Lindsay, J. (2004). Auditory navigation performance is affected by waypoint capture radius. Proceedings of the Tenth International Conference on Auditory Display (ICAD2004), Sydney, Australia.

Walker, B. N., \& Lindsay, J. (in press). Navigation performance with a virtual auditory display: Effects of beacon sound, capture radius, and practice. Human Factors. 